Portland State University

PDXScholar

\title{
Building Community and Bridging Cultures: the Role of Volunteer Tutors in Oregon's Latino Serving Community-Based Organizations
}

Troy Vaughn Hickman

Portland State University

Follow this and additional works at: https://pdxscholar.library.pdx.edu/open_access_etds

Part of the Applied Linguistics Commons, and the Bilingual, Multilingual, and Multicultural Education Commons

Let us know how access to this document benefits you.

\section{Recommended Citation}

Hickman, Troy Vaughn, "Building Community and Bridging Cultures: the Role of Volunteer Tutors in Oregon's Latino Serving Community-Based Organizations" (2009). Dissertations and Theses. Paper 4053. https://doi.org/10.15760/etd.5937

This Thesis is brought to you for free and open access. It has been accepted for inclusion in Dissertations and Theses by an authorized administrator of PDXScholar. Please contact us if we can make this document more accessible: pdxscholar@pdx.edu. 


\section{THESIS APPROVAL}

The abstract and thesis of Troy Vaughn Hickman for the Master of Arts in Teaching English to Speakers of Other Languages were presented July 9, 2009, and accepted by the thesis committee and the department.

COMMITTEE APPROVALS:

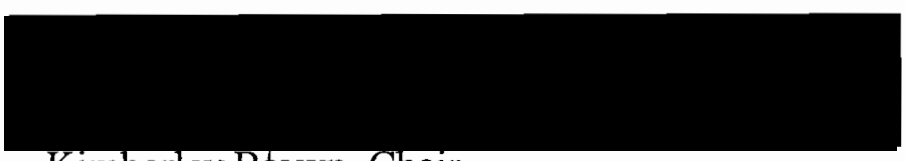

Kimberley Bfown, Chair

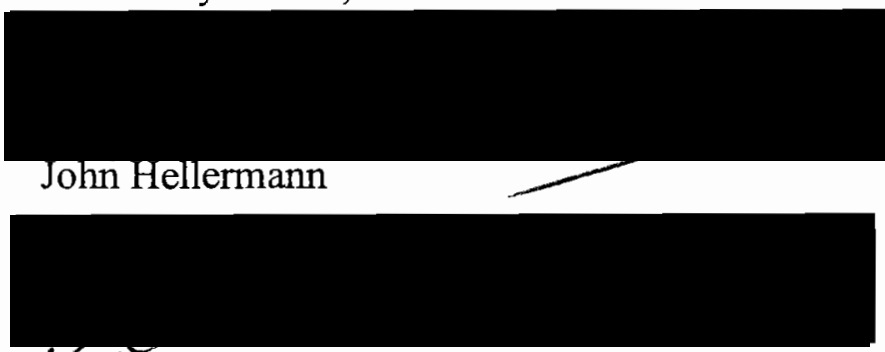

Stephen Reder

DEPARTMENT APPROVAL:

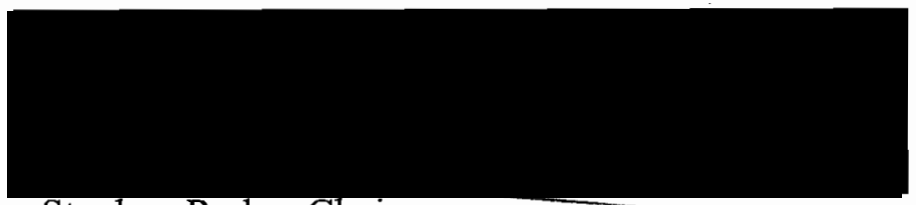

Stephen Reder, Chair

Department of Applied Linguistics 


\begin{abstract}
An abstract of the thesis of Troy Vaughn Hickman for the Master of Arts in Teaching English to Speakers of Other Languages presented July 9, 2009.
\end{abstract}

Title: Building Community and Bridging Cultures: The Role of Volunteer Tutors in Oregon's Latino Serving Community-Based Organizations.

Literature for and about successful volunteer literacy programs highlight and advocate for practices that inform administrators and trainers of the needs and expectations of volunteer tutors. Applications of this knowledge can affect the type of policies that administrators implement in their programs and the type of support that they provide for their tutors. This project was an opportunity for the researcher to reflect on his experiences as a consultant and trainer with community-based programs and to increase his understanding of the volunteers in order to assist in future administration and training work.

Community-based volunteer literacy programs across Oregon are unique in many ways, including the communities they serve, the curricula they use, the policies they implement, and their positions in the community. A multiple case study was used to explore the volunteer tutor pools of two community-based programs. Data was collected from tutors through two formal survey instruments and formal interviews. The interviews were recorded, transcribed and coded around themes related to the 
process of becoming tutors, tutor persistence, tutor challenges, and the impact of tutoring on volunteers. Findings were drawn from each case and were compared across cases, revealing factors that bind these programs together.

The results demonstrate that tutors across both cases enter into cultural contact zones as they engage their tutees and grow through their increased understandings about issues of importance in the Latino community and through improving their tutoring skills. Tutors enter into these programs feeling prepared and qualified from previous experiences, interests and skills related to language learning, teaching, or working across cultures. They face challenges in addressing the diverse needs of their tutees, which is compounded by the irregular attendance of their tutees that breaks the flow of small group instruction and limits the tutees' progress. When communicating about the factors that motivate them to continue, or persist, tutors cite their relationships with their tutees and having a sense of effectiveness as tutors. These tutors were encouraged by the motivation of their tutees and the sharing nature of their tutees in these contact zones. 
BUILDING COMMUNITY AND BRIDGING CULTURES: THE ROLE OF VOLUNTEER TUTORS IN OREGON'S LATINO SERVING COMMUNITYBASED ORGANIZATIONS

by .

TROY VAUGHN HICKMAN

A thesis submitted in partial fulfillment of the requirements for the degree of

\author{
MASTER OF ARTS \\ in \\ TEACHING ENGLISH TO SPEAKERS OF OTHER LANGUAGES
}

Portland State University

2009 


\section{DEDICATION}

For my grandparents, Anita and Victor Hickman. Thank you for your love and dedication. I wish you were here to share the moment. 


\section{ACKNOWLEGEMENTS}

I would like to thank the members of my thesis committee, Kim Brown, John Hellermann, and Steve Reder. Thank you for your support, kind words, and dedication to my education. Also, thank you to Tucker Childs and Janet Cowal. Your passion for linguistics caught my eye and altered my trajectory. A special thank you to my family for pushing me to finish my degree after five long, but rich years. Your support and gentle prodding has not gone unnoticed. Finally, thank you to my partnerin-life, Selina. It was a joy to share this experience with you. You're the best. 


\section{TABLE OF CONTENTS}

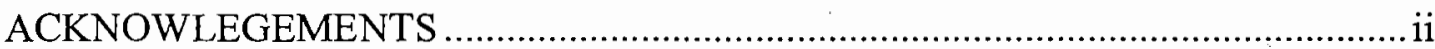

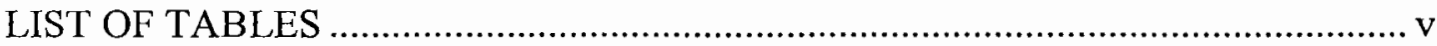

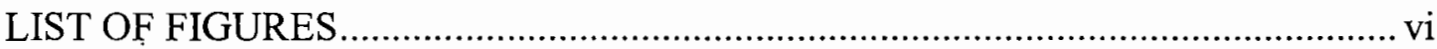

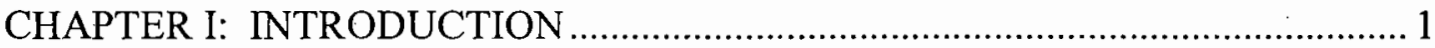

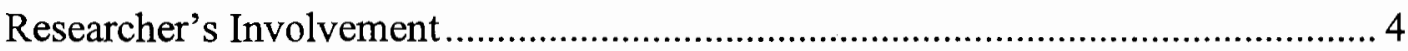

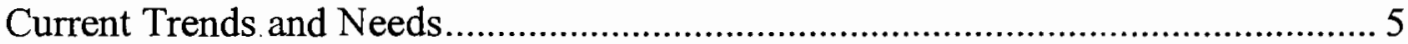

Volunteer-Driven Programs .............................................................................. 7

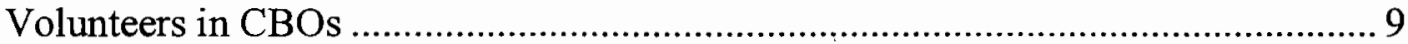

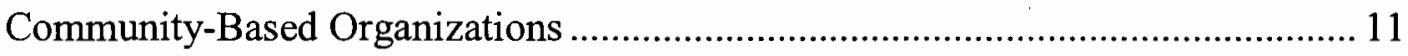

The Rise of Adult Literacy Education in the United States .................................... 12

Adult English Language Literacy ..................................................................... 13

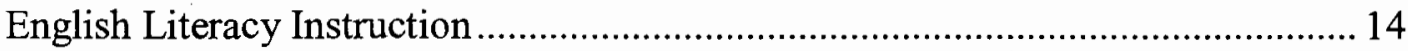

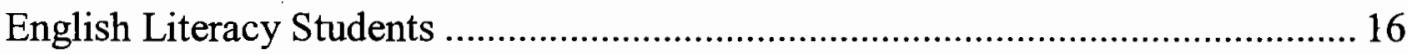

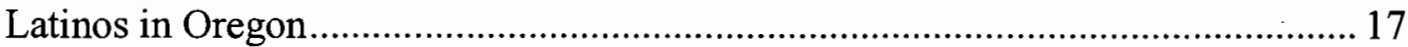

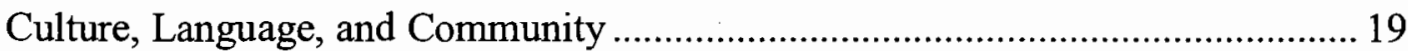

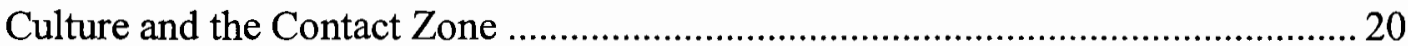

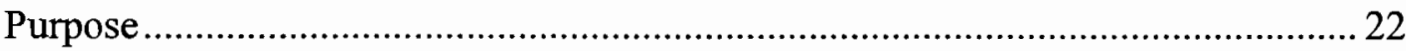

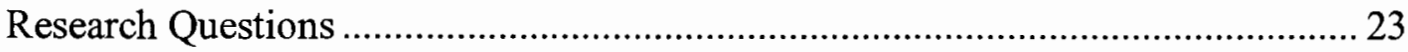

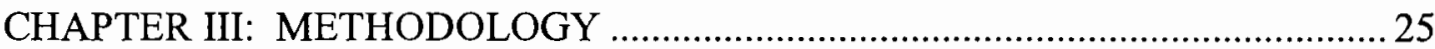

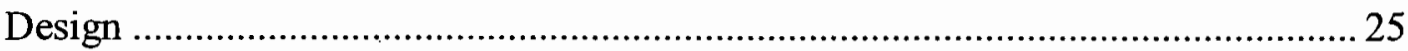

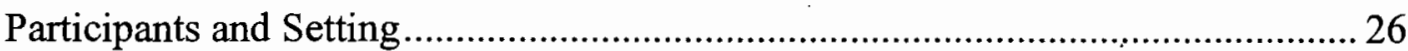

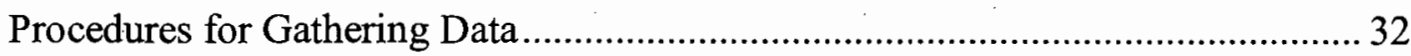

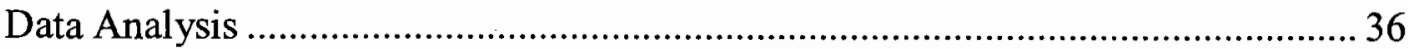

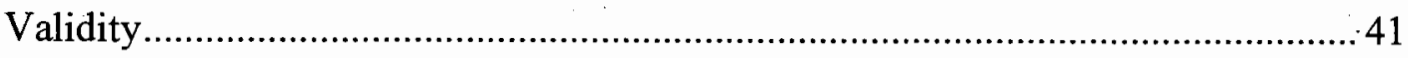

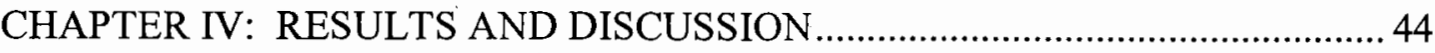

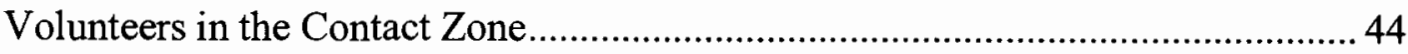

Volunteers: Becoming Engaged as Tutors ........................................................... 46

Differences between the Two Cases ...................................................................... 47

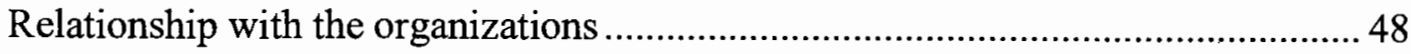

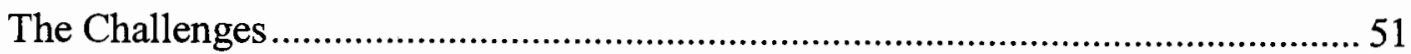




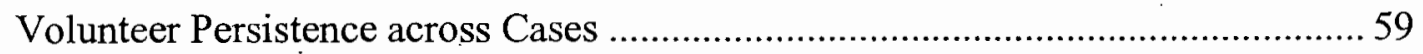

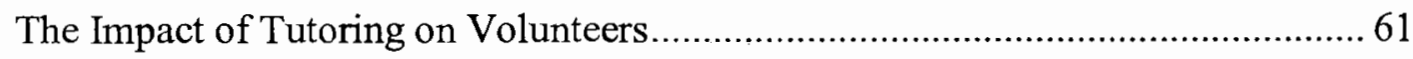

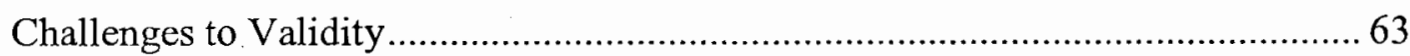

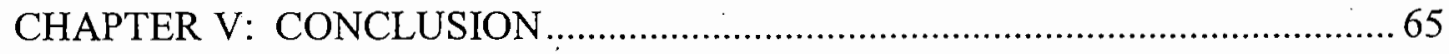

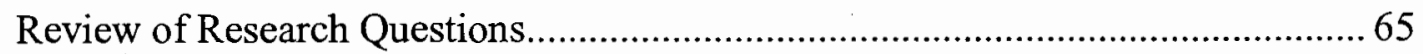

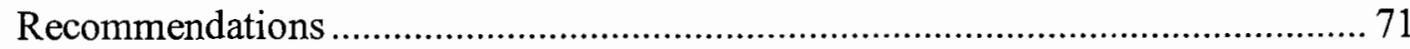

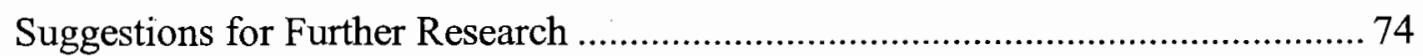

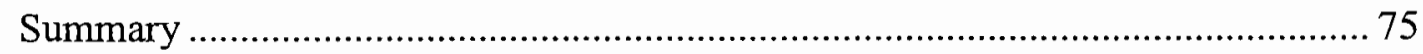

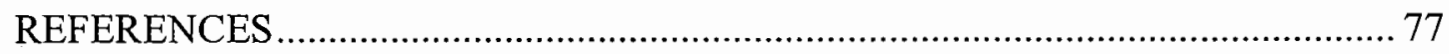

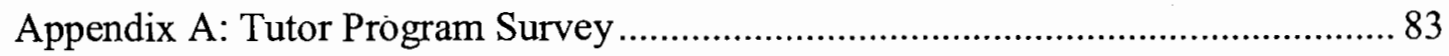

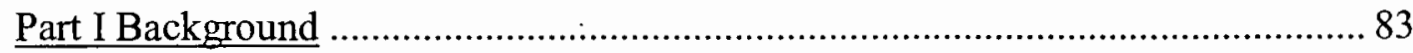

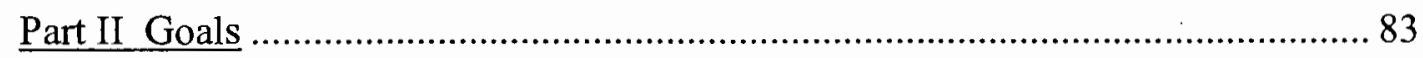

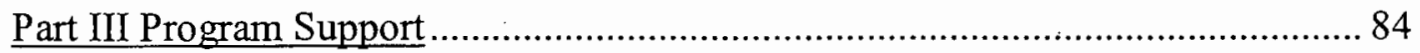

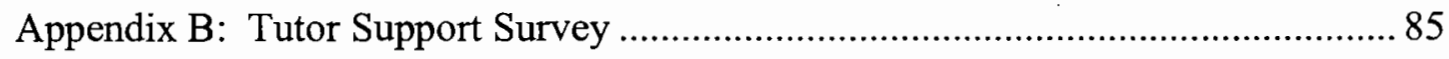

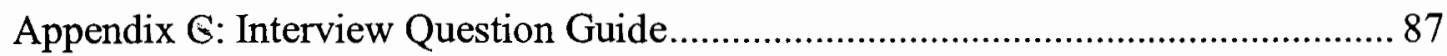

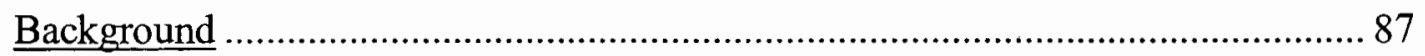

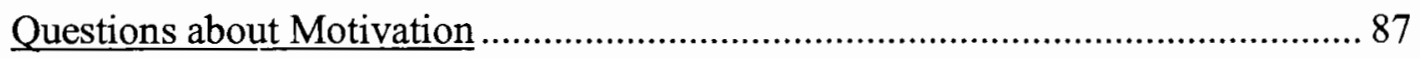

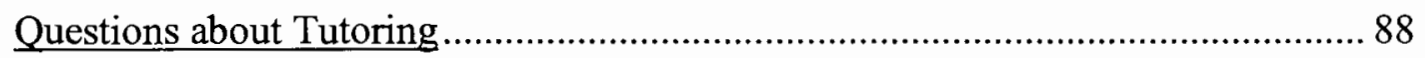

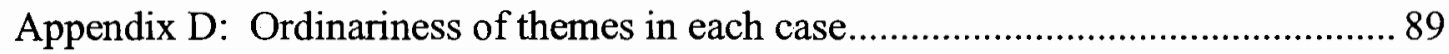

Appendix E: Findings from surveys and interviews for two cases .......................... 90

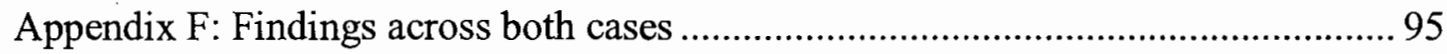

Appendix G: Assertions from findings based on instances for final report ............... 96

Appendix H: Interview Transcript - George - SKCC........................................... 112

Appendix I: Interview Transcript - Beulah - SKCC ......................................... 118

Appendix J: Interview Transcript - Victor - St. Joseph Parish .............................. 124

Appendix K: Interview Transcript - Victor - St. Joseph Parish.............................. 132

Appendix L: Interview Transcript - William - St. Joseph Parish ......................... 139 


\section{LIST OF TABLES}

Table 1: Summary of Data Collection Activities ..................................................... 36

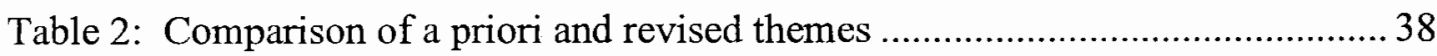

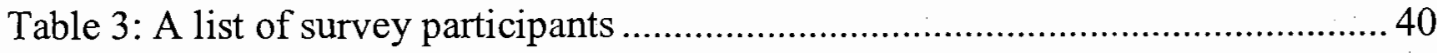

Table 4: A list of interview participants ................................................................. 41

Table 5 Reasons cited by volunteers for becoming tutors ..................................... 47

Table 6: Comments from tutors about the various skills and needs of their tutees .... 53

Table 7: Comments from tutors regarding challenges around attendance.................54

Table 8: Comments regarding challenges around activities and materials ................ 55

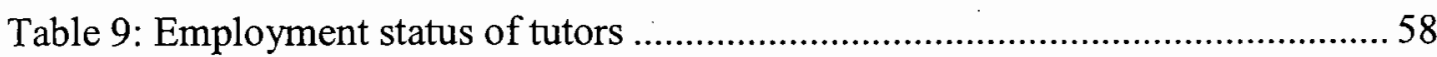




\section{LIST OF FIGURES}

Figure 1: Suburban and rural areas in Oregon with increasing Hispanic populations. 18

Figure 2: Topics of interest for skill development in both cases 


\section{CHAPTER I: INTRODUCTION}

This study explores the role of the volunteer tutor in community-based, English literacy programs that serve adults in immigrant Latino communities. As the Latino population rapidly increases in suburban and rural communities across Oregon, institutions in these areas struggle to meet the needs of the community members. Waiting lists for services through Oregon's community colleges are becoming increasingly common as the demands for workers to speak, read and write in English increases. To meet the needs of the English language-learning communities, community-based organizations (CBOs) are folding English literacy programs into their existing services, many of which are volunteer-driven.

Various $\mathrm{CBO}$ s in Oregon are embedded in immigrant communities and are active, for example, in places such as neighborhood community centers, housing centers, farm worker unions, and communities of faith. These organizations are often accessible to the Latino community, both linguistically and culturally, and they are often places where Latino immigrants feel safe and comfortable. Some organizations, such as communities of faith or housing centers, serve both native-born U.S. Citizens and Latino immigrants and view volunteer-driven literacy programs as ways to bring these groups together and to explore cultural gaps that exist between the two groups.

The focus of this study is on the role of the volunteer. The purpose is not to advocate for a volunteer-driven model over a trained professional-driven model. Instead, the purpose is to reveal, or outline the day-to-day activities in volunteerdriven programs to understand the needs and challenges of those that drive these 
programs. It is an opportunity for me to reflect on my experiences as trainer and consultant for community-based programs and to inform my practices for future work. It is also an opportunity for me to better understand and bring to light the effect of these programs on those that dedicate their time and service to their community through English literacy programs in an age that is characterized by themes such as increased immigration, cultural tension, an aging population, and service to community.

Community-based programs across the state are unique in many ways, including the communities they serve, the curricula they use, the policies they implement, and their positions in the community. A multiple case study is used for this project to explore the volunteer tutor pools at two different community-based programs in and around Salem, Oregon. Findings are drawn from the data collected for each case and made available for comparison across cases. Comparisons across the cases allow for assertions to be made about what binds these programs together, regarding the role of the volunteer tutor.

Data was collected through multiple instruments. Tutors completed two formal surveys and participated in formal, follow-up interviews. One survey instrument was used to collect information about volunteers' interests in further skill development. The other survey instrument was used to collect information about the reasons that volunteers became involved in tutoring, the likes and dislikes of tutors, the challenges that the tutors faces, and some demographic information about the tutors. Through the surveys, tutors selected answers to questions from lists of prepared, possible answers and provided information through open-ended questions. 
The results of this study revealed that tutors across both cases entered into a cultural contact zone as they engaged their tutees. Tutors and tutees brought their cultural frameworks to the tutoring session and negotiated their views on a number of issues and topics including education, employment, political policy, literacy, family relationships, faith, gender roles, immigration, shopping, cooking, etc. Tutors discussed the tutoring session as being a safe place where tutees could ask questions and could push themselves academically. As tutors entered into these programs they felt prepared and qualified from previous experiences, interests and skills related to language learning, teaching, or working across cultures. Although tutors often received some initial training and orientation, they faced challenges in addressing the diverse needs of adult English language learners and in dedicating the time needed to prepare for and execute lessons that address the needs of their tutees. The erratic attendance of their tutees also posed challenges to tutors. Irregular attendance broke the flow of the instruction in small group settings and, in the minds of tutors, seemed to limit the progress that students could have demonstrated. As tutors continued over time, they sought to improve their skills and effectiveness as tutors. When communicating about the factors that encouraged them to continue, or persist, tutors cited their relationships with their tutees and having had a sense of effectiveness as a tutor.

Most tutors in this study focused on their tutoring skills and sought to improve their abilities as tutors. As a result of their experiences, they felt that they had become more effective as tutors. In addition, tutors expressed that their understanding of the Latino immigrant community had increased. Tutors gained an understanding of the 
Latino culture as well as their own culture. They communicated about having an increased understanding of issues that were important to their tutees. Among the many issues were themes such as education, work, discrimination, difficulties around communication, and feeling misunderstood. Tutors in both cases expressed a desire to develop their skills around communicating across cultures and to improve their understanding of the Latino culture.

\section{Researcher's Involvement}

Volunteerism and community involvement have always been of interest to me. Many years ago I volunteered at a local community college to tutor English communication and literacy skills to an adult man who was nearly three times my age. He was an accomplished science teacher from Vietnam who had spent some time in a prison camp. Even though I was a college graduate with strong academic skills, I was unprepared for that experience in many ways. I had to rediscover grammatical concepts that I hadn't thought about in years. I was confronted with cultural phenomena that I hadn't thought about, previously, as being cultural constructs, like the day that he asked me for advice on what to do if someone in his family died. I learned more from him than he did from me, and I was shy to ever call myself a tutor when I often felt that I was the tutee. Through the process, though, we formed a bond and together we studied English and culture and I was so honored on the day that he pulled from his pocket and gave to me as a gift two pieces of paper with hand-written, powerful poems that narrated some of his experiences in the prison camp. 
This experience has propelled me into my career as an instructor and as a literacy program consultant and trainer. Over the past three years I have I have consulted with community-based organizations to establish volunteer-driven programs across Oregon. I assisted programs with implementing policies, creating curriculum, and with training tutors. In working with over 15 programs across the state, I have seen the needs in the community for additional English literacy services in a time when federal and state budgets are shrinking and when foundations are granting less money as they struggle with small returns from their endowments.

\section{Current Trends and Needs}

My narrative as a volunteer tutor is one of many. The United States has a long history of volunteerism and community driven support around adult English literacy, and although there is always a personal element to these services, the presence of these services is often motivated by economic factors and immigration (Sticht, 2002; Cook, 1977). In the mid-1800s, industrial centers across the United States saw dramatic increase in their non-English speaking, immigrant populations. During this time labor unions, settlement houses, and neighborhood houses - such as the Hull House in Chicago - organized English language and literacy programs for their communities. More recently a network of literacy programs surfaced in the 1960s and 1970s under the direction of national organizations such as Literacy Volunteers of America and Laubach Literacy, International. This network created a volunteer-driven model in which volunteers provided "tutelage" to those seeking to improve language and literacy skills. Locally, a series of literacy councils surfaced in Oregon under the 
direction of Oregon Literacy (Sticht, 2002; Houle, 1992; Knowls, 1977; Addams, 1910).

The recent spike of the Hispanic population in Oregon has accompanied an increase in community-based language and literacy programs. Since 1990, the Hispanic population has risen from $4.2 \%$ of the State's total population to an estimated $10.6 \%$ in 2007 (US Census Bureau, 1990; US Census Bureau, 2009). Although the Latino community certainly has a rich history in Oregon and has contributed to Oregon's historical narrative in many ways, this population shift across the state is, arguably, the community's most salient contribution to date, changing the social and economic fabric of many rural and suburban communities in Oregon.

Although the population shift has brought diversity and increased industry to these regions it has also provided the institutions in these communities with challenges to meet the changing needs of the community, particularly needs around adult education and English literacy assistance. When accessing these services, immigrants face a number of barriers, such as waitlists, long work schedules, and a need for childcare among others. Meanwhile, immigrant families are faced with unique social and economic issues that arise, some -for example - growing out of tensions that arise between immigrant parents and children as the youth embrace the new language and the new culture more quickly than immigrant parents.

To address the needs of Latinos in Oregon, there is an increase in communitybased language and literacy services that provide additional opportunities for the language learning community. The Oregon Community Foundation (OCF) partnered with Oregon Literacy to begin the English for Speakers of Other Languages (ESOL). 
initiative in 2005, which focused on creating additional language and literacy services while developing the capacity of community-based organizations (CBOs) to provide these services. In a needs analysis of Latino communities, OCF concluded that CBOs demonstrated the potential to address barriers that prevent adult English language learners from accessing instruction. CBOs demonstrated an ability assist with childcare, provide services in targeted - high need areas, and recruit and support volunteers to tutor language and literacy skills.

\section{Volunteer-Driven Programs}

The role of the volunteer literacy program and the community volunteer is controversial and tenuous. Since I began working with CBOs through the ESOL Initiative in 2005 to recruit; train; and support tutors, I listened to stakeholders from around the state debate the value of the volunteer-based model. Some expressed concerns that community volunteers lacked training around language instruction and working across cultures. Others, however, advocated that the volunteer-driven model provided the community with opportunities for sharing cultural viewpoints and an opportunity to bring the community together. To address the issues raised by critics, tutoring programs struggle to provide support through materials and training to their tutors as they rely on foundation grants and donations from supporters for materials and money for tutor training. 


\section{CHAPTER II: LITERATURE REVIEW}

In this chapter I will lay a foundation for interpreting the relevance of the this study's findings and I will explore the relationship that these findings have to other research related to intercultural communication, acculturation, social phenomena, strategies used in language and literacy programs, and volunteerism. I will define relevant terms and present concepts related to the role of the volunteer tutor including the community-based organization, English language and literacy instruction, culture, acculturation, and contact zones, spaces where communities come into contact.

Provided in the initial part of the chapter is information regarding the history of English literacy programs in Oregon. The presentation of the history of literacy volunteers in the United States and in Oregon places the current efforts of communitybased organizations in context. The presentation will focus on the historical role of community-based organizations in providing English literacy services and on information about legislative acts that have helped to shape the current adult education system, which includes community-based programs. Next I will outline research that provides insight into the reasons that literacy volunteers become tutors and I will outline best practices for incorporating volunteers into a literacy program.

Volunteer literacy programs focus on expanding the English literacy skills of adults in their communities. I provide here a definition of adult English literacy, which outlines the relevance of the multiple dimensions of literacy, both inside and outside of the literacy program. This discussion highlights the diversity of those engaged in literacy programs and the barriers that they face in accessing literacy 
services. It also focuses on what works in English literacy programs, including policies and strategies that are effective in assisting those with limited literacy.

The latter part of the chapter explores the complexities of acculturation in communities. Outlined here are definitions of culture, acculturation, and contact zones. Research is presented on social phenomena related to the challenges that the Latino community faces related to the process of acculturation. A brief picture of the Latino community in Oregon is also presented, highlighting the recent influx of Latinos in Oregon. Finally, the concept of the contact zone is presented. The contact zone is a space where communities come into contact and is presented here so that it may be applied to literacy tutoring programs, drawing attention to the potential hallmarks and pitfalls that result from contact zones to aid in analyzing the role of the volunteer tutor.

\section{Volunteers in $C B O s$}

Many CBOs have contributed to Oregon's current adult literacy landscape. Most notable is the contribution from a network of volunteer literacy programs that were built upon models provided by national programs such as Literacy Volunteers of America and Laubach Literacy, International. Many of these volunteer literacy programs have been supported within Oregon's community college system; others were part of a network established by the non-profit, Oregon Literacy, Inc. In 1985, Oregon Literacy, Inc. and the Oregon's community college literacy and basic education programs partnered to develop a standardized tutor training for all volunteer tutors, the Training for Effective Literacy Tutors (TELT) (Walker \& Strawn, 2004). 
In 1998, 71\% of the adult education personnel in Oregon were volunteers (U.S. Department of Education, 1999). These volunteers received a training consisting of materials, activities, and a process for training master trainers from around the state. Programs in rural areas had limited access to tutor training prior to this time. Volunteer literacy tutoring programs partnered together in regions to tap into federal grants to maintain the training as well as fund materials and other operating costs. However, since the passing of the Workforce Investment Act in 1998, an act of federal legislation designed to improve employment and literacy training programs in the United States, many community-based programs have not had the capacity to maintain the performance accountability measures required to receive federal funds. Although the role of these volunteer programs has diminished, volunteer programs and volunteer tutor trainers still dot the Oregon landscape and the TELT training is still the core of many volunteer training workshops in Oregon (Walker \& Strawn, 2004).

Volunteers entering into these programs have very different backgrounds and experiences with teaching literacy and language, and they cite many different sources of motivation as they become engaged as tutors. Listed below are some of the more common motivational factors supplied by volunteer tutors (Miller, 1982): (a) learning new skills and developing talents, (b) improving the community, (c) gaining experience leading to a paid job or college degree, (d) meeting people and socializing, (e) expressing love and concern for others, and (f) filling time in a meaningful way. To ensure that tutoring meets the expectations of volunteers, it is important for program coordinators to understand the reasons that volunteers become tutors and to 
support these volunteers in a way that allows tutors to excel and continue, or persist, over time.

To assist with incorporating diverse sets of volunteers into a functioning literacy program, Laubach Literacy, International has identified and outlined a set of best practices for adult literacy programs to implement (Alamprese, 1996). They outline standards for programs related to recruiting, placing, training, supporting, providing orientation, evaluating, and tracking volunteers. To retain volunteers over time, the Laubach program recommends that program coordinators provide tutors with a rich understanding of their roles, the challenges, and responsibilities of the position from the outset through orientation and training. This process encourages tutors to set appropriate goals and sets them up with the opportunity to meet their personal goals.

\section{Community-Based Organizations}

The term "community-based organization" (CBO) is used in a variety of contexts. In this research the use of the term is based on the definition provided in the Workforce Investment Act (WIA) of 1998 (U.S. Department of Labor, 1998). WIA defines a CBO as a private, nonprofit organization that is representative of a community or a significant segment of a community and that has demonstrated expertise and effectiveness in the fields of literacy instruction or workforce investment. For this research, the term $\mathrm{CBO}$ includes organizations that have identified a need in the community and have demonstrated a capacity for developing the expertise around literacy instruction. CBOs, in the context of this thesis, also work closely with or serve English language learning communities. Examples of 
community-based organizations include family and social service providers, employment agencies, cultural groups, immigrant and refugee organizations, faithbased organizations, volunteer literacy programs, community development organizations, and other such organizations.

\section{The Rise of Adult Literacy Education in the United States}

In the United States, the history of adult literacy services has been influenced by a number of movements and themes; however, a few themes are chief among them: the economy, immigration, views on culture and acculturation, and an increasing perception of literacy education as community service/charity (Cook, 1977; Sticht, 2002). Throughout the history of adult literacy services in the United States, community groups have not only raised awareness of the important role of literacy among immigrants, but have often been seen as access points to immigrant communities for delivering instruction.

Today, much of the adult education system in Oregon is funded through state and federal funds, the result of the Adult Education Acts (AEA) of 1964, 1991, and 1998. The AEA of 1998 is commonly referred to as the Workforce Investment Act. The AEA of 1964 established the Adult Basic Education program as part of the Economic Opportunity Act, and in 1966, the AEA was expanded to provide additional services to those with limited English proficiency (Rice, J.K. \& Stavrianos, M., 1995). In 1998, the Workforce Investment Act was signed into law, which consolidated the Adult Education Act with the National Literacy Act and the Job Training Partnership Act. Under the WIA, federal and state funding is provided to an agent designated by 
the state. Both the federal and state governments evaluate each state's progress by monitoring the degree to which it achieves the goals stated in its plan (TracyMumford, 2000; U.S. Department of Labor, 1998).

These legislative acts made English literacy services available through both the public sector and through CBOs, and, therefore, such services are provided to English language learners and adult literacy students today in Oregon. These services are primarily offered through the community colleges or through organizations partnering with community colleges. They are termed 'low cost' as they are subsidized by state and federal monies. Despite the low cost for participants, there are still barriers for adult learners and organizations to access and provide literacy services. Barriers for students often center on the need for childcare, transportation, and their hectic work schedules (Chisman \& Crandall, 2007; Condelli, Wrigley, \& Yoon, 2002; Guth \& Wrigley, 1992; National Center for Education Statistics, 1998; Walker \& Strawn, 2004).

\section{Adult English Language Literacy}

In general terms, English language literacy is one's ability to understand and use the English language to communicate one's ideas in various social contexts while understanding and communicating the cultural information underlying the text or conversation. In surveying the profiles and practices of programs in the United States that were providing literacy instruction for adult immigrants, Wrigley (1993) points out that to realize the literacy level of an L2 student is to identify the student's: (a) understanding of how to use the target language to communicate, (b) ability to 
interpret printed information in the target language, and (c) understanding of the underlying cultural concepts that are encoded into the target language.

Ethnographic and anthropological research has influenced contemporary views of literacy. Quigley (1997), Wrigley (1993), and other theorists describe literacy as multidimensional. Instructors and students focus on a plurality of literacies, both inside and outside of the classroom. Inside the classroom, Wrigley (1993, p. 451) observed instructors assisting students to gain confidence and skills in many dimensions, including: (a) functional literacy, where instruction focused on applying literacy to accomplish everyday tasks; (b) sociocultural literacy, where instruction raised awareness about how literacy practices differ among groups; (c) expressive literacy, where instruction focused on using literacy to express ideas, thoughts, and feelings related to personal experience or reflections in life; and (d) critical literacy, where instruction focused on using literacy to critically examine and comment on one's position in society.

\section{English Literacy Instruction}

Each individual English literacy program is unique, in part, because of the priorities that are placed on these various dimensions of literacy. Through literacy instruction, programs may provide students with socio-cultural knowledge, empower students to gain the ability to communicate one's experience and reflections, increase students' abilities to critically reflect and interpret one's social position, and encourage the development of functional skills (Wrigley, 1993). Some instructional programs focus on functional literacy while others may focus on other dimensions of literacy, 
such as the social role of literacy. These priorities may be linked to an organization's mission statement, to an instructor's personal teaching philosophy, or to the needs of the students in the setting (Quigley, 1997). No matter the priority of the program, programs seek to be effective and adopt effective techniques and activities to reach intended outcomes.

In surveying the practices of programs across the United States, Condelli, Wrigley, and Yoon (2002) identified three major practices that are related to successful programs. Successful programs (a) provided learner-centered instruction by linking instruction to real events outside the classroom, (b) used the students' $\mathrm{L} 1$ as an aid to instruction, and (c) made more instructional time available to students and increased the intensity of instruction.

Chisman and Crandall (2007) build on these ideas when looking at the effect of program policies and strategies on learner gains. Like Condelli, Wrigely and Yoon (2002), they determined that community college programs providing learner-centered instruction were more effective when compared to programs that did not, as were programs that provided more intense instruction. Policies regarding student attendance also played a role in program effectiveness. When focusing on enrollment policies, Chisman \& Crandall (2007) concluded that programs that managed their enrollment, as opposed to having an open entry and open exit policy, demonstrated greater learner gains. Also related to greater learner gains was intensity of instruction. Programs that demonstrated greater effectiveness were those that provided between 12 to 24 hours of instruction per week in contrast with programs that provided instruction between six to eight hours per week. They also incorporated strategies for students to 
engage in language study outside of the classroom. These programs created instructional modules that encouraged students to interact with native speakers outside of the classroom as a part of their class projects in the classroom.

\section{English Literacy Students}

The needs of English language literacy students are diverse. Students enrolled in these programs often vary widely in age, educational background, work experiences, and goals for using reading, writing, speaking, and listening skills outside of the classroom. For students in these programs, being literate in their second language means different things in different social contexts. For example, some might have the skills needed to read a work order in a manufacturing setting, but might struggle with completing health-care forms or identifying information in a news article. For each student these skills are immediately relevant in various social contexts such as shopping, operating a computer, accessing health-care, understanding directions on medicine labels, filling out tax forms, operating a vehicle, using public transportation, and so on (Condelli, Wrigley, \& Yoon, 2002; Guth \& Wrigley, 1992; Kim \& Creighton, 2000; National Center for Education Statistics, 1998; Wrigley, 1993).

Students in English literacy classrooms are diverse and face a number of challenges with accessing and persisting in classrooms. In Oregon there were 359,867 foreign-born persons, equaling nearly $10 \%$ of Oregon's total population in 2006 . Of the foreign born population, 253,264 people had moved from another country to Oregon since the year 2000 (U.S. Census Bureau, 2006). In the United States, as in 
Oregon, a majority of students enter traditional language and literacy programs at the most basic levels (Chisman \& Crandall, 2007; Walker\& Strawn, 2004). This often results in students being placed on waiting lists and entering into classes that are large in size. Compounding these challenges are the need for childcare, awareness of the classes, transportation, and the cost of attending, giving students few options in the type of literacy instruction that meets their needs, be it focusing on functional skills, socio-cultural knowledge, expressive skills, or building on critical perspectives.

\section{Latinos in Oregon}

Although Oregon's immigrant population is diverse, the increasing percentage of the Hispanic population in Oregon is impacting local communities, especially in rural areas such as Hermiston, Woodburn, Independence and Monmouth, St. Paul, and Phoenix and in outer urban communities such as Hillsboro, Medford, and northeast Salem. Since 1990 there has been a dramatic increase in Hispanic immigrants settling in Oregon, in part due to economic factors, social networks, and immigration policies (Stephen, 2007; Stephen, Mendoza, \& Magaña, 2008). As of 2006, it was estimated that $10.2 \%$ of Oregon's total population was of Hispanic descent, up from $8 \%$ of the population in 2000 . It was also estimated that $14 \%$ of those living in Oregon spoke a language other than English in their home; this percentage was up from $12 \%$ of the population in 2000. (U.S. Census Bureau, 2006; U.S. Census Bureau, 2000). 
Figure 1: Suburban and rural areas in Oregon with increasing Hispanic populations

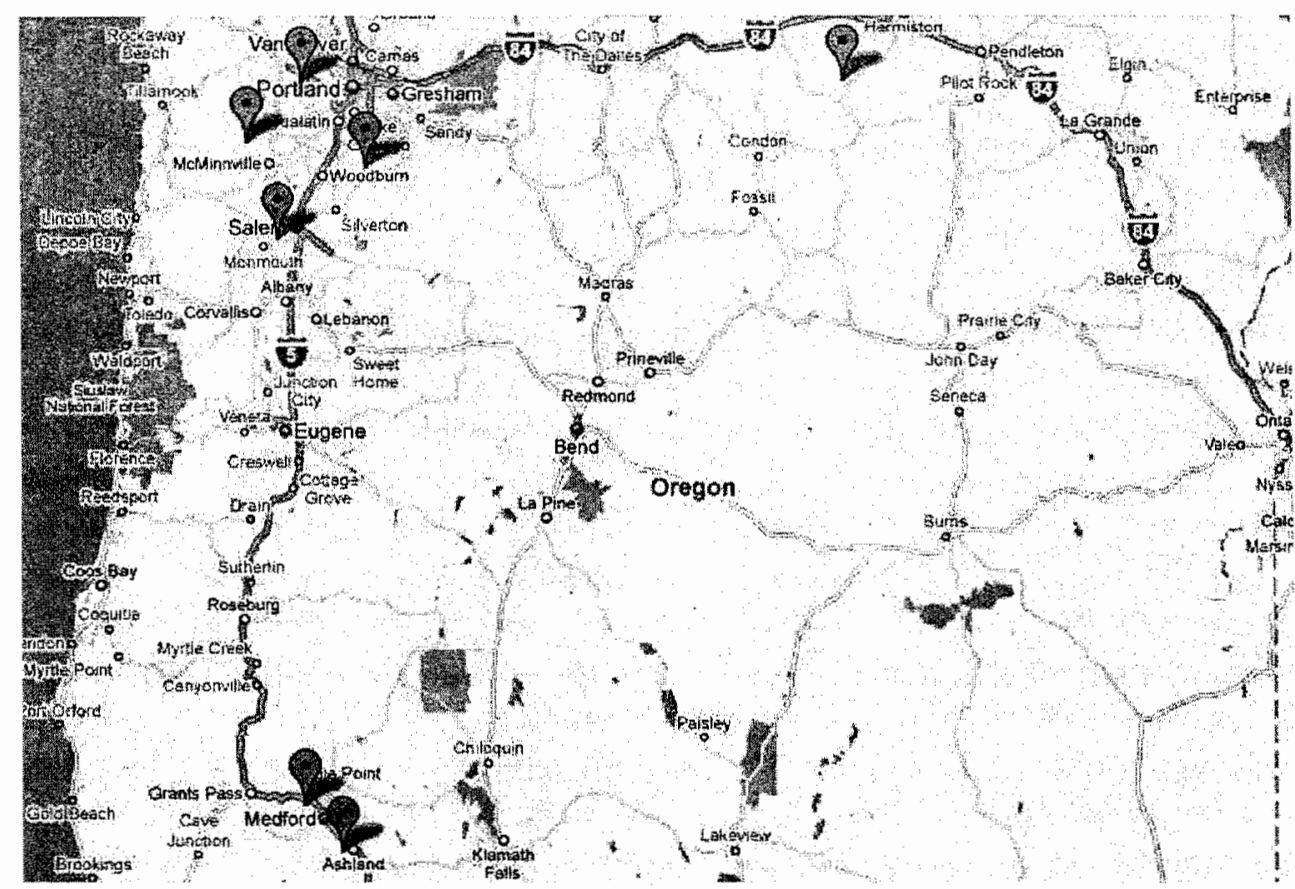

In the twentieth century, Oregon's agricultural community was a major source of employment for immigrants, especially in the 1940s and 1970s. With these opportunities came waves of immigrants from agricultural regions in Mexico such as Michoacán, Oaxaca, and Guanajuato. During the 1970s, Latino-led and Latinoserving organizations formed to provide support for recently arrived immigrants. Organizations such as the Valley Migrant League, the Willamette Valley Immigration Project, and Pineros y Campesinos Unidos del Noroeste (PCUN) formed, providing a template for many organizations that have replicated these programs and services across Oregon. These organizations supported individuals in acculturating by providing adult education, legal assistance, skills training, day care, and other 
linguistic, cultural and social supports (Kissam \& Stephen, 2006; Stephen, Mendoza, \& Magaña, 2007; Stephen, 2007).

\section{Culture, Language, and Community}

Immigrants settling into a new country and community face daily challenges with interpreting and understanding a new language and culture. On one hand immigrants must acquire these skills in order to live and communicate while, on the other hand, they face decisions about preserving their cultural heritage and ethnic identity through language and customs (Rivera-Mills, 2000). The notion of acculturation provides a framework for viewing this complex and multidimensional change.

Acculturation is the process of gaining cultural knowledge as groups of individuals from different communities come into contact. The development of cultural knowledge includes, among many phenomena, the acquisition of language, an increased understanding of the nuances of communication and social interaction, and an increased understanding of forces that have shaped the culture such as history and art (Moyerman \& Forman, 1992; Padilla \& Perez, 2003). Although most research into acculturation measures the change of those becoming immersed by a host culture, according to this definition, change occurs within the host culture as well. Furthermore, this phenomenon is visible within individuals as well as in groups. Individuals and groups, in developing identity, may be seen to accept and reject various behaviors, values, and beliefs from the cultures within which they are participants (Cabassa, 2003). 
There is an increasing amount of literature about the complexities of acculturation, especially related to Latino immigrants in the United States. These complexities have a social impact on these groups. Among these complexities are stresses related to language brokering and to differentiated levels of acculturation between generations within a family (Martinez, McClure, \& Eddy, 2009; Martinez, 2006; Marín \& Marín, 1991). Language brokering is the process of children acting as language interpreters for families outside the home and is common among recently arrived families where children learn the language more quickly than their parents. Martinez, McClure, \& Eddy (2009) surveyed Latino immigrants in Oregon, finding that families in higher language brokering contexts demonstrated higher levels of stress. The stress is often compounded when children accept the host culture more readily than their parents. Among the adolescents in those families, there is a relationship between these stresses and challenges and academic performance, mental health, and substance abuse.

\section{Culture and the Contact Zone}

Culture is at the heart of any discussion about communities and the dynamics related to communities coming into contact. Anthropologist Jill Brody (1993, p. 39) defines culture as a means of understanding oneself in relation to others and the world. She defines culture as "a distinctively human way of organizing, interacting, and understanding each other and the world." Building on this, Crawford and McLaren (2003) propose that culture is continually under construction, and that the frameworks that individuals create to conceptualize the world are in flux and influenced by 
experience and empathy. These frameworks are intersubjective, meaning that these frameworks are shared within communities, that they are constructed, in part, through consensus.

Communicating across cultures hinges on one's ability to construe experience through other world views or cultural frameworks. The Development Model of Intercultural Sensitivity (Bennett, Bennett, \& Allen, 2003) builds upon this pluralist approach to culture in providing a rubric for understanding and for measuring one's cultural competency. This model develops from the idea that one sees the world through one's constructed perspective, that one construes meaning through the summation of one's experiences. Through communication or interaction with others, one analyzes and realizes the differences among the constructs of individuals, calling these constructs into question. With increased contact and communication with others, especially those from different communities, one deconstructs one's cultural constructs. As deconstruction flourishes, one moves to another stage of intercultural sensitivity.

Anthropological and sociological research has revealed a great deal about the dynamics of communities as they come together. This collusion is something that Pratt (1990) refers to as the contact zone, a temporal, social, and sometimes physical space where two or more communities come into contact. Actors in these zones often view their rules of interaction as being governed by a single set of rules; they perceive that all of the participants are engaged in the same game. But this is not likely always the case. Actors come from different social classes, different countries, different ways of life, but the legitimacy of actions within the contact zone is often defined from the 
point of view of those with authority. The product of the contact zone is dependent upon the approaches and sensitivity of those involved.

As an educator, Pratt views her classrooms as a contact zone, a place where she promotes interactions that are characterized by oppositional discourse, parody, and questioning of cultural constructs. Such interactions, she argues, avoid the pitfalls of the contact zone: miscomprehension between actors, incomprehension, and absolute heterogeneity of meaning. Instead, they promote collaboration, critique, mediation, and what Pratt refers to as transculturation - a process through which the subordinate group creates and communicates their perspective through the media of the dominant group. As an educator, Pratt stresses the importance of divining from classroom contact zones a culturally sensitive learning environment. Tutoring programs, when viewed as contact zones, have the potential to create either hallmarks or pitfalls. At the center of these programs are volunteer tutors with various backgrounds, interests, and skills engaging in the contact zone.

\section{Purpose}

This study explores the role of volunteer literacy and English for Speakers of Other Languages (ESOL) tutors in two Latino-serving community-based organizations that have participated in the grant-funded ESOL Initiative in the Salem area. The initiative developed out of a partnership between the Oregon Community Foundation's Latino Partnership Project and Oregon Literacy. The aim of the initiative was to increase the capacity of community groups, enabling them and empowering them to provide additional support to the English language learning 
community while providing additional opportunities for community members to support education and to reach out and engage others across cultural boundaries.

By collecting and analyzing data from tutors in two of the ESOL Initiative organizations, I set out to draw conclusions about the role of the volunteer across the two cases. For the past three years I have worked with ESOL Initiative tutors and program coordinators to access funding, develop curriculum, train tutors, and create policies unique to the needs of each program. This study was a chance for me to reflect on my work as a trainer and as a consultant for community-based program as a part of the ESOL Initiative and was an opportunity to enhance my role as a trainer and an advocate in the future. As a result, I hope to walk away with an enhanced understanding of how volunteers become engaged as tutors, the factors that motivate tutors to persist, and the impact that these experiences have on tutors, both personally and professionally.

\section{Research Questions}

To understand the role of the tutor in this context, I set out to explore a number of themes that emerged from my experiences with ESOL Initiative organizations over the past few years, especially my time spent with two participating organizations over the past few months. The themes to be explored are related to the experiences and expectations of volunteers as they become engaged as tutors, the factors related to tutor persistence, the successes and challenges that tutors experience, and the personal changes that tutors experience as a result of their experiences. Volunteer persistence is defined as the act of tutors continuing or the intention of continuing beyond the 
required commitment coupled with acts or displayed interest in improving their skills and effectiveness as tutors. Through this research, I have sought to address the following research questions:

1. How do community volunteers become engaged as tutors in community-based ESOL literacy programs?

2. What factors contribute to the persistence of volunteer English tutors?

3. What challenges do volunteers face that are unique to English literacy tutoring?

4. How do the experiences of tutoring impact volunteers? 


\section{CHAPTER III: METHODOLOGY}

Design

In designing this project I leveraged a qualitative, multiple case study methodology. The idea of exploring two cases began during the exploration phase of the project as I began visiting the organizations that provided volunteer-driven English literacy tutoring programs. At the time, I was both beginning the research and was an employee at Oregon Literacy working on the ESOL Initiative. I was conducting field visits to funded CBOs and also attempting to choose one of the six ESOL Initiative CBOs as a case study for this thesis project. These site visits gave me close access to the programs where I met many of the program's participants. The organizations also provided me with information about their programs by sharing surveys collected from each programs' participants, attendance records, program budgets, and promotional materials such as program brochures and fliers.

Over time, the uniqueness of each organization began to surface in my mind, including the unique role of the volunteer within each organization. For example, I learned that programs were recruiting volunteers through different means and that volunteers in some programs were working one-on-one with individuals while others were working in groups as large as 10 to 15 people. It also seemed that each organization was comprised of a unique set of participants with unique goals and skills, and although each organization began using an identical curriculum, the curriculum evolved separately within each organization as it was adapted by each set 
of tutors to meet their strengths and experiences as well as the needs of the participants in each setting.

It became clear, through my experiences, that generalizing the roles of volunteers across cases would be challenging as the volunteers' experiences were unique to the individual and often engaged within the context of each organization. Generalizations and assertions about the role of the volunteer tutor, based on the study of a single case, to the ESOL Initiative's CBOs as a whole, no matter how systematically the data was collected and evaluated, would be dangerous and such claims would be weak and unsubstantiated. So, I chose to explore two related cases in order to allow information about more than one case to surface and to collect findings for each case. By systematically analyzing and comparing the findings cases, I was able to make assertions about what binds these two cases together and what makes them inextricably autonomous in regards to the role of the volunteer tutor.

In this study, each case is a set of volunteers within a single organization. The themes that I set out to explore from the outset were themes that I felt might be present across cases based on my previous experiences with the programs, particularly past experiences with collecting data, through a survey questionnaire, from ESOL Initiative tutors. The themes were general and related to tutor expectations, motivations, rewards, philosophies, and challenges.

\section{Participants and Setting}

The organizations that have participated in the ESOL Initiative have ranged from communities of faith to charitable non-profits to immigrant and cultural 
organizations. The participating non-profit organizations have had various missions including the provision of legal services to those in need, supporting at-risk youth, the provision of affordable housing, and the provision of support to farm workers.

Although the organizations are very different, they have all had experience working in the Latino community, they all have bilingual staff, and, more significantly, they are all volunteer-driven.

I selected two organizations from this pool to participate in this multiple case study designed to explore the role of the community volunteer. The role of the volunteer could be explored in any of these organizations, and it would likely appear to be unique in each case. The purpose of the multiple case study is to explore the concept that is being studied to see how it is different and similar in each case (Stake, 2006) so that assertions may be made about what bind the cases together. In an effort to strengthen any assertions that would result from this study, two organizations were selected because of their similarities and differences. Although their similarities were discussed above, they are different in many ways. They recruit volunteers differently, they provide different types of orientations for their tutors, they use different methods to match their tutors and tutees together, they provide different levels of support to their volunteers, and they provide different types of literacy services.

To illustrate the similarities and differences between the two cases, they are described in detail below. Pseudonyms were not used in place of the organizations actual names. I made this choice because the identity of the organization is a key to understanding the roles of the volunteer in each organization. As will be outlined later, it is difficult to separate the volunteer from the organization, which are 
institutions in their communities. The role of the institutions in the community are often multidimensional in that they bring people together for social gatherings, community events, social services, and faith-related services. In understanding the role of the tutor in each organization, it is important to understand the contexts within which these organizations are set.

St: Joseph Parish is a catholic church located in downtown Salem, Oregon, near the downtown business district and a few blocks away from the State Capitol. St. Joseph is the largest Catholic Church in the Salem area; it is comprised of a Spanishspeaking congregation and an English-speaking congregation. Although the church provides services in both Spanish and English, the two congregations rarely combine activities despite the large number of community activities the church provides. The church has made efforts to bring the congregations together by offering bilingual services at Christmas and Easter. They have also organized multicultural events which highlight music and food from various cultures.

Among the reasons program organizers at St. Joseph cited for starting up ESOL and literacy services was the potential to bring the Spanish speaking and English-speaking congregations together. In the plan submitted to Oregon Literacy, St. Joseph's organizers documented a plan for promoting the program within the church, requesting that members from the English-speaking congregation fill the role of tutors. The organizers planned to promote the program to both congregations through church announcements, fliers, and through the church's bulletins.

The program's leaders identified other reasons for building the program. They identified a need for increased economic and educational opportunities for the Latino 
community. During their first year, if they were successful, they planned to partner with a local school. They planned to focus language and literacy instruction in ways which would enhance the ability of Latino parents to communicate with their children's teachers.

Currently, St. Joseph provides three types of ESOL and literacy support. They offer conversation groups on the weekends through a program called "Conversation Partners." This is a drop-in program on Saturday mornings where those looking to practice their conversation skills can walk in and be matched with a conversation partner or can work in a small group with a fluent English speaker facilitating the group. The program coordinator provides materials that can be used to start conversations or to be used as props through which a conversation can be guided. The groups are facilitated by a core group of volunteers that attend the program nearly every Saturday, rotating as necessary.

In addition to the conversation groups, St. Joseph provides structured, small group language and literacy instruction, which they refer to as the ESOL Program. The ESOL Program is similar to a classroom-style format; groups range in size from as few as two members to as many as 15 members. These small groups are volunteerled, and in the first year of the program the St. Joseph ESOL Program recruited 29 tutors. Of those tutors, fifteen completed a tutor training workshop that was available to tutors volunteering for any of the ESOL Initiative programs.

Upon entry into the ESOL Program, tutors meet with each student and assess the student's goals and speaking and listening skills. Based on information revealed through the assessment, tutors place students into small groups or sometimes into a 
one-on-one tutoring arrangement. The program uses the outcome-based National Reporting System (NRS) framework for dividing students into leveled groups for instruction. The NRS was designed for State-administered, federally funded adult education programs as a guideline for measuring student proficiency and measuring student progress. The NRS framework for English as a Second Language is comprised of six levels: Beginning ESL Literacy, Low Beginning ESL, High Beginning ESL, Low Intermediate ESL, High Intermediate ESL, and Advanced ESL (National Reporting System, 2009). St. Joseph provides materials for tutors that correlate with the instructional outcomes for the NRS levels. Because St. Joseph primarily serves students with the most basic English proficiencies, they organize separate instruction for each of the following groups: beginning, low beginning, and high beginning levels. As they serve fewer advanced students, St. Joseph provides a single group for students who place into the intermediate or advanced levels.

The final literacy-related service that St. Joseph provides is within the context of preparing for the US Citizenship exam. This program has been led by the same volunteer for three years. He has attended workshops for ESOL training as well as workshops led by the United States Citizenship and Immigration Service (USCIS) to prepare for tutoring content around citizenship. The instruction focuses on completing the necessary forms, preparing for the interview, preparing for the literacy test, and some instruction around United States history.

The second of the two cases is the Southeast Keizer Community Center (SKCC). The community center is located within the Salem Mennonite Church, which is located in Keizer, Oregon. The church's facilities are in near constant use. 
The Center, which is led by the church's pastor, organizes a number of services for the community including meals, youth activities such as homework clubs and sporting events, activities for seniors, and activities around promoting social justice. The church is located in a neighborhood that is largely Spanish-speaking, and lends the facility to its "sister" church, La Vida Nueva, for church and social activities.

The Southeast Keizer Community Center (SKCC) began its program with the modest goal of enrolling 15 people each term in the program. They approached the project as being a resource for their community. The Center drafted expected outcomes of the project from the beginning. They expected that participants would be more comfortable with the English language, be better able to converse in English, and would improve their ability to fill out various legal, employment, and health-related forms, as well as tax documents. Last year the center served 43 students with the assistance of 12 volunteer tutors. The center raised money to make child care available for those attending the program and partnered with the Migrant Family Literacy Program to improve its curriculum and to recruit additional participants.

Each year since the SKCC program's inception, volunteer tutors at SKCC have led small group activities around English language and literacy. At the outset of the program, SKCC attempted to organize their groups based on a variety of factors including NRS levels and student goals. Over time, however, program participants often requested to be in groups with family members or friends or were limited to participate in certain groups by their work schedules. In an attempt to maintain the sense of community that is a part of their mission, SKCC tutors often provide instruction to multiple level groups. Although the participants within each group often 
range widely in English proficiency level, educational backgrounds, and goals, the members of the group often have a strong rapport. SKCC tutors still assess each student during an initial intake session and work with students to meet their goals.

\section{Procedures for Gathering Data}

To gain a rich understanding of the tutoring activities at each of the organizations I collected data from the CBOs and tutors through a variety of means, including two survey questionnaires and follow up interviews. My experiences with these organizations over the past three years guided the case selection and informed the questions that I used to elicit data through the surveys and the interviews. During that time I acquired general knowledge of the programs as I worked with program coordinators and tutors to start up their programs and to evaluate the trajectory of the ESOL Initiative through grant applications, grant reports, conversations, fliers and other materials. Program coordinators from each of the two cases invited me, on several occasions, to visit their program where I had the opportunity to see the tutors in action, view the physical space where the tutoring programs operate, and to meet and talk informally with participants, both tutors and language learners.

I collected the data between March and April of 2009 through two survey questionnaires and through interviews with tutors at both St. Joseph Parish and the Southeast Keizer Community Center. I worked with the program coordinators at both CBOs to raise awareness about the research project and to assist with distributing the survey questionnaires to their active tutors. Project coordinators distributed two survey questionnaires, an informed consent form, and a stamped envelope that 
included the researcher's home address to each of their active tutors. The program coordinator at St. Joseph Parish distributed twenty one surveys while the program coordinator at SKCC distributed eight surveys and consent forms to the organization's active tutors. Twelve surveys were returned from St. Joseph Parish and five were returned from SKCC.

During the data collection process, I took steps to provide confidentiality for the participants and to make participation accessible and rewarding. When conducting outreach for the project, I worked with program coordinators to inform the tutors that they were not required to participate. On the consent form, participants documented their level of interest and availability for participating in a follow up interview. Each tutor could indicate if they were "not at all interested," "somewhat interested," or "very interested," and were asked to provide a phone number to assist me in setting up appointment times for the interviews. Tutors were informed that they could discontinue their participation at any time. In total, I conducted five formal interviews, three formal interviews with tutors from St. Joseph Parish and two formal interviews with tutors from SKCC.

The surveys used in this project were adapted from two previous surveys and are available in Appendices A and B. The first survey instrument, the Tutor Program Survey in Appendix A, was developed for the Oregon Community Foundation and Oregon Literacy to gain feedback from volunteer tutors for the purpose of evaluating the programs participating in the ESOL Initiative (Hickman \& Ostrogorsky, 2007). This survey was used to collect demographic information about the tutors, information 
about the reasons that volunteers became involved as tutors, information about how they access support, information regarding challenges and goals as well as information about likes and dislikes about tutoring. Tutors were asked to select from a prepared list of reasons for getting involved and were provided the opportunity to give additional information in response to an open ended question. They were also asked to select various means of support from a list, and were also given space to provide additional comments. The survey allowed tutors to share information about their challenges, likes and dislikes through open ended questions. As program coordinators asked for the results of this survey to assist them in their annual reports, this survey was collected on a document separate from the other survey.

The second survey instrument used, the Tutor Support Survey, was adapted from a survey used in a 1998 Portland State University TESOL thesis by Janet Blackwood. It was originally used to better understand the background and training experiences of tutors in faith-based English language mission programs. In the original survey, tutors were asked to select from a prepared list of topics regarding the areas in which they received training in preparation for teaching English as a foreign language. In adapting the survey for this thesis, tutors were asked to indicate, from the list of training topics, areas in which they would like to develop their skills. It also collects information regarding preferred methods for developing their skills. A version of this survey is available in Appendix B.

To enrich the data collected through the surveys, tutors from each case were approached to complete a follow-up interview. Interviews allowed me to collect 
richer data by documenting stories and narratives from the tutors about their experiences. The interviews allowed me to revise my working themes and focus on issues that began to emerge from the survey questionnaires. The questions were designed to highlight the uniqueness of each tutor's situation and to ascertain the commonalities among the tutors that bring significance to the role of the volunteers in community-based literacy programs.

Tutors were given the opportunity to decline to participate in the interview, and every tutor interviewed signed the informed consent documents. All interviews were conducted over the telephone, and each participant consented to have the interviews recorded. All interviews consisted, at the core, of seven standard questions. Each interview, however, differed from others as different clarifying questions were presented to each tutor in order to explore the unique experiences and views of each tutor. I conducted three interviews with tutors from St. Joseph Parish and two tutors from Southeast Keizer Community Center. The core interview questions are listed in Appendix C, and transcripts from the interviews appear in Appendices J-N.

The table below summarizes the data collection process. It details the number of surveys that were distributed at each organization, the number of surveys returned from each organization and the number of follow up interviews conducted at each site. 
Table 1: Summary of Data Collection Activities

\begin{tabular}{|l|l|l|}
\hline Activity & St. Joseph & SKCC \\
\hline Surveys Distributed & 21 & 8 \\
\hline Surveys Collected & 12 & 5 \\
\hline Percentage of Surveys Returned & 57 & 63 \\
\hline Interviews Conducted & 3 & 2 \\
\hline
\end{tabular}

Data Analysis

In carrying out a case study, it is important to account for impressions, both the impressions of the researcher and of the participants. Impressions should be managed in a way that reflects the case accurately and limits reflections of bias (Stake, 2006). Although I cannot claim that the study is without bias, I took steps to strengthen the claims that the findings of this case study are manifestations of the cases, rather than my own impressions. In analyzing the data, a track developed by Stake (2006) was replicated. The track outlines a step by step process for analyzing each case, comparing cases, and making assertions about the relationships between the cases. The steps include: 
1. Documenting a priori themes

2. Documenting survey and interview data

3. Revising and developing themes

4. Determining the prominence of themes for each case

5. Documenting findings for each case

6. Making tentative assertions regarding themes across cases

7. Making final assertions and provide documented evidence

In preparation for collecting and analyzing the experiences of the community volunteers, I drafted a set of eight a priori themes to help guide the process. These themes were a collection of ideas and potential experiences that I expected to document from tutors. As the project moved forward I continually revisited the themes. Some of these ideas were honed to reflect the actual experiences of tutors that were being collected. Other themes emerged anew during the process; while yet other themes were dropped from the analysis of this thesis because there was no data to support the ideas.

In the table below, the a priori themes are listed in the left column, next to the final list of themes. Of the a priori themes, the first and the second themes were merged for form the first revised theme, factors related to volunteers becoming engaged as tutors. The third and fourth themes were merged to form the second revised theme, factors faced by volunteers that are unique to tutoring English literacy. A priori themes numbered $4,5,6$, and 7 were reconsidered in light of the data collected from the tutors. These ideas are touched upon in chapter four within the 
discussion of the third revised theme, factors related to tutor persistence. The fourth revised theme was not among the original list of themes, but emerged during the initial formal interview with a tutor. Questions were asked to all tutors regarding this theme. Finally, a priori theme number eight was dropped from the analysis as little data emerged on the topic.

Table 2: Comparison of a priori and revised themes

\begin{tabular}{|c|c|}
\hline A Priori Themes & Revised Themes \\
\hline $\begin{array}{l}\text { Theme 1: Volunteers seek out the role of a tutor } \\
\text { for personal reasons, often with the goal of } \\
\text { communicating across cultures, }\end{array}$ & $\begin{array}{l}\text { Theme 1: Factors related to volunteers becoming } \\
\text { engaged as tutors. }\end{array}$ \\
\hline $\begin{array}{l}\text { Theme 2: Volunteers seek out the role of a tutor } \\
\text { to be connected with their community or to } \\
\text { improve their community }\end{array}$ & $\begin{array}{l}\text { Theme } 2 \text { : Challenges faced by volunteers that are } \\
\text { unique to tutoring English literacy. }\end{array}$ \\
\hline $\begin{array}{l}\text { Theme 3: Volunteers have unexpected challenges } \\
\text { related to cultural differences }\end{array}$ & Theme 3: Factors related to tutor persistence. \\
\hline $\begin{array}{l}\text { Theme 4: Volunteers face unexpected challenges } \\
\text { around teaching methods }\end{array}$ & $\begin{array}{l}\text { Theme 4: Factors related to the impact of tutoring } \\
\text { on volunteers. }\end{array}$ \\
\hline $\begin{array}{l}\text { Theme 5: Volunteers face many barriers that may } \\
\text { prevent them from continuing }\end{array}$ & \\
\hline $\begin{array}{l}\text { Theme 6: Volunteers access support in a variety } \\
\text { of ways and seek to improve their techniques. }\end{array}$ & \\
\hline $\begin{array}{l}\text { Theme 7: Volunteers seek out resources to } \\
\text { address their unmet support needs. }\end{array}$ & \\
\hline $\begin{array}{l}\text { Theme 8: Volunteers are motivated by various } \\
\text { philosophies that may influence their teaching } \\
\text { philosophies }\end{array}$ & \\
\hline
\end{tabular}


After completing the analysis I was able to make assertions regarding the cases using the four major themes as a framework. The a priori themes and the revised themes are similar in many ways. They both focus on the reasons that tutors become involved, the challenges that they face, and the support that they receive. The revised themes, however, are more robust and are supported by the unique experiences of tutors themselves.

To document and analyze survey questionnaires, data from each survey was entered as a record into an Access database. Several queries and reports were run for each organization to assist in organizing the data. Responses were sorted according to the type of question asked: questions about demographic information, questions about becoming engaged as a tutor, and questions about types of support and development. The information that was entered into the database was anonymous. The primary key associated with each record was an anonymous code, which corresponded to a codename that was attached to each collected survey. As the reports were produced, survey responses were associated with codenames. Once the reports were created, the transcribed responses to open ended questions were coded according to the emerging themes. These responses were sorted by theme and made available for further analysis.

As is indicated in the table below, surveys were collected from seventeen tutors, five of whom tutored at SKCC and twelve of whom were tutors at St. Joseph Parish. The participants are listed according to the code attached to each set of surveys collected. I received one survey that did not accompany a signed informed 
consent form; I removed this from the set of surveys that I compiled for analysis. All records documenting the collected data are being securely stored for the next year in a file cabinet at my home and will then be destroyed. Table 3: A list of survey participants

\begin{tabular}{|l|l|}
\hline St Joseph Parish & $\begin{array}{l}\text { Southeast Keizer } \\
\text { Community Center }\end{array}$ \\
\hline SJ1 & SKCC1 \\
\hline SJ2 & SKCC2 \\
\hline SJ3 & SKCC3 \\
\hline SJ4 & SKCC4 \\
\hline SJ5 & SKCC5 \\
\hline SJ6 & \\
\hline SJ7 & \\
\hline SJ8 & \\
\hline SJ9 & \\
\hline SJ10 & \\
\hline SJ11 & \\
\hline SJ12 & \\
\hline
\end{tabular}

Follow up interviews were used to enrich the data collected from the survey questionnaires. Each interview was recorded and later transcribed using Express Scribe transcription software. I took steps to protect the privacy of the tutors by attaching pseudonyms to the transcripts in the place of the tutors' real names. These pseudonyms are used in the following analysis. A list of the interview participants appears in Table 4 below. Three tutors participated from St. Joseph Parish, and two 
tutors from SKCC also participated. The transcripts from each interview were coded according to the revised themes. The transcripts are available in Appendices H-L:

The coded excerpts from the interviews appear as evidence to support assertions about the two cases in Appendix G.

Table 4: A list of interview participants

\begin{tabular}{|l|l|}
\hline Saint Joseph Parish & Southeast Keizer Community Center \\
\hline Victor & Beulah \\
\hline Anita & George \\
\hline William & \\
\hline
\end{tabular}

\section{Validity}

Factors for ensuring validity, both internal and external, have been considered in designing this study, and steps have been included into the research process to strengthen the validity, or trustworthiness of the study. Trustworthiness of a study, according to Guba and Lincoln (1985), is bolstered by adhering to four trustworthiness criteria: credibility, transferability, dependability, and confirmability. All four constructs, as they relate to this study, are considered below.

Credibility refers to how accurately the data relates to the complex phenomena or the focus of the research. Credibility is achieved here by triangulating the research and by using surveys that have been used effectively in other research. The data was not collected through a single means, but was collected through two separate survey questionnaires and through follow up interviews. I had worked with Oregon Community Foundation to create the Tutor Survey over the course of two years, pilot testing it in the process. I later had experience with not only administering the survey, 
but also discussing the survey results and the quality of the information collected with program coordinators.

Confirmability refers to how objective the research is. In this study, much of the data collection process revolved around a priori themes and hypotheses about the role of the volunteer. To protect against the contamination of these expectations on the final analysis, a log was maintained and matrices were used document the information collected that was collected to maintain progressive subjectivity, assuring that the a priori themes were refined, and others removed, throughout the process. To aid in refining the working themes, the data collected from the cases was documented in detail; the interviews were transcribed and coded for analysis.

Transferability refers the how applicable the research findings are to another setting or case. To address this issue related to external validity, I collected the data in a way that I could later provide rich descriptions of volunteer experiences within the context of each case. To strengthen claims that the conclusions could be generalized to other organizations in the ESOL Initiative, the descriptions of the tutors' experiences were first analyzed within the context of their particular case, allowing conclusions to be drawn about the ordinariness of the experiences within each case. They are then made available for analysis across the two cases to understand, not only the commonalities of the cases, but also the ways in which they differ.

Dependability refers to the degree to which the findings are consistent and could be repeated. For this study, I worked with an advisor as well as with the program coordinator to ensure that the data was dependable and that conclusions drawn from the data were consistent with the information gathered. 
It is important that programs participating in this research project benefit from the project and find value in the process. Both of the selected programs and the volunteers participating in the program agreed to participate in the project as a partner. Program coordinators viewed this as an opportunity to learn more about their volunteers as well as the roles of volunteers at other organizations. Volunteers also had the opportunity to reflect on their experiences, add to their personal narrative, and voice any unmet needs for support as well as any development opportunities that they were seeking out. 


\section{CHAPTER IV: RESULTS AND DISCUSSION}

The Results and Discussion chapters have been combined in an effort to clearly summarize the data that was collected from two cases. In this chapter, I will present findings from each of the two cases, but will intentionally highlight findings that are ordinary across both cases, findings that will lead to some general assertions about the role of the volunteer tutor in these two cases. I cannot make claims about the role of the volunteer tutors across all communities nor can I make assertions about the role of the community volunteer in every ESOL Initiative organization. However, with each assertion that I make regarding the role of the volunteer in these two cases, I will attempt to provide rich descriptions of the context regarding the significant situations from which these assertions developed.

This chapter is composed of five major parts; each section corresponds to a theme that was held in common among the two cases. Within each section, the themes are often broken down into subsections to explore the nuances of each theme. The five major themes of this discussion are: (a) the tutoring session as a contact zone (b) factors related to volunteers becoming engaged as tutors, (c) challenges faced by volunteers that are unique to tutoring English literacy, (d) factors related to tutor persistence, and (e) factors related to the impact of tutoring on volunteers.

\section{Volunteers in the Contact Zone}

Through the oral interviews, tutors discussed - each in their own way- their role in the contact zone. They provided anecdotes from their tutoring sessions regarding discussions around culture that took place in their tutoring sessions, about 
activities that they designed to focus on culture, and about realizations that they had about culture through their interactions with tutees. William, a tutor at St. Joseph's Conversation Partners program told about a time when he developed conversation and role play activities to assist a tutee to communicate with her children's teachers and to help her daughter with a school project. William and his tutee talked about the education systems in Mexico and in the United States. They talked about who to contact at the school or in the school district with various types of questions. William said, "There are a lot of different things that come up, and that is what I like about it." For Beulah, an immigrant herself, tutoring activities were a means for her to learn about her students and their experiences as immigrants. She sees her tutoring environment as a safe place, a place where tutees "can ask questions besides language, social questions."

The tutors' role in the contact zone was not always confined to their tutoring sessions, but spread into their everyday lives. Victor, a tutor at St. Joseph, described his experiences as a customer at a fast food restaurant where he witnessed a Latino worker being reprimanded by his supervisor for not performing a task, an event that was escalated - in part- due to miscommunication. The Latino worker was unable to express, in English, why he was unable to carry out his duties and later expressed his frustration to Victor regarding his inability to communicate in English. After having worked closely with English language learners as a tutor, Victor talked about how he viewed this situation with much more empathy than he would have previous to his experience as a tutor. 


\section{Volunteers: Becoming Engaged as Tutors}

Individuals follow unique and varied paths as they become engaged as volunteer tutors at community-based organizations. However, through the questionnaires and interviews, common ideas and experiences surfaced from volunteers regarding their process for becoming engaged as tutors, which were both personal and professional. Tutors cited a number of life experiences and skills that prepared them and qualified them for the role of a language or literacy tutor, including: (a) interests in people and their community, (b) skills and experiences from previous teaching experience, (c) skills and empathy from previous language study, (d) knowledge and empathy gained from previous cross-cultural experiences.

In a survey questionnaire administered to tutors at both sites, volunteers identified their reasons for beginning as tutors by selecting appropriate responses from a given set of nine choices; they were instructed to select all of the reasons that applied to them from the following list: (a) was asked to volunteer, (b) to meet new people, (c) to practice my language skills, (d) because I am a member or supporter of this organization, (e) to prepare me for a career, (f) to learn or develop new skills, (g)to be involved in and contribute to my community, (h) to learn and share about culture, and (i) other. Participants that selected "other" were provided space to elaborate on their choices and processes for becoming involved as a tutor. Table 5 summarizes the participants' responses to survey questions regarding the reasons that volunteers chose to become involved as tutors. Differences and similarities between the two cases can be seen. 
Table 5 Reasons cited by volunteers for becoming tutors

\begin{tabular}{|c|l|l|l|l|l|l|}
\hline & $\begin{array}{l}\text { Was asked } \\
\text { to } \\
\text { volunteer }\end{array}$ & $\begin{array}{l}\text { To meet } \\
\text { new people }\end{array}$ & $\begin{array}{l}\text { To practice } \\
\text { Spanish } \\
\text { skills }\end{array}$ & $\begin{array}{l}\text { Because I } \\
\text { am a } \\
\text { member of } \\
\text { this } \\
\text { organization }\end{array}$ & $\begin{array}{l}\text { To } \\
\text { prepare } \\
\text { for a } \\
\text { career }\end{array}$ & $\begin{array}{l}\text { To be } \\
\text { involved in } \\
\text { the } \\
\text { community }\end{array}$ \\
\hline St Joseph & $18.2 \%$ & $36.4 \%$ & $45.5 \%$ & $45.5 \%$ & $0.0 \%$ & $72.7 \%$ \\
\hline SKCC & $80.0 \%$ & $20.0 \%$ & $0.0 \%$ & $20.0 \%$ & $0.0 \%$ & $80.0 \%$ \\
$\mathrm{~N}=5$ & & & & & & \\
\hline
\end{tabular}

Differences between the Two Cases

St. Joseph volunteers, unlike tutors at SKCC, cited their interest in the Spanish language and their desire to practice their Spanish language skills as they became engaged as tutors. Nearly half of the tutors that completed a questionnaire noted that they became involved because they perceived the tutoring role to be an opportunity to practice their Spanish skills. In a follow up interview, Victor, from St. Joseph, elaborated on his intent to practice his Spanish as he began tutoring. He said, "I was trying to learn the language, and I thought this would be nice to get involved with this and I could practice my Spanish. That was my first interest." Another volunteer, Anita, mentioned that she met other St. Joseph volunteers at a class to study Spanish. She became involved in the tutoring program soon after. Although past experiences with language learning influenced tutors at SKCC, none of them indicated this as a reason for getting involved, and neither of the tutors interviewed spoke any Spanish. I will explore topic of previous language study in more detail below. 


\section{Relationship with the organizations}

As mentioned earlier, the organizations in both cases are imbedded within the Latino immigrant communities and serve the Latino communities. It is important to note that in both cases, tutors cited their relationship with the organization or with people within the organization as a key to their involvement. Many of the tutors at SKCC attended the Mennonite church, which houses the community center. Although only $20 \%$ of those surveyed at SKCC cited their church membership as a reason for their involvement, tutors discussed their relationship to the church and to the program coordinator, who is also the church's pastor, as a key to their involvement. As documented in the table above, $80 \%$ of SKCC tutors indicated that they were asked to volunteer. Most were asked to tutor by the pastor and center coordinator. When asked why he became involved, George, a tutor at SKCC, said that it was "probably [the pastor]. I've been involved with the community center and worked with [the pastor] in a variety of settings. I was aware of the interest that the ESL program had been getting [from the community]. We were all aware of this."

The tutors at St. Joseph were open about the connection between their church membership and their involvement. Many of the tutors at St. Joseph Parish were members of the church, and they cited their involvement with the church as a primary reason for their recent activity. They read about it in church bulletins and heard about it from priests and other church members. Not only were most tutors members of the church, but nearly three quarters of the tutors surveyed cited this as one of the reasons that they became involved. St. Joseph Parish provides services in both Spanish and 
English, and one outcome for this program was to bring these two congregations closer together and create a sense of community.

\section{Interest in People and Community}

Two of the most common reasons expressed by tutors for getting involved were because of their interests in the community and to meet new people. As is seen in Table 5 above, volunteers across both cases communicated about the need in their communities for additional English literacy services and their interest in the people around them. Over $70 \%$ of the tutors from each case identified community involvement as their primary reason for becoming a tutor. Beulah, a tutor from SKCC, described the need in her community by saying that for "the Spanish [speakers] who live in the US, the focus is trying to help them on a daily basis with their struggle with being in a totally different society." She goes on to discuss her curiosity and her drive to acquaint herself with her students and to learn from them. She says, "I can be very curious. I can ask them to tell me about their culture so that I can learn from them while I teach them something about English."

\section{Previous Teaching Experience}

Tutors in both cases expressed that they became involved, in part, because of teaching skills and experiences that they could apply through volunteer work. Both retired teachers and teachers that were both currently in and temporarily out of the workforce volunteered as tutors for both organizations. Anita, a tutor at St. Joseph Parish, discussed her teaching experiences. She said, "In my career, I was an elementary school teacher. I retired in 2000 and had time to do volunteer work. I was 
a teacher so I had teaching skills, but I thought I would rather work with adults rather than children for a while, for a change." She gave an example about how her teaching experience contributes to her volunteer work. She said, "I always do a lesson plan before the class. I usually have five or six things in the plan that I want to do or that I hope to do." She speculated that, compared to volunteers without teaching experience, her teaching experiences and skills give her confidence to volunteer in this capacity. "Often," she said, "people that have not taught say they would never be able to do that. Whereas retired teachers are the ones that are the most open to it, at least the less fearful of it."

\section{Previous Language Study}

Volunteers from both organizations referred to their previous language study experiences when communicating about their decisions to volunteer as an English literacy tutor. Some referred to their experiences with living in other countries, others referred to formal language training, and still others referred to language instruction and activities. Most commonly, however, volunteer tutors referred to empathy when talking about making decisions to become volunteers. Both Victor, from St. Joseph and George, from SKCC talked about their struggles with learning a language as older adults. George, a retired teacher, traveled and volunteered in Brazil and China. Talking about his experience in Brazil, George said that "I experienced the reality of learning a new language as an older adult. I found it very difficult and so that gave me a sense of, perhaps, empathy." For Beulah, a tutor at SKCC, English was a language in which she was fluent, but German was her native language. She referred to the 
experience of learning English as being "extremely frustrating," and claimed to

"struggle with learning languages." She went on to say that "I can teach it [English] and also from my experience with learning English myself, maybe I have a bit more patience with my students."

\section{The Challenges}

When comparing the role of tutor to other types of volunteer work, tutors from both of these two cases discussed challenges that are unique to the tutoring role. Through the data collection process, I collected and coded information from tutors about the challenges associated to their tutoring, challenges that tutors did not face in other volunteer work. The information was elicited from tutors through open answer questions on a survey instrument and through responses to interview questions. Some challenges were unique to individuals, some were unique to organizations and some were present in both cases, although they were not always equally present between the two cases.

The analysis below primarily focuses on the challenges that surfaced among both organizations, challenges related to four concepts. First, tutors faced challenges with extensive time commitments, both the duration of the commitment and the time needed each week to prepare and carry out lessons. Second, tutors were challenged to meet the diverse needs of learners, especially in group settings where the tutees had varied backgrounds, skill-sets, and needs. Third, tutors faced challenges in working with a population that struggled to attend tutoring on a regular basis. Finally, tutors 
were challenged in their efforts to create activities and create materials for lessons that would be of interest to their tutees.

Meeting Diverse Needs of Students

ESOL Initiative tutors that led small group tutoring sessions communicated about the diverse needs of the students that comprised their groups and challenges related to assessing the needs of students and providing meaningful, authentic instruction. As is seen in Table 6 below, tutors struggled to meet the needs of students who had limited literacy or low education in their native language. Beulah, a tutor at SKCC discussed her challenges in detail. Some of her students had low education in their native language. When using terms to describe grammatical concepts such as tenses, she struggled. She said, "I ask if they have 6 years of education or 8 years of education in Mexico. They don't have the grammatical terminology, for example, like the simple present or the perfect past." Related to this, which is presented in more detail below, are issues related to finding materials and creating activities that are of interest and appropriate to tutees. 
Table 6: Comments from tutors about the various skills and needs of their tutees

\begin{tabular}{|l|l|l|}
\hline Participant & Organization & Challenges \\
\hline SJ7 & St Joseph Parish & $\begin{array}{l}\text { Illiteracy in native language; I need to move away from } \\
\text { "written" materials to more "visual" and conversational } \\
\text { lessons }\end{array}$ \\
\hline SJ9 & St Joseph Parish & $\begin{array}{l}\text { I will say there are different levels in my group. Each } \\
\text { member in my group has a unique style of learning. }\end{array}$ \\
\hline Beulah & SKCC & $\begin{array}{l}\text { At least here you have a real variety of learners. Some } \\
\text { are very good in the oral part, but struggle in the } \\
\text { written part. To find exercises that everybody can } \\
\text { benefit from, I think it is the most challenging. It is not } \\
\text { really the learners; for me, the challenging part is to } \\
\text { find the right exercises. - Beulah }\end{array}$ \\
\hline SKCC5 & SKCC & $\begin{array}{l}\text { The greatest challenge is meeting the needs of the } \\
\text { individual class members. Everyone comes from } \\
\text { different ability groupings }\end{array}$ \\
\hline
\end{tabular}

Erratic Attendance and Hours of Instruction

Tutors in both cases noted that students struggled with regular class

attendance. This posed a challenge to tutors in their efforts to maintain continuity in their activities and instruction, both within a given tutoring session and from week to week. Despite the fact that each program had different attendance and enrollment policies and sought to limit attendance barriers for tutees in different ways, tutors from both organizations saw this as a challenge. Not only was it frustrating for tutors to maintain continuity in the classroom, tutors also communicated that limited and spotty 
attendance affected the tutees' ability to grow. One St. Joseph tutor, SJ10, commented through the survey questionnaire that "one class a week is not immediately effective." In addition, SJ10 felt that students had a variety of needs, or barriers, which prevented them from attending even once per week. SJ10 wrote that, "Student needs mean frequent absences." Table 7 documents tutor responses from both organizations related to student attendance. More tutor responses regarding issues related to student attendance is listed in Appendix G.

Table 7: Comments from tutors regarding challenges around attendance

\begin{tabular}{|l|l|l|}
\hline Participant & Organization & Challenges \\
\hline SJ11 & St Joseph Parish & $\begin{array}{l}\text { Some students are unable to attend all classes each week - } \\
\text { transportation problems (few and demands of family care } \\
\text { (most frequently)). }\end{array}$ \\
\hline SJ2 & St Joseph Parish & $\begin{array}{l}\text { The student attendance is not as consistent as I would want. } \\
\text { As parents they have many obligations and things do interfere } \\
\text { with their best intentions of learning English. }\end{array}$ \\
\hline SJ3 & St Joseph Parish & $\begin{array}{l}\text { Inconsistent attendance of our students is frustrating to our } \\
\text { tutors. }\end{array}$ \\
\hline SKCC5 & SKCC & $\begin{array}{l}\text { Sometimes attendance is not as regular as it could be and } \\
\text { creates the dilemma of trying to keep everyone at the same } \\
\text { place. }\end{array}$ \\
\hline SKCC1 & SKCC & The class varies a lot from week to week in attendance. \\
\hline
\end{tabular}

\section{Creating Activities and Using Materials}

Experienced and inexperienced tutors alike, for both of these ESOL Initiative organizations, documented issues related to preparing activities and creating materials that met the needs of their tutees. Anita, a St. Joseph tutor with eight years of tutoring experience talked about the limitations of materials available to her and provided 
insight into the amount of time and effort that she provided to create and find supplemental materials. "There is no perfect material, and you know that as well as I do," she said during an interview. She continued, "So we are constantly looking around for materials to supplement what we are doing." Some tutors have purchased their own materials as is doçumented in survey questionnaire responses. A St. Joseph tutor, SJ6 noted that his/her favorite book for the students with which he/she was working was a book that was not part of the organization's curriculum. Other tutor comments appear below, in Table 8, regarding the issues they face around materials. Table 8: Comments from tutors regarding challenges around activities and materials

\begin{tabular}{|l|l|l|}
\hline Participant & Organization & Challenges \\
\hline SJ3 & St Joseph Parish & $\begin{array}{l}\text { Also, The books for adults learning English are not perfect } \\
\text { but I understand there is not such a thing available. So, we } \\
\text { do the best we can with what we have. }\end{array}$ \\
\hline SJ5 & St Joseph Parish & $\begin{array}{l}\text { My students like to practice reading - it is hard to find } \\
\text { materials of appropriate difficulty (LifePrints 3 level). }\end{array}$ \\
\hline SJ6 & St Joseph Parish & $\begin{array}{l}\text { I'd like to use other books after the first two (literacy }+ \\
\text { book one) of the LifePrints. My favorite is Side by Side } \\
\text { (book one goes to simple past). }\end{array}$ \\
\hline SKCC5 & $\begin{array}{l}\text { Southeast Keizer } \\
\text { Community } \\
\text { Center }\end{array}$ & $\begin{array}{l}\text { Get more creative in planning and structuring the sessions. } \\
\text { More training i.e. workshops would probably be } \\
\text { advantageous. }\end{array}$ \\
\hline
\end{tabular}

Still, tutors take pride in their role and expressed interest in developing their skills in a variety of areas. In Table 8 above, SKCC 5 expressed an interest in developing skills around creatively planning and structuring sessions, possibly through workshops. Echoing that idea in a follow up interview, George discussed ideas related to workshops or trainings that would allow tutors to share ideas. A trainer, he 
suggested should "have activities that engage students in listening skills. If the students could experience listening skills, reading skills, speaking skills in each session that would be helpful, and also the writing skills."

Tutors overwhelmingly expressed interest in developing their skills through data collected in a survey questionnaire. Tutors communicated about tutoring skills and areas of knowledge that they sought to develop through workshops or trainings. Through the survey questionnaire tutors were asked to identify content areas in which they would be interested in developing their tutoring skills further. They were asked to mark any skill area that they would like to develop from a list of 19 possible content areas. The content areas are listed in the Figure 2 below. Each tutor identified at least 3 content areas, and tutors identified, on average, 8 content areas in which that they would like to further develop their skills. Tutors at SKCC expressed interest in developing their skills in nearly every category. The exceptions were the categories related to the Spanish language. St. Joseph's tutors expressed a greater interest in studying Spanish as a means to improve their tutoring. They also expressed an interest in exploring areas in which Spanish speakers struggled, including grammar and pronunciation skills. Overall, the most commonly selected topics for further development were problem areas for Spanish-speakers, teaching strategies, cultural awareness, leading conversations, and teaching vocabulary. 
Figure 2: Topics of interest for skill development in both cases

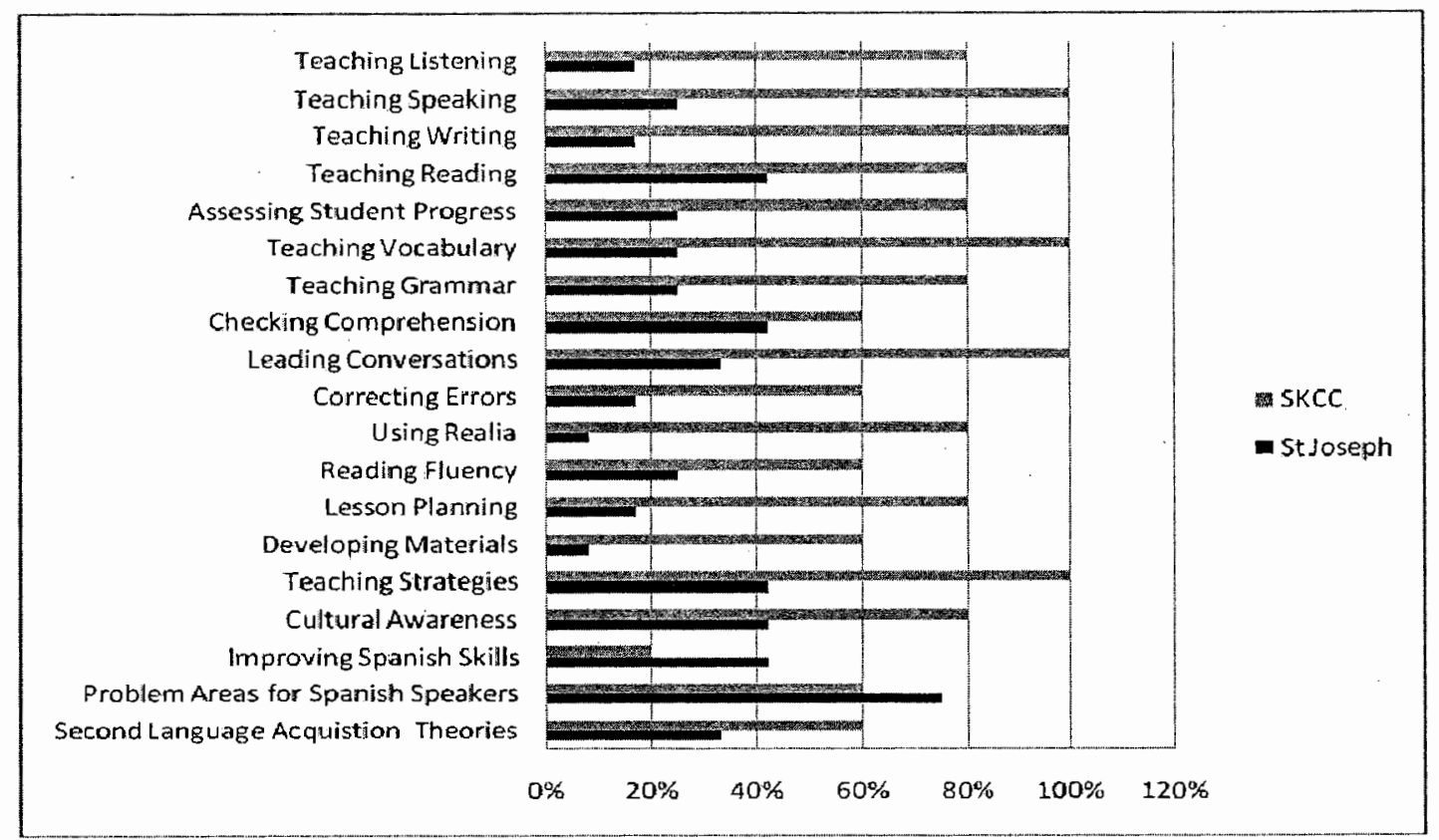

\section{Time Commitments}

Tutoring requires an extensive time commitment, both the duration of the commitment and the time needed each week to prepare and carry out lessons.

Program coordinators ask tutors to commit to a three month term and to volunteer at least once a week during that three month term. Tutors at St. Joseph Parish's

Conversation Partners program, however, have more flexibility. They can coordinate with one another to ensure that the program is fully staffed each Saturday and take time off as needed. Unlike the English Literacy tutors at St. Joseph, they do not plan lessons each week. They arrive and lead conversations in a drop-in program. William chose to become involved in this program because of the flexibility when compared to 
the ESOL Literacy tutoring program. "I don't want to take on too much more in the way of real hard, hard, what's the word, real hard schedule. A softer schedule works," he said during the interview.

Most tutors at both SKCC and St Joseph, however, are asked to meet the commitment requirements as they become engaged as tutors. A majority of these tutors are not in the workforce. Most are retired, but five of the sixteen tutors that revealed their age in the survey questionnaires work at least part-time. Two of the tutors are studying at a college part-time. A breakdown of the surveyed tutors' employment status is listed in the table below.

Table 9: Employment status of tutors

\begin{tabular}{|c|c|c|c|}
\hline $\begin{array}{c}\text { Number of Tutors } \\
\text { Surveyed }\end{array}$ & $\begin{array}{c}\text { Number of Tutors not } \\
\text { in the workforce }\end{array}$ & $\begin{array}{c}\text { Number of tutors } \\
\text { working full-time }\end{array}$ & $\begin{array}{c}\text { Number of tutors } \\
\text { working part-time }\end{array}$ \\
\hline 17 & 12 & 3 & 2 \\
\hline
\end{tabular}

In preparation for each tutoring session, tutors set aside time, in addition to the time they designate for tutoring, for preparation. Beulah, a mother of two young children, works in the home with her children. She said in the interview, "For me it is really rewarding because I get out of the house and can focus on someone else, other than my kids, and I think it is the same for them." She discussed her challenges related to this type of volunteer work at SKCC compared to her other volunteer work as a baker. "Language classes is way more, you need way more time than other things. In my baking I just go there and use the recipes; I don't need to prepare at all. 
But language, to prepare for language, especially if you want to mix in the culture and build on what you did last week, to incorporate everything, is very time intensive." Anita, a tutor at St. Joseph alluded to the time she spent preparing for her tutoring sessions. For her, finding materials that would meet the needs of her students was a time consuming process, but she sought to incorporate new materials in each of her lesson plans and structure a number of activities around those materials.

\section{Volunteer Persistence across Cases}

All seventeen tutors that completed the survey questionnaire for this study (tutors across both cases) indicated that they planned to continue as tutors although some had planned to take a term off. To better understand what motivated them to continue, the comments collected from tutors through the questionnaires' open ended questions and interview questions were collected, coded and compiled. Although the reasons for tutors' continued motivation varied, responses generally clustered around the following themes: a sense of effectiveness as a tutor, motivation and appreciation of tutees, relationships, and personal connections.

As noted above, people that have volunteered as tutors in both of these cases spend a greater amount of time and energy with tutoring when compared to other volunteer work they have done. One factor that motivates tutors to continue is seeing improvement in their tutees and realizing the effectiveness of their labor. Tutors express a sense of satisfaction when they experience success and see the effect of their work in their tutees' "growth." Beulah of SKCC says, "I like teaching and tutoring languages because you can really feel the students grow," and William of St. Joseph 
Parish adds, "You are able to see growth. And that is something that I like a lot." Tutors take pride in their ability to teach language and literacy skills. One tutor, SJ11, commented on the survey questionnaire that she/he was motivated by the "small successes," listing improved pronunciation and communication skills that she/he could see in her/his tutees. Another tutor from SKCC mentioned that all of the lesson planning and preparation was worth the effort when things "work out." Other tutor comments can be found in Appendix I.

Many tutors pursued these positions as a means to meet new people and noted that tutoring differed from other volunteer work, in part, because of the social nature of the position. These relationships are a factor in tutor persistence; for tutors that sought to build these relationships, this role met their expectations. Anita was a retired elementary school teacher that chose to tutor adults, in part, because of the relationships. Of her work at St. Joseph, she talked about her reasons for continuing as a tutor. She said that she liked "the fact that it is a long term type of thing, you know that you establish a relationship. You are able to see growth. And that is something that I like a lot." She referred to her students as being "charming and gracious," and that some of her students who have worked with her the longest have invited her and her husband to family events such as weddings. She said, "We will always go if we can at all go."

Tutors were also motivated by the determination as well as the appreciation that was displayed by their tutees. Beulah, a tutor at SKCC was impressed that she could not leave after a tutoring session without her tutees expressing their thanks. Victor, a tutor from St. Joseph Parish, also expressed pride in his work, saying that "I 
was able to give these people something that was very useful and they were extremely grateful to have." Tutors were also motivated to continue because of the drive that their tutees displayed. For some tutors, the drive of their tutees was unexpected. Victor, a tutor at St. Joseph Parish talked about how some of his students had received college degrees before moving to the United States and that their education was not recognized here in the United States. One student, he said, was "doing this because she wants her daughter to have a better life." He continued, saying that "they all really realize how important this is and they like the one-on-one attention." Another tutor George, from SKCC, agreed. His tutees come with a desire to learn "because," he said, "they have a specific need. Students that I work with have a desire to learn the language."

\section{The Impact of Tutoring on Volunteers}

Through the relationships that tutors build as a part this volunteer work, many become more aware of the culture and needs of the Latino immigrant community. In the anecdote above, Victor from St. Joseph Parish expressed an understanding of one of the issues that English language learners face when they arrive in the United States. His advice to others was to not judge without taking the opportunity to understand. He provided a number of stories about seeing immigrants in the community being discriminated against or treated as though their limited English was indicative of lesser intelligence. Anita, another tutor from St. Joseph also commented on the impact that her experiences had on her. In an interview, Anita discussed the personal impact of her tutoring experience. 
It has made me more aware of the needs of immigrants and the problems that immigrants face here in the United States. It has made me much more sensitive to them and what is going on in their lives. I think it is best for me to be sensitive and interested.

Other tutors relayed stories about the needs of their tutees. Beulah talked about her group, which was made up of mostly women who were mothers. For them, this was a much needed experience to focus on something other than their children and to be social through English. Her tutees will often ask questions about social and cultural issues. She says that this is an opportunity for them "to be challenged intellectually, academically."

Tutors talked about other impacts that their experiences had on them. Over the course of their time as tutors, they accumulated skills, materials, and a sense of what works well with their tutees. Despite the challenges with meeting the diverse needs of their students, tutors communicated about activities that worked well, activities that students liked. Victor talked about the need to move quickly from one activity to another to maintain tutees' interest. George has found a conversation activity that his tutees like and so he adapts it to each session that he leads. Because her students enjoyed reading stories so much, Anita was able to bring stories that she clipped from the newspaper that the students found interesting. Each tutor talked about improving their skills, but William was the most forthright when talking about his improved ability, which was due, primarily, to an increase in confidence. William said in an interview, "Now I feel more confident about what is going on." He continued, "[people] have been coming for some time now, so, you know, more often than not, 
they are folks that come in Saturday morning that I know now by sight. And now by sitting down and having a chit-chat on Saturday morning, that anxiety and tentative feeling about it is not there anymore."

\section{Challenges to Validity}

My experience with these programs, and the ESOL Initiative, put me in a unique position as a researcher. My experience provided me with a good working knowledge of the cases. I was familiar with the physical spaces, the demographics that were served at each case, and, with some of the tutors and tutees at each site. My relationships with the tutor coordinators at each site provided leverage for me as I collected surveys and contacted tutors for interviews. Their support and interest in the project helped create buy-in from the tutors. Also, the survey instruments and interview questions were well informed and tested through previous contact with these programs.

My position, however, also limited the study in some ways. It affected the validity around confirmablity and transferability. Although the tutors were comfortable working with me during the research process, they also, I felt, wanted to put their work and their programs in a positive light. The participation in this project was low, especially regarding the follow-up interviews. Although many of the tutors were busy and some were out of town during the data collection period, I suspect that some tutors chose not to participate because of my relationship to the project. It is possible that they were nervous about answering questions that might negatively affect their program, or it is possible that they were hesitant as they feared that their 
responses would be associated with them by their program coordinator. Program Coordinators, indeed, were curious about who was participating and were checking in about the project to learn more about the project's status. Despite the mechanisms in place to protect the tutors' identities, it is very possible that that some preferred not to risk their privacy and chose not to participate.

My familiarity with the programs also created challenges for me in making assumptions and in asking some guiding questions to tutors. I'm sure this background knowledge influenced the data collection and analysis process. That said, I was forced to challenge my assumptions on many occasions and tutors, too, challenged my assumptions during the process. Regarding the issue of transferability, the study is limited in scope. The two participating organizations were similar in many ways, including the region in which they operated. For any claims to be transferred to the ESOL Initiative groups as a whole, this study should be expanded to include a more diverse set of cases, including cases from southern and central Oregon. The cases in these studies drew their volunteers primarily from within their organizations. Other CBOs partner with other organizations, such as universities, to recruit volunteers. To build on this research and to strengthen claims associated with this research, consideration should be given to organizations that recruit volunteers through other means. 


\section{CHAPTER V: CONCLUSION}

This chapter is divided into four major sections. The first section reviews each research question that I set out to address through this project and provides a summary of the findings related to each research question. Included are references to other related research and research from which this work developed. The second section reviews the scope and limitations of this study. This is followed by the third section, which focuses on potential research that could either develop out of this project or could fill in gaps that this project could not address. The final section summarizes the project, both from both a personal and professional point of view, and highlights important findings from this project.

\section{Review of Research Questions}

\section{Volunteers Becoming Engaged as Tutors}

The first research question was developed, originally, to explore themes related to the reasons that volunteers cited for becoming tutors. By collecting and presenting a set of data developed from tutors' responses to open-ended survey and interview questions, I sought to build on the work of Miller (1982), who surveyed tutors and analyzed the responses that volunteers selected from a prepared list of reasons for becoming tutors. As I collected the data, however, the question became broader and multi-dimensional. It became clear that I could not address the reasons that tutors gave for volunteering without exploring their relationships with the organizations with which they were volunteering as well as the life experiences and goals that the tutors 
brought with them. The question was redrafted to address, more generally, the process by which tutors became involved, which included their reasons for volunteering, their relationships with the organizations, and their experiences that attracted them to this work.

I expected that tutors' reasons for becoming engaged as tutors would mirror some of the responses provided by tutors in Miller's study: (a) to improve the community, (b) meet people and socialize, and (c) express concern with others. As language tutors, I also expected that they would express an interest in working across cultures and possibly practicing their Spanish language skills. I discovered this to be true. However, only tutors at St. Joseph Parish indicated that they volunteered, in part, to practice their Spanish language skills. Tutors confirmed that they began volunteering for these reasons, but more importantly, they discussed the unique paths that they followed as they engaged in this challenging work.

To meet those challenges, tutors discussed the important role that their interests, strengths and experiences played. These experiences, interests and skills of tutors are related to previous or current teaching experiences, previous or current language learning experiences, interpersonal communication, experiences with acculturation from living abroad or from immigrating to the United States, and previous experiences around critical incidents in which they deconstructed their own cultural frameworks.

Although these skills and experiences gave tutors a sense of empathy and practical tools that they applied as tutors, they would likely not have become involved if they had not been recruited through their social networks and through their 
relationships these organizations or cases. They were either asked by their friends and associates, as was the case at Salem-Keizer Community Center or they were active members of the organizations that were providing the service, as was the case at St. Joseph Parish. Through these relationships volunteers were able to enter into the role of the tutor and apply their interests, experiences and skills that prepared them for and qualified them for tutoring, including: (a) interests in people and their community, (b) skills and experiences from previous teaching experience, (c) skills and empathy from previous language study, and (d) knowledge and empathy gained from previous crosscultural experiences. Tutors not only referred to these themes as factors for engaging them initially, but also referred to these when reflecting on the many challenges that they face.

\section{Challenges Unique to Volunteering as a Tutor}

As I worked with community groups, through the ESOL Initiative, to recruit and train tutors to work as English literacy tutors, it was important for me to recognize and understand some of the challenges that tutors experienced. The implications of this data can improve support for tutors, enable coordinators to assist tutors in creating realistic expectations about the role of a tutor, and better prepare tutors for this role. In these cases the demands on tutors were high when compared to other volunteer work. Tutors, in these cases, were challenged with meeting the unique and diverse needs of tutees, by the erratic attendance of students, and by the time commitments that are often required of them. 
Tutors struggled to meet the diverse needs of their tutees as participants. Participants of English literacy classrooms vary widely in age, educational background, work experiences, and goals for using reading, and writing and listening skills outside of the classroom (Condelli, Wrigley, \& Yoon, 2002; Guth \& Wrigley, 1992; Kim \& Creighton, 2000; National Center for Education Statistics, 1998; Wrigley, 1993). In this study the diversity of tutees' needs was evidenced through volunteer accounts in both cases. Although tutors in these cases were supplied with materials and a curriculum, tutors indicated that they spent a great deal of time preparing their lessons and creating activities to supplement the lessons from their curriculum materials in order meet the needs of their tutees. They especially struggled to assist tutees with low education and limited L1 literacy skills.

In surveying the practices of programs across the United States, Condelli, Wrigley and Yoon (2002) concluded that one practice common across successful programs was the act of making more instructional time available to students and increasing the hours of instruction made available to students. Tutor accounts from both cases seem to support this conclusion. One of their biggest challenges was working with tutees that were unable to attend the tutoring sessions regularly. Tutors discussed some of the barriers that existed for their tutees, including long and erratic work schedules as well as family obligations. Some advocated for changing attendance policies and commented about how the erratic attendance disturbed the flow of the activities in their tutoring sessions. In general they felt that their tutees needed more hours of instruction to show improvement and that their tutees' attendance made the task of demonstrated improvement even more challenging. 
Despite the challenges, the tutors surveyed and interviewed in this study overwhelmingly planned to continue and demonstrated a strong interest in building on their acquired skills and experiences to become more effective in their pursuits. They looked to be more creative in their lessons and indicated a variety of topics and skills that they would like to improve to meet the needs of their students. The idea that tutors sought to develop their skills to be more effective is closely related to persistence, the act of tutors continuing in and expanding their role.

\section{Factors Related to Volunteers Persisting as Tutors}

Volunteer persistence is defined, here, as the act of volunteers continuing as tutors or citing the intention to continue beyond the basic commitment requirements coupled with a displayed interest in improving their skills and effectiveness as tutors. Tutors were asked, both in the surveys and in the interviews, to describe what they liked about tutoring and to describe how their work as volunteer tutors met or did not meet their expectations. Many of the responses from tutors focused on reasons why they planned to continue as tutors despite the demands that were placed on them. Themes surfaced from volunteers about the factors that motivated them to continue, including having a sense of effectiveness as a literacy tutor, witnessing the motivation and appreciation of their tutees, and forming relationships and personal connections. Not only did all of the tutors participating in these cases indicate that they planned to continue, but they also cited interests developing their skills to be more effective and to expand their role as tutors. 
Instructors in effective English literacy programs provide learner-centered instruction (Condelli, Wrigely, \& Yoon, 2002). Tutors in these cases dedicated a great deal of time outside of the tutoring sessions to identify materials and activities they could bring to the tutoring session to supplement the curriculum. Tutors communicated about being motivated when their tutees showed an interest in the lessons that they had planned, and they talked about seeing the growth that students showed as a result of these activities. Through interaction with their tutees during tutoring sessions, tutors better understand the goals and needs of their tutees; through these interactions tutors also increase their understanding of the social issues, outside of the program, that are important to the Latino community.

\section{Factors Related to the Impact of Tutoring on Volunteers}

This theme also developed during the data collection process. I did not expect it to have such a presence in this study from the outset. It was during an initial interview with a tutor from St. Joseph Parish that this theme surfaced, multiple times. In subsequent interviews with tutors this theme was addressed through more direct questions. Their answers provided insight into how their experiences affected them both personally and professionally as tutors, often providing insight into the tutoring session as a contact zone.

Pratt (1990) described a contact zone as a temporal, social, and sometimes physical space where communities come into contact, which is a perfect description of these tutoring environments. There were likely to be salubrious as well as perilous products of these contact zones, but tutors concentrated on the positive when talking 
about their experiences and the impact that their experiences had on them. Pratt (1990) listed some products of a culturally sensitive contact zone, which included collaboration, critique of culture, and mediation. There was evidence that all of these products were manifested through these tutoring groups. Tutors described their interactions with students discussing cultural gaps in issues related to work, education, and gender roles to name a few. It was no surprise, then, when tutors spoke about their increased awareness of both the Anglo and Latino communities and some of the stresses associated with acculturation, especially within the Latino community.

Another factor related to persistence was the references made by tutors about plans to expand their role and increase their effectiveness as tutors. They communicated about improving their effectiveness by honing their skills, stockpiling experience and activities, and gaining their confidence as they watched their students grow. Again, tutors spoke about the importance of crafting lessons that met the needs of the students outside the classroom and seeing the students grow both in and outside of the classroom. Tutors took their role seriously and viewed their ability to be effective as very important. This is evidenced, in part, by the interest that they expressed in a variety of topic areas and means for developing their skills and, in part, by talking about their growth from their experiences.

\section{Recommendations}

This study focused on the role of community volunteers in two organizations. Many communicated about their experiences, including experiences with confronting different cultural viewpoints and perspectives as they worked with language learners. 
They had the opportunity to critique and discuss cultural viewpoints, for example, around work, education, gender roles, family relationships, and other social constructs. They demonstrated an interest in their community and in their ability to provide students with skills and knowledge that could be applied outside the classroom. Although they had little formal training in teaching English literacy for adults, they each brought with them skills and experiences that they could apply and potentially share with other tutors.

Because of the skills and experiences that tutors brought with them and because they demonstrated interest in developing their skills further, additional training opportunities and opportunities for tutors to come together to share their expertise and to hone their skills are needed. These events could be formal and/or informal. Attendance could be required or tutors could attend voluntarily. It is likely that tutors themselves could organize some of these events and work with program coordinators to focus on topics that are important to them. Such events would give tutors the opportunity to share activity ideas and materials that worked well for them in the past. Additional formal events could provide a structured approach to researching topics of common interests. As tutors struggle with time and creativity around preparing learner-centered.lessons, a product of each of these training events should be activities, materials, or lesson plans that tutors could immediately apply in their tutoring sessions. Topics deserving attention, as indicated by data collected in this study, are working with multi-level groups, providing instruction for tutees that have limited literacy skills in their first language, reflecting on cultural constructs, and 
on understanding the Latino culture. These are essential to increasing tutor skills and for building communities and cultural bridges.

Tutors in both cases cited challenges related to attendance that should be reflected on by community-based programs when creating policies and procedures. The organizations in this study built their programs around the idea of increasing access to English literacy instruction for members of their communities. Accessibility is an important part of these programs' missions, and this access makes their programs integral to the community. Tutors, however, suggested that loose attendance policies inhibited their ability to be effective. Other research suggests that managed enrollment and increased hours of instruction are best practices. Community-based programs should reflect on their attendance requirements and policies and find a balance that creates access for tutees, but also sets tutees and tutors up for success.

A final recommendation for these community programs is to focus on creatively increasing the hours of instruction. Programs should assist tutors in designing activities for tutees that could be completed by tutees outside of the tutoring session. Some programs incorporate project-based learning into their framework, providing activities for tutees to carry out between sessions. These projects often focus on community involvement but may be something as simple as surveying the eating habits of their friends, families and coworkers or comparing the type of advertisements on television in English with television in Spanish. Activities should focus on speaking and listening as well as reading and writing skills. These projects should support the goals of the tutees and should have practical and immediate applications in the tutees' lives. 


\section{Suggestions for Further Research}

The data collected through this study was very broad and covered a variety of aspects related to the role of the volunteer tutor within community-based programs that could be explored in more detail. One example of a topic that deserves a more indepth analysis is the tutoring session as a contact zone. A number of products come from these sessions that could be categorized and explored in more depth. Observation and more refined questions through surveys and interviews provide some rich, meaningful information about what comes out of these contact zones including autoethnographic texts, texts through which people describe themselves through representations that others have created of them, and transculturation, a process through which the subordinate group creates and communicates their perspective through the media of the dominant group.

Another topic that could be explored is an analysis of tutoring programs as communities of practice. In this study, tutors in both cases learned through their practice. Little was revealed, however, about how the tutors interacted and shared their knowledge within their communities. Wenger describes a community of practice as a collective learning environment where a group of practitioners come together to engage and learn about a common topic. As tutors bring with them strengths and experiences, they have the ability to engage others around those topics (Wenger, 1998). Such a project could be another case study or an action research study where the researcher organizes activities for tutors to come together to discuss issues and to share ideas. 
Another aspect of this study that deserves more attention is around the idea of persistence. Every tutor that participated in this study expressed plans to continue tutoring. Many tutors, however, do not continue for various reasons. A more balanced perspective on topics such as tutor challenges and factors related to volunteer persistence would include data collected from tutors that left their tutoring positions. Data could be collected through surveys and interviews or could be collected through a longer term case study that included observations over a longer period of time.

\section{Summary}

This project draws together a rich set of volunteer experiences that has not only strengthened my understanding of the role of the community volunteer, but has strengthened my role in community activism and volunteerism during a time that is characterized by themes such as increased immigration, cultural tension, an aging population, service to community, and the application of research related to service learning and situated learning. In working with volunteers it is important to understand the assets that volunteers bring with them in terms of knowledge and experience and to utilize these assets to strengthen any volunteer literacy program.

Most tutors are curious about themselves and about those that they work with, and many want nothing more than to serve the individuals in the program and build community. In programs that have limited resources, volunteers struggle with a number of challenges, but they are resourceful. Program coordinators, trainers, and program advocates can support tutors by organizing them to build on what they already have. In closing, Beulah, from SKCC might have summed up the role of the 
community volunteer best. When talking about her interaction with tutees in this contact zone, she said, "I can be very curious. I can ask them to tell me about their culture so that I can learn from them while I teach them something about English." May we all be curious and share what we have. 


\section{REFERENCES}

Addams, J. (1910). Twenty years at Hull-House. New York: Macmillan.

Addams, J. (1930). The second twenty years at Hull-House. New York: Macmillan.

Alamprese, J. (1996). National quality standards for volunteer literacy programs.

(Report no. ED417267). Retrieved from the Educational Resources

Information Center:

http://www.eric.ed.gov/ERICDocs/data/ericdocs2sql/content_storage_01/0000 019b/80/15/49/01.pdf.

Blackwood, J. (1998). Training for volunteer teachers in church-affiliated English

language mission programs. Portland, OR: Portland State University.

Bennett, Janet M.; Bennett Milton J.; Allen, Wendy. (2003). Developing intercultural competence in the language classroom. In Lange, Dale L.; Paige, Michael R. (Eds.), Culture as the Core: Perspectives on Culture in Second Language Learning. (pp. 237-270). Greenwich, CT: Information Age Publishing.

Brody, Jill (2003). A linguistic anthropological perspective on language and culture in the second language curriculum. In Lange, Dale L.; Paige, Michael R. (Eds.), Culture as the Core: Perspectives on Culture in Second Language Learning. (pp. 37-51). Greenwich, CT: Information Age Publishing.

Crawford, Linda M. \& McLaren, Peter (2003). A critical perspective on culture in the second language classroom. In Lange, Dale L.; Paige, Michael R. (Eds.), Culture as the Core: Perspectives on Culture in Second Language Learning. (pp. 127-154). Greenwich, CT: Information Age Publishing. 
Cabassa, L. J. (2003). Measuring acculturation: Where we are and where we need to go. Hispanic Journal of Behavioral Sciences. Vol. 25 (2), 127-146.

Chisman, F.P. \& Crandall, J. (2007). Passing the torch: Strategies for innovation in community college ESL. Retrieved from the Council for Advancement of Adult Literacy: http://caalusa.org/eslpassingtorch226.pdf.

Collier, Virginia P. (2007). How long: A synthesis of research on academic achievement in a second language. TESOL Quarterly, Vol. 23 (3), 509-531.

Condelli, L.; Wrigley, H. \& Yoon, K. (2002). What works for adult ESL Literacy students. Study summary. (Report no. ED482789). Retrieved from Educational Resources Information Center: http://www.eric.ed.gov/ERICDocs/data/ ericdocs2sq1/content_storage_01/0000019b/80/1b/95/f2.pdf .

Cook, W. D. (1977). Adult literacy education in the United States. Newark: International reading Association.

Guth, G. \& Wrigley, H. (1992). Adult ESL literacy programs and practices. A report on a national research study. (Report No. ED348895). Retrieved from Educational Resources Information Center: http://www.eric.ed.gov/ERICDocs/ data/ericdocs2sql/ content_storage_01/0000019b/80/38/27/06.pdf.

Guth, G. (1993). Profiles of adult ESL literacy programs. TESOL Quarterly, 27(3), $533-537$.

Hickman, T. \& Ostrogorsky. T. (2007). ESOL initiative evaluation plan. [White Paper]. Oregon Community Foundation.

Houle, C. O. (1992). The literature of adult education: A bibliographic essay. San 
Francisco: Jossey-Bass.

Kim, K., \& Creighton, S. (2000). Participation in adult education in the United States: 1998-99. (Report No. 2000-027). Retrieved from the National Center for Education Statistics:

http://nces.ed.gov/pubsearch/pubsinfo.asp?pubid=2000027.

Kissam, E. \& Stephen, L (2006). The new pluralism in Woodburn Oregon: $A$ community study conducted in 2003-2004. Retrieved from the University of Oregon: http://wnw.uoregon.edu/pdf_imm/Short\%20Woodburn-Final\%20915.pdf.

Knowles, M. S. (1962). The adult education movement in the United States. New York: Holt, Rinehart \& Winston.

Lincoln, Y. S. \& Guba, E. G. (1985). Naturalistic inquiry. Beverly Hills, CA: Sage. Marin, G., \& Marin, B. V. (1991). Research with Hispanic populations. Thousand Oaks, CA: Sage.

Martinez, C., McClure, H., \& Eddy, M. (2009). Language brokering contexts and behavioral and emotional adjustment among Latino parents and adolescents. The Journal of Early Adolescence, 29(1), 71-98.

Martinez, C. (2006). Effects of differential family acculturation on Latino adolescent substance abuse. Family Relations, 55(3), 279-291.

Miller, J. (1982). Tutoring: The guidance and counseling role of the tutor in vocational preparation. Further Education Unit. (ERIC Document Reproduction Service No. ED 218506)

Moyerman, D. \& Forman, B. (1992). Acculturation and adjustment: A meta-analytic 
study. Hispanic Journal of Behavioral Sciences, 14(2), 163-200.

Newman, C.; Grognet, A.; \& Crandall, J. (2002) LifePrints: ESL for Adults.

Syracuse, NY: New Readers Press.

National Reporting System (2009). About NRS. Retrieved from the National Reporting System: http://www.nrsweb.org/about/.

National Center for Education Statistics (1998). Adult participation in English-as-asecond language (ESL) classes [Fact sheet]. Retrieved from: http://nces.ed.gov/pubs98/web/ 98036.asp.

Padilla, A. \& Perez, W. (2003). Acculturation, social identity, and social cognition: A new perspective. Hispanic Journal of Behavioral Sciences, 25(1), 35-55.

Pratt, J. L. (1996). Arts of the contact zone. In D. Bartholomae \& A. Petrosky (Eds.), Resources for teaching ways of reading: An anthology for writers (pp. 460460). Boston: Bedford Books.

Quigley, B. A. (1997). Rethinking literacy education: The critical need for practicebased change. San Francisco: Jossey-Bass.

Rice, J.K. \& Stavrianos, M. (1995). Adult English as a second language programs: An overview of policies, participants, and practices. (Report No. ED388115). Retrieved from Educational Resources Information Center: http://www.eric.ed.gov/ERICDocs/ data/ericdocs2sq1/content_storage_01/0000019b/80/14/36/ab.pdf.

Rivera-Mills, S. (2000). New perspectives on current sociolinguistic knowledge with regard to language use, proficiency, and attitudes among Hispanics in the United States. Lewiston, NY: The Edwin Mellen Press. 
Stake, R. E. (2006). Multiple Case Study Analysis. New York, NY: The Guilford Press.

Sticht, T. J. (2002). The rise of the adult education and literacy system in the United States: 1600-2000. In Comings, J.; Garner, B.; \& Smith, B. (Eds.), The Annual Review of Adult Learning and Literacy (Vol. 3, pp. 10-43). Retrieved from: http://www.ncsall.net/ $? \mathrm{id}=576$

Stephen, M., Mendoza, M., \& Magaña, M. (2007). Latin American immigration. In R. Bussell (Ed.), Understanding the immigrant experience in Oregon: Research, analysis, and recommendations from University of Oregon scholars in rural Oregon (pp. 44-55). Retrieved from the University of Oregon: http://www.uoregon.edu/ / lerc/pdfs/immigrationenglish.pdf

Stephen, L. (2007) Transborder lives :Indigenous Oaxacans in Mexico, California, and Oregon. Durham: Duke University Press.

Tracy-Mumford, F. (2000). The year 1998 in review. In J. Comings, B. Garner, \& C. Smith (Eds.), Annual review of adult learning and literacy (Vol. 1, pp. 1-24). San Francisco: Jossey-Bass.

U.S. Census Bureau (1990). 1990 Census of Population and Housing. [Fact sheet]. Retrieved from:

http://www.2010census.biz/prod/1/90dec/cph4/tables/cph4tb39/table-01.pdf U.S. Census Bureau (2000). Census 2000 demographic profile highlights [Fact sheet]. Retrieved from: http://factfinder.census.gov/servlet/ACSSAFFFacts? event $=$ Search\&_lang $=$ en\&_sse $=$ on \& geo_id $=$ 04000US41\&_state $=04000$ US41. 
U.S. Census Bureau (2006). 2006 American community survey data profile highlights [Fact sheet]. Retrieved from: http://factfinder.census.gov/servlet/ ACSSAFFFacts?_event $=$ Search\&_lang $=$ en\&_sse $=$ on\&geo_id $=04000$ US $41 \&$ state $=04000$ US41.

U.S. Census Bureau (2009). US census bureau quick facts [Fact sheet]. Retrieved from: http://quickfacts.census.gov/qfd/states/41000.html

U.S. Department of Education (1998). Adult education: Human investment impact 1992-1996 [Data set]. Retrieved from Office of Vocational and Adult Education: http://www.ed.gov/offices/OVAE/9499hinvest.html.

U.S. Department of Education (1999). State administered adult education program: 1998 adult education personnel [Fact sheet]. Retrieved: http://www.ed.gov/offices/OVAE/ 98personnel.html.

U.S. Department of Labor (1998). Workforce Investment Act of 1998 [Public law 105220]. Retrieved from:

http://www.doleta.gov/USWORKFORCE/WLA/wialaw.pdf.

Walker, C. \& Strawn, C. (2004). Oregon shines! Adult education and literacy in Oregon community college. Retrieved from the Council for Advancement of Adult Literacy: http://caalusa.org/oregonfinal.pdf.

Wenger, E. (1998). Communities of practice: Learning, meaning, and identity. Cambridge: Cambridge University Press.

Wrigley, H. (1993). One size does not fit all: Educational perspectives and program practices in the U.S. TESOL Quarterly, 27(3), 449-465. 
Part I Background

1. Organization:

2. Age

3. Have you completed an ESOL Tutor Training? $\square$ Yes $\square$ No

4. Do you currently work? $\square$ full time $\quad \square$ part time $\quad \square$ not currently

5. Do you currently attend school? $\square$ full time $\square$ part time $\square$ not currently

\section{$\underline{\text { Part II Goals }}$}

6. Please indicate the reason(s) that you chose to volunteer as a tutor (Check all that apply):

$\square$ I was asked to volunteer

$\square$ To meet new people

$\square$ To practice my language skills

$\square$ I am a member or supporter of this organization

$\square$ To prepare me for a career

$\square$ To learn or develop new skills

$\square$ To be involved in and contribute to my community

$\square$ To learn and share about culture

$\square$ Other (please explain)

7. What were your personal goals for becoming a tutor? 
8. Did this experience meet your expectations? $\quad \square$ Yes $\square$ No If no, can you explain what could have been improved?

\section{Part III Program Support}

9. What has aided you most in planning lessons and tutoring?

$\square$ Program Coordinator

$\square$ Websites

$\square$ Fellow Tutors

$\square$ Tutor Training

$\square$ Learners

$\square$ Books

$\square$ Workshops

$\square$ Other (Please Explain)

10. Please describe one, or more, challenge(s) that you are facing as a tutor and what type of support might best help you face that challenge.

11. What elements of your tutoring program do you like best?

12. What elements of your program could be improved?

13. Do you plan to continue as a tutor? $\square$ Yes $\square$ No. If no, can you explain why not? 


\section{Appendix B: Tutor Support Survey}

1. Below are topics in which English tutors/teachers often seek support (through books, websites, conversations, trainings, etc.) to improve their abilities. Please select topics that you might seek out to improve your abilities. .

$\square$ Theories of Second Language

$\square$ Using Realia or Authentic Materials

Acquisition

$\square$ Correcting Errors

$\square$ Problem areas for Spanish Speakers

Leading Conversations

learning English

$\square$ Checking comprehension

$\square$ Learning or Improving Spanish

Teaching Grammar

$\square$ Culture Awareness training

$\square$ Teaching Vocabulary

$\square$ Teaching strategies

Assessing students' progress

$\square$ Developing materials

$\square$ Teaching Reading

$\square$ Lesson Planning

$\square$ Teaching Writing

$\square$ Cooperative Learning

$\square$ Teaching Speaking

$\square$ Role Playing

Teaching Listening

$\square$ Reading Fluency

Ohter

2. In which of the following formats would you like to access this support (please mark all that apply):

$\square$ Working with your program coordinator

$\square$ Websites

$\square$ Books

Videos/Audio Training
Talking with fellow tutors

$\square$ Tutor Training Workshops

$\square$ Mentors

$\square$ Community Education 
$\square$ Other (Please

Explain) 


\section{Appendix C: Interview Question Guide}

Listed below are a series of example questions and topics that may be addressed during the interview. The line of questioning may change slightly depending on the information revealed in the surveys and through other interview questions. However, all questions will be asked with the purpose of understanding the role of the volunteer tutor. No personal questions will be asked. At the outset of the interview, all subjects will be reminded to only answer what they are comfortable answering.

\section{Background}

Q: When did you begin volunteering as a tutor/ how long have you been a volunteer. tutor at $\mathrm{X}$ ?

Q: How would you describe your relationship with this organization?

\section{Questions about Motivation}

A best practice for literacy programs is to ensure that volunteers walk away from their time as a volunteer having met their goals and fulfilled their expectations. I am interested in understanding why people become tutors and what their expectations are as they begin as a tutor.

Q: Could you think back to when you began as a tutor and describe to me how you got involved as a tutor?

Follow up: Tell me about when you first considered this role, what attracted you to it? Q: Have you done other volunteer work? Describe ways that make volunteering as a tutor different? Could you provide specific examples? 
Q What do you like most about tutoring?

What do you like least about tutoring?

\section{Questions about 'Tutoring}

Here are a couple of questions to help create a picture of what you do as a tutor. Could you give me an example of an activity that worked well for you?

Q: How did you develop the activity?

Follow up: What resources did you use?

Follow up: What materials did you use?

Q: Could you tell me about a time where something didn't go as you expected it to?

Follow up: How did you react and what happened?

Q: Do you see your student(s) outside of the tutoring program?

Q: How has your time as a tutor changed you? What is different about you now compared to when you began? 
Appendix D: Ordinariness of themes in each case

$\mathbf{W}=$ highly unusual situation, $\quad \mathbf{U}=$ somewhat unusual situation, $\quad$ blank = ordinary situation $\mathbf{H}=$ high manifestation, $\mathbf{M}=$ some manifestation, blank = almost no manifestation

\begin{tabular}{|l|l|l|}
\hline Multicase Themes & St Joseph & Southeast Keizer \\
& Community Center \\
\hline Theme 1 & U & H \\
\hline Theme 2 & M & M \\
\hline Theme 3 & & \\
\hline Theme 4 & H & H \\
\hline
\end{tabular}


Appendix E: Findings from surveys and interviews for two cases

$\mathrm{H}=$ high importance; $\mathrm{M}=$ middling importance; $\mathrm{L}=$ low importance. A high mark indicates that this theme is of high importance and is indicated in this theme.

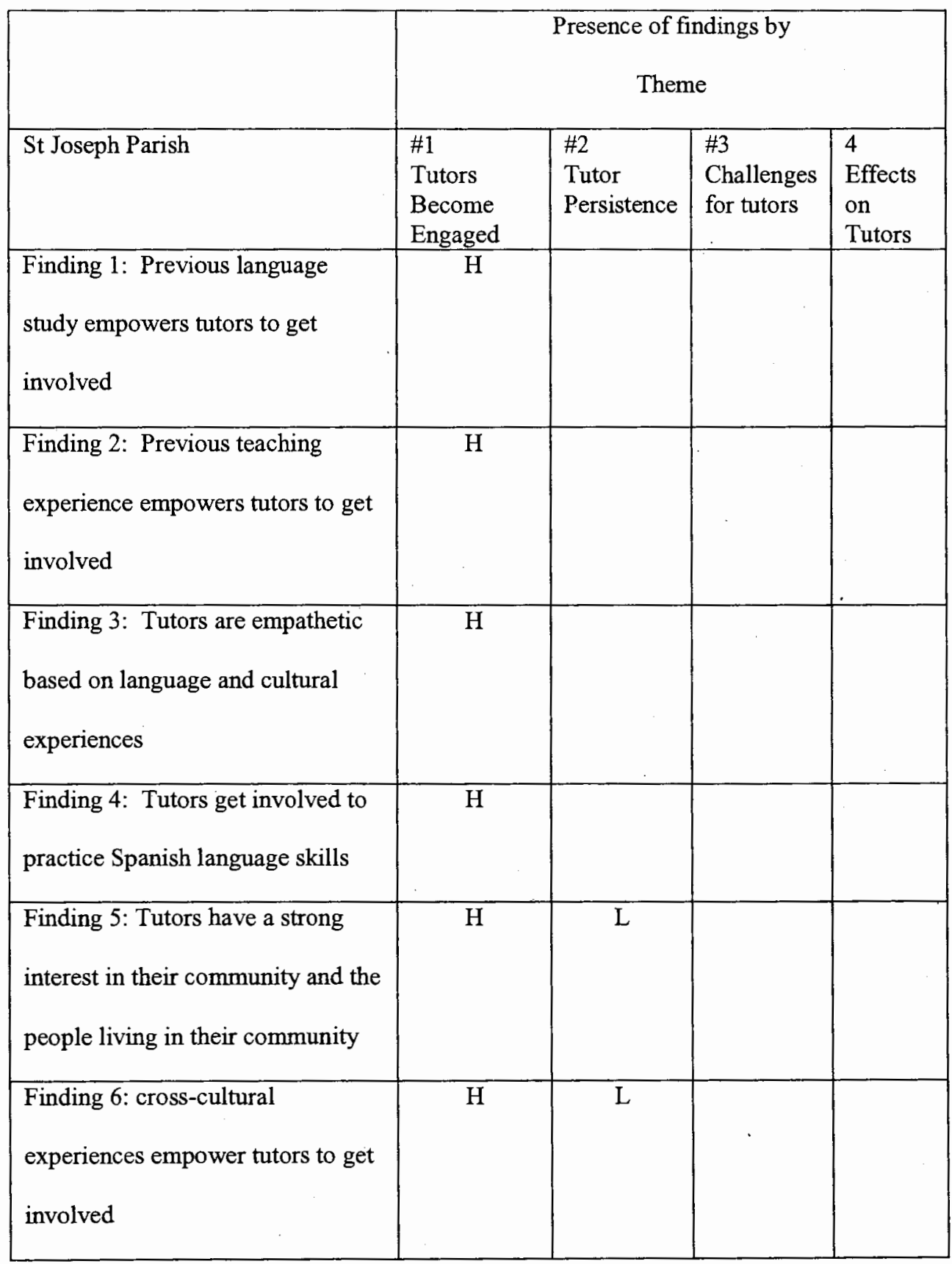




\begin{tabular}{|c|c|c|c|}
\hline $\begin{array}{l}\text { Finding 7: Volunteers cited their } \\
\text { membership in the church as a } \\
\text { reason for getting involved }\end{array}$ & $\overline{\mathrm{H}}$ & & \\
\hline $\begin{array}{l}\text { Finding 8: Volunteers are } \\
\text { rewarded when they are effective } \\
\text { with their teaching }\end{array}$ & & $\mathrm{H}$ & \\
\hline $\begin{array}{l}\text { Finding 9: Volunteers are } \\
\text { rewarded when they feel } \\
\text { connected with the community and } \\
\text { they feel that they are contributing } \\
\text { to the welfare of the community }\end{array}$ & & $\mathrm{H}$ & \\
\hline $\begin{array}{l}\text { Finding 10: Volunteers are } \\
\text { rewarded by appreciation } \\
\text { expressed by language learning } \\
\text { participants. }\end{array}$ & & $\mathrm{H}$ & \\
\hline $\begin{array}{l}\text { Finding } 11 \text { : Volunteers are } \\
\text { challenged by the time } \\
\text { commitment - both the duration of } \\
\text { the commitment and the time for } \\
\text { preparing and carrying out lessons }\end{array}$ & & & $\overline{\mathrm{H}}$ \\
\hline $\begin{array}{l}\text { Finding 12: Volunteers are } \\
\text { challenged by inconsistent } \\
\text { attendance of students }\end{array}$ & & & $\mathrm{H}$ \\
\hline $\begin{array}{l}\text { Finding 13: Volunteers are } \\
\text { challenged in creating activities } \\
\text { and lesson plans with limited } \\
\text { resources }\end{array}$ & & & $\mathrm{H}$ \\
\hline
\end{tabular}




\begin{tabular}{|c|c|c|c|c|}
\hline $\begin{array}{l}\text { Finding 14: Volunteers increase } \\
\text { their understanding of issues that } \\
\text { are faced by those with limited } \\
\text { English language skills that are } \\
\text { living in the U.S. }\end{array}$ & & & & $\mathrm{H}$ \\
\hline $\begin{array}{l}\text { Finding 15: Volunteers reportedly } \\
\text { increase their skills and } \\
\text { effectiveness as teachers over time. }\end{array}$ & & & & $\mathrm{H}$ \\
\hline $\begin{array}{c}\text { Southeast Keizer Community } \\
\text { Center }\end{array}$ & $\begin{array}{c}\text { \#l } \\
\text { Tutors } \\
\text { Become } \\
\text { Engaged }\end{array}$ & $\begin{array}{c}\# 2 \\
\text { Tutor } \\
\text { Persistence }\end{array}$ & $\begin{array}{c}\# 3 \\
\text { Challenges } \\
\text { for tutors }\end{array}$ & $\begin{array}{l}4 \\
\text { Effects } \\
\text { on } \\
\text { Tutors }\end{array}$ \\
\hline $\begin{array}{l}\text { Finding 1: previous language } \\
\text { study empowers tutors to get } \\
\text { involved }\end{array}$ & $\mathrm{H}$ & $\mathrm{L}$ & & \\
\hline $\begin{array}{l}\text { Finding 2: previous teaching } \\
\text { experience empowers tutors to get } \\
\text { involved }\end{array}$ & $\mathrm{H}$ & $\mathrm{L}$ & & \\
\hline $\begin{array}{l}\text { Finding 3: Tutors are empathetic } \\
\text { based on language and cultural } \\
\text { experiences }\end{array}$ & $\mathrm{H}$ & & & \\
\hline $\begin{array}{l}\text { Finding 4: Tutors have a strong } \\
\text { interest in their community and the } \\
\text { people living in their community }\end{array}$ & $\mathrm{H}$ & $\mathrm{L}$ & & \\
\hline $\begin{array}{l}\text { Finding 5: Tutors were targeted } \\
\text { and encouraged to participate by } \\
\text { coordinator }\end{array}$ & $\mathrm{H}$ & & & \\
\hline $\begin{array}{l}\text { Finding 6: cross-cultural } \\
\text { experiences empower tutors to get }\end{array}$ & $\mathrm{H}$ & $\bar{M}$ & & \\
\hline
\end{tabular}




\begin{tabular}{|c|c|c|}
\hline involved & & \\
\hline $\begin{array}{l}\text { Finding } 7 \text { : Volunteers are } \\
\text { rewarded when they are effective } \\
\text { with their teaching }\end{array}$ & $\mathrm{H}$ & \\
\hline $\begin{array}{l}\text { Finding } 8: \text { Volunteers are } \\
\text { rewarded when they feel } \\
\text { connected with the community and } \\
\text { they feel that they are contributing } \\
\text { to the welfare of the community }\end{array}$ & $\mathrm{H}$ & . \\
\hline $\begin{array}{l}\text { Finding 9: Volunteers are } \\
\text { rewarded by appreciation } \\
\text { expressed by language learning } \\
\text { participants. }\end{array}$ & $\mathrm{H}$ & \\
\hline $\begin{array}{l}\text { Finding 10: Volunteers are } \\
\text { challenged by the time } \\
\text { commitment - both the duration of } \\
\text { the commitment and the time for } \\
\text { preparing and carrying out lessons }\end{array}$ & & $\mathrm{H}$ \\
\hline $\begin{array}{l}\text { Finding 11: Volunteers are } \\
\text { challenged by inconsistent } \\
\text { attendance of students }\end{array}$ & & $\vec{H}$ \\
\hline $\begin{array}{l}\text { Finding 12: Volunteers are } \\
\text { challenged by the way that } \\
\text { students are placed into the } \\
\text { classroom }\end{array}$ & & $\mathrm{H}$ \\
\hline $\begin{array}{l}\text { Finding 13: Volunteers are } \\
\text { challenged in creating activities }\end{array}$ & & $\mathrm{H}$ \\
\hline
\end{tabular}




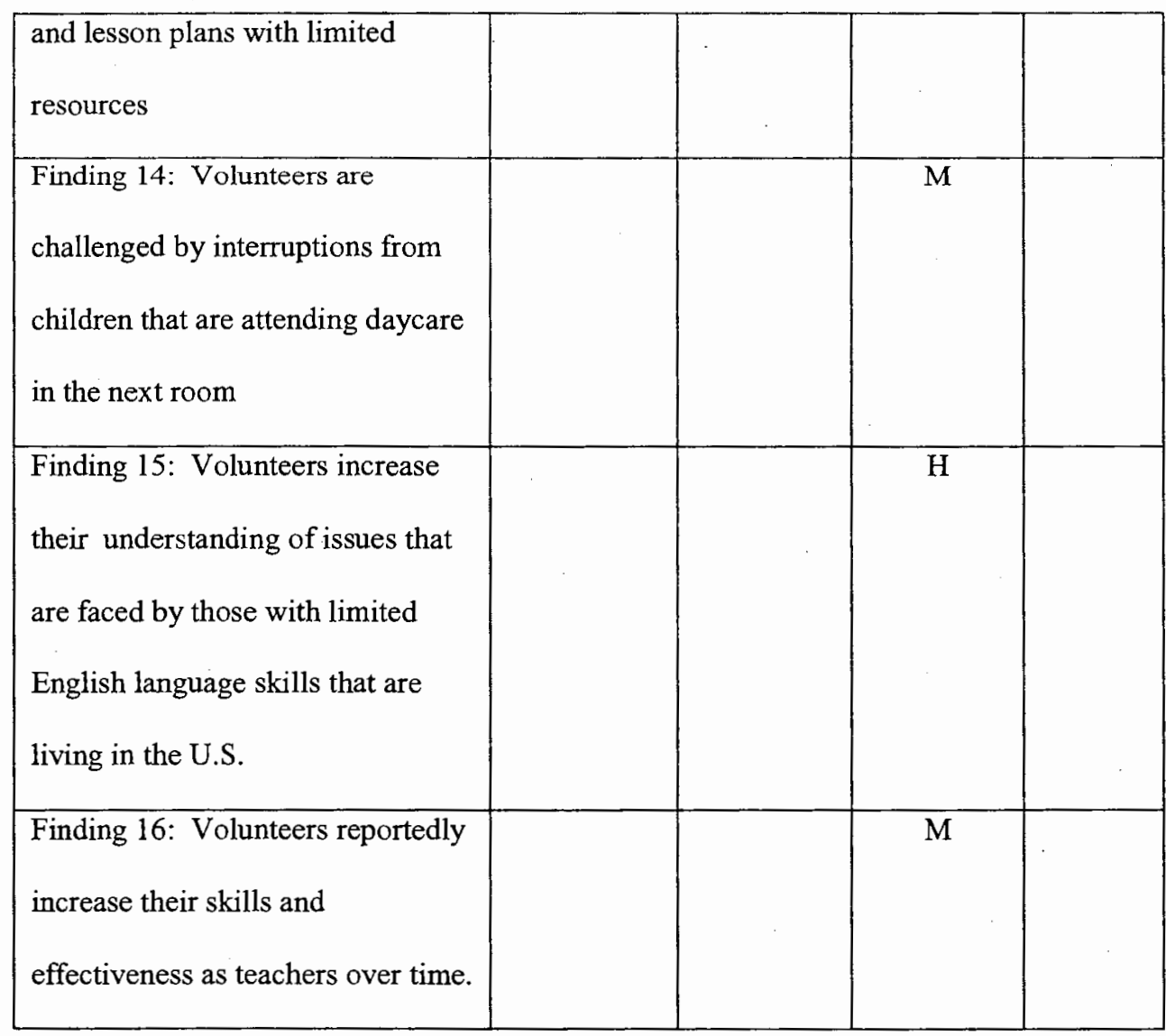




\section{Appendix F: Findings across both cases}

Finding 1: Previous language study empowers volunteers to become tutors
Finding 2: Previous teaching experience empowers volunteers to become tutors

Finding 3: Empathy empowers volunteers to become tutors

Finding 4: Tutors have a strong interest in their community and the people living in their community

Finding 5: Tutors have cross-cultural experiences that empower volunteers to become tutors

Finding 6: Tutors are motivated when they are effective with their teaching

Finding 7: Tutors are motivated when they form relationships with tutees and feel connected with their community.

Finding 8: Volunteers are motivated by appreciation expressed by tutees.

Finding 9: Volunteers are challenged by the time commitment - both the duration of the commitment and the time for preparing and carrying out lessons

Finding 10: Volunteers are challenged by inconsistent attendance of students

Finding 11: Volunteers are challenged in creating activities and lesson plans with limited resources

Finding 12: Volunteers increase their understanding of issues that are faced by those with limited English language skills that are living in the U.S.

Finding 13: Volunteers reportedly increase their skills and effectiveness as teachers over time. 
Appendix G: Assertions from findings based on instances for final report

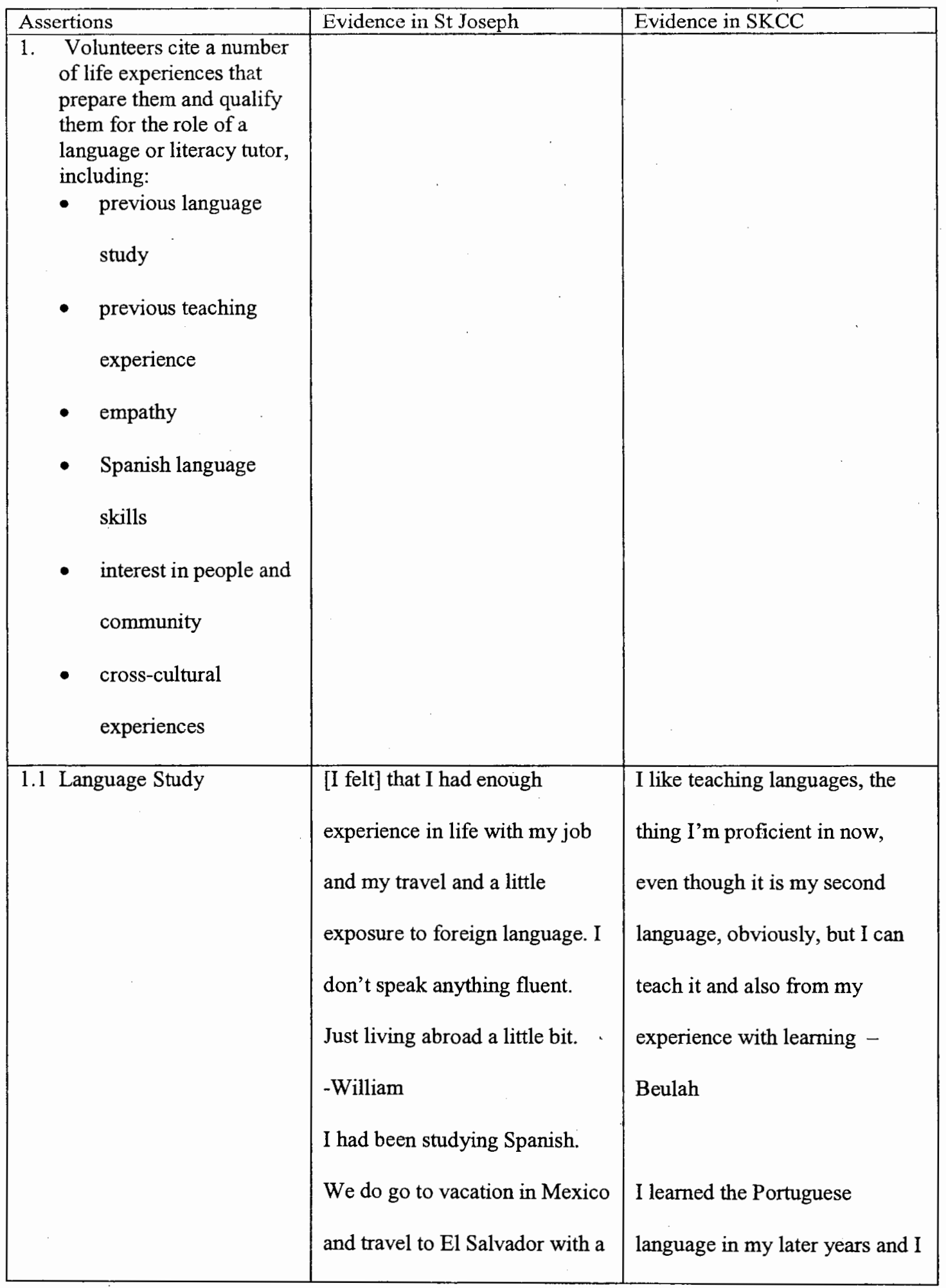




\begin{tabular}{|c|c|c|}
\hline & $\begin{array}{l}\text { church project. - Anita } \\
\text { I can be empathetic because I } \\
\text { am trying to learn Spanish. I } \\
\text { can understand much of the } \\
\text { travail there. } \\
\text { I was a student of Spanish. I } \\
\text { was trying to learn the } \\
\text { language, and you try to go to } \\
\text { Mexico and try to teach English } \\
\text { to people that try to speak } \\
\text { Spanish and see how far you } \\
\text { get. - Victor } \\
\text { I felt like there was something } \\
\text { there that I might be able to } \\
\text { pass along to somebody else } \\
\text { and also having done that - } \\
\text { William } \\
\text { it all alone. - sj6 }\end{array}$ & $\begin{array}{l}\text { experienced the reality of } \\
\text { learning a new language as an } \\
\text { older adult I found very difficult } \\
\text { and so that gave me a sense of } \\
\text { perhaps empathy for adults who } \\
\text { come will go....learn a new } \\
\text { language. - George } \\
\text { I recognize, again, the difficulty } \\
\text { in learning a language. It helps } \\
\text { me to understand people's } \\
\text { frustration level. That is the } \\
\text { most important that I have, } \\
\text { realizing that this is difficult for } \\
\text { them, to learn a language. It } \\
\text { helps me to understand the } \\
\text { frustration. - George } \\
\text { English can be extremely } \\
\text { frustrating. - Beulah }\end{array}$ \\
\hline 1.2 Teaching Experience: & $\begin{array}{l}\text { In my career, I was an } \\
\text { elementary school teacher. I } \\
\text { retired in } 2000 \text { and had time to } \\
\text { do volunteer work. I was a } \\
\text { teacher so I had teaching skills, }\end{array}$ & $\begin{array}{l}\text { I had been a teacher and I also } \\
\text { worked with a variety of } \\
\text { settings with teaching. I was a } \\
\text { Special Ed teacher for quite a } \\
\text { few years. I was also involved }\end{array}$ \\
\hline
\end{tabular}




\begin{tabular}{|c|c|c|}
\hline$\cdot$ & $\begin{array}{l}\text { but I thought I would rather } \\
\text { work with adults rather than } \\
\text { children for a while, for a } \\
\text { change. - Anita } \\
\text { I always do a lesson plan before } \\
\text { the class. I usually have five or } \\
\text { six things in the plan that I want } \\
\text { to do or that I hope to do. - } \\
\text { Anita } \\
\text { Often, people that have not } \\
\text { taught say they would never be } \\
\text { able to do that. Whereas retired } \\
\text { teachers are the ones that are } \\
\text { the most open to it, at least the } \\
\text { less fearful of it. - Anita }\end{array}$ & $\begin{array}{l}\text { in a variety of other educational } \\
\text { things. - George } \\
\text { One skill is my sense of being a } \\
\text { teacher and I can prepare } \\
\text { lessons quite well and evaluate } \\
\text { the progress quite adequately. } \\
\text { - George } \\
\text { I've volunteered tutoring } \\
\text { German and English before on a } \\
\text { prior basis at different } \\
\text { universities. This is the first } \\
\text { one that I've done continuously. } \\
\text { - Beulah }\end{array}$ \\
\hline 1.3 People \& community & $\begin{array}{l}\text { [I got involved] To meet a need. } \\
\text { To be available. - Survey } \\
\text { Response } \\
\text { [I got involved to] build a } \\
\text { bridge between the Anglos and } \\
\text { the Latinos in our community. - } \\
\text { Survey Response } \\
\text { With this [volunteer work] I am } \\
\text { working with other people. } \\
\text { There is definitely greater } \\
\text { satisfaction from working with } \\
\text { people. - Victor }\end{array}$ & $\begin{array}{l}\text { I wanted to be more involved in } \\
\text { our Spanish [speaking] } \\
\text { community. - SKCC5 } \\
\text { I like teaching and tutoring } \\
\text { languages because you can } \\
\text { really feel the students grow. - } \\
\text { Beulah } \\
\text { The learners they are not, the } \\
\text { Spanish [speakers], who live in } \\
\text { the US The focus is trying to } \\
\text { help them on a daily basis with } \\
\text { their struggle with being in a }\end{array}$ \\
\hline
\end{tabular}




\begin{tabular}{|c|c|c|}
\hline & 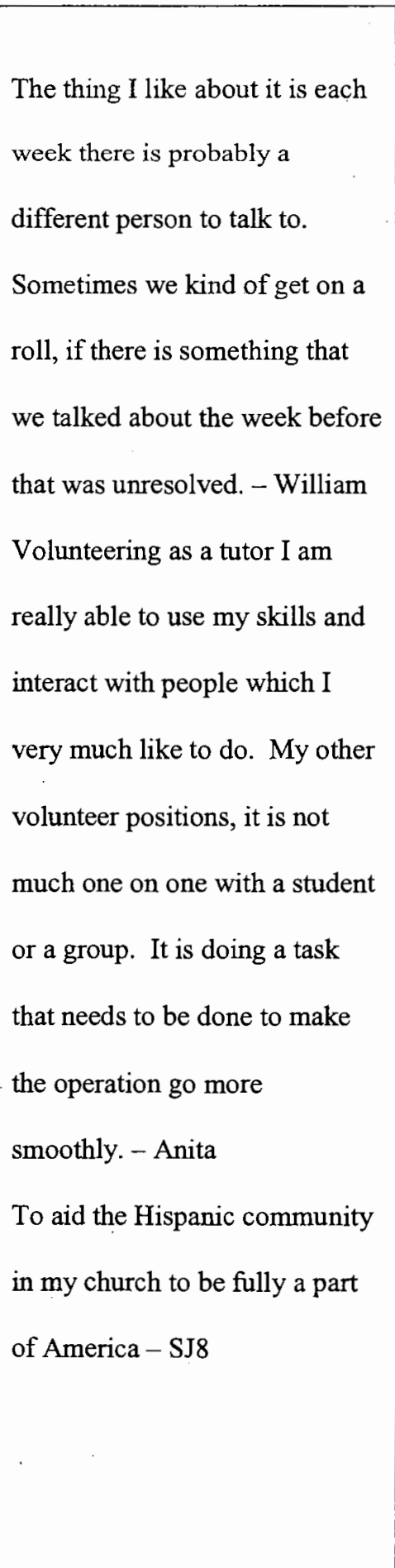 & 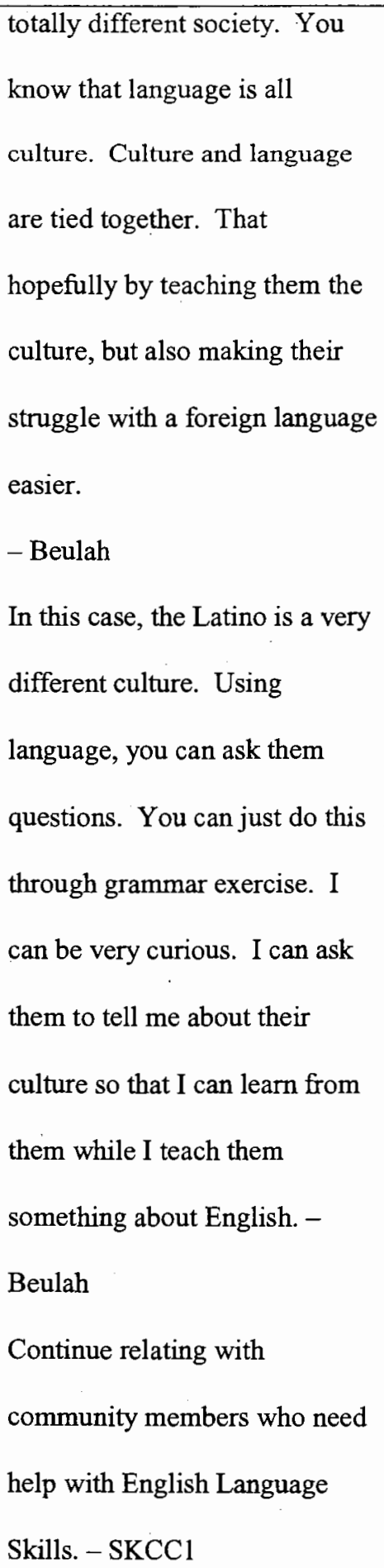 \\
\hline 1.4 Cross-cultural experiences & $\begin{array}{l}\text { I felt like there was something } \\
\text { there that I might be able to }\end{array}$ & $\begin{array}{l}\text { In this case, the Latino is a very } \\
\text { different culture. Using }\end{array}$ \\
\hline
\end{tabular}




\begin{tabular}{|c|c|c|}
\hline - & $\begin{array}{l}\text { pass along to somebody else } \\
\text { and also having done that, also } \\
\text { appreciate.. or... the students or } \\
\text { the participant's experiences } \\
\text { and what it is like living in a } \\
\text { foreign land. - William } \\
\text { I do very much like working } \\
\text { with them and I love the Latino } \\
\text { culture. There is something } \\
\text { about them that is very } \\
\text { charming and gracious and I do } \\
\text { learning. -Victor } \\
\text { probably don't have a lot of } \\
\text { very much enjoy that. - Anita } \\
\text { they have in communicating } \\
\text { with English speaking persons. } \\
\text { The first thing you realize is the } \\
\text { communication difficulties that } \\
\text { the also got to be aware }\end{array}$ & $\begin{array}{l}\text { language, you can ask them } \\
\text { questions. You can just do this } \\
\text { through grammar exercise. I } \\
\text { can be very curious. I can ask } \\
\text { them to tell me about their } \\
\text { culture so that I can learn from } \\
\text { them while I teach them } \\
\text { something about English. } \\
\text { I learned in Brazil for a while. I } \\
\text { learned the Portuguese language } \\
\text { in my later years and I } \\
\text { experienced the reality of } \\
\text { learning a new language as an } \\
\text { older adult I found very difficult } \\
\text { and so that gave me a sense of } \\
\text { language. - George } \\
\text { come will go out to the } \\
\text { langs empathy for adults who }\end{array}$ \\
\hline $\begin{array}{l}\text { Theme } 2 \\
\text { Volunteers are motivated to } \\
\text { continue for various reasons } \\
\text { including: }\end{array}$ & & \\
\hline
\end{tabular}




\begin{tabular}{|c|c|c|}
\hline $\begin{array}{l}\text { a sense of } \\
\text { professionalism and } \\
\text { effectiveness as a } \\
\text { tutor } \\
\text { - a connection with the } \\
\text { community } \\
\text { appreciation from } \\
\text { students along with a } \\
\text { sense of filling a need } \\
\text { in the community. }\end{array}$ & . & \\
\hline $\begin{array}{l}2.1 \text { Sense of professionalism } \\
\text { and effectiveness }\end{array}$ & $\begin{array}{l}\text { It is so gratifying once you } \\
\text { teach them or they catch } \\
\text { something, you are so delighted } \\
\text { that they understand that you } \\
\text { feel more of a high; the } \\
\text { endorphins really take over } \\
\text { your body when you walk out } \\
\text { of there. I walk out of my class } \\
\text { o Tuesday nights and I feel } \\
\text { great because I was able to give } \\
\text { these people something that was } \\
\text { very useful and they were } \\
\text { extremely grateful to have. - } \\
\text { Victor } \\
\text { You are able to see growth. } \\
\text { a lot. - William }\end{array}$ & $\begin{array}{l}\text { They become frustrated because } \\
\text { of the speed in which they are } \\
\text { learning does not satisfy their } \\
\text { wishes. Those are some of the } \\
\text { frustrations that also are rewards } \\
\text { in the fact that they are } \\
\text { improving the language skills. } \\
\text { [What I enjoy is] teaching and } \\
\text { watching the students improve - } \\
\text { SKCC4 } \\
\text { Having students progress in }\end{array}$ \\
\hline
\end{tabular}




\begin{tabular}{|c|c|c|}
\hline & $\begin{array}{l}\text { I've seen them progress from } \\
\text { being shy and halting to being } \\
\text { much more comfortable and } \\
\text { much more fluent and } \\
\text { conversant. I think that is nice } \\
\text { for somebody to hear. It gives } \\
\text { them some confidence, a little } \\
\text { more than sitting there having } \\
\text { someone else kind of take the } \\
\text { dead for them. I've enjoyed that } \\
\text { pronunciation and accurate } \\
\text { English commentary + } \\
\text { practice that forces } \\
\text { vronuch. - William } \\
\text { each small success - } \\
\text { I sJ11 } \\
\text { useful and they were extremely } \\
\text { Tuesday nights and I feel great } \\
\text { because I was able to give these } \\
\text { people something that was very }\end{array}$ & $\begin{array}{l}\text { their speaking and } \\
\text { comprehension. - SKCC5 }\end{array}$ \\
\hline 2.2 The motivation of their & What some of these folks have & students that I work with have a \\
\hline
\end{tabular}




\begin{tabular}{|c|c|c|}
\hline $\begin{array}{l}\text { tutees and the appreciation that } \\
\text { they receive from tutees }\end{array}$ & $\begin{array}{l}\text { done in Mexico, per, or Costa } \\
\text { Rica, some of them just amaze } \\
\text { me. Some of the challenges } \\
\text { that they have... You don't just } \\
\text { judge people by how they look } \\
\text { or how they act. You need to } \\
\text { find out more about them. - } \\
\text { Victor } \\
\text { You know, the students we } \\
\text { have are very motivated, of } \\
\text { course, they try very hard. - } \\
\text { Anita } \\
\text { grateful to have. - Victor } \\
\text { They are really realize how } \\
\text { important this is and they like } \\
\text { the one on one attention - } \\
\text { something that was very useful } \\
\text { and they were extremely } \\
\text { Thas able to give these people } \\
\text { Ther }\end{array}$ & $\begin{array}{l}\text { desire to learn the language and } \\
\text { that if a specific need, which } \\
\text { they know they would gain by } \\
\text { having a ability to speak the } \\
\text { language and so they come with } \\
\text { a deep desire -- George } \\
\text { They really, I mean every single } \\
\text { day, none of them leave without } \\
\text { telling me how much they } \\
\text { appreciate my work and help. } \\
\text { That is probably the most } \\
\text { rewarding, the people thanking } \\
\text { you because they can't give the } \\
\text { monetary reward. Working } \\
\text { with grateful learners, like this.- } \\
\text { Beulah }\end{array}$ \\
\hline 2.3 Relationships and & $\begin{array}{l}\text { There is something about them } \\
\text { that is very charming and } \\
\text { gracious and I do very much } \\
\text { enjoy that. - Anita } \\
\text { The fact that it is a long term }\end{array}$ & $\begin{array}{l}\text { Getting to know the students - } \\
\text { cultural sharing and exchange. } \\
\text { - SKCC5 } \\
\text { There is not a single Friday }\end{array}$ \\
\hline
\end{tabular}




\begin{tabular}{|c|c|c|}
\hline & $\begin{array}{l}\text { type of thing, you know that } \\
\text { you establish a relationship. } \\
\text { You are able to see growth. } \\
\text { And that is something that I like } \\
\text { a lot; I like that interpersonal, - } \\
\text { Anita } \\
\text { One guy was a career air force } \\
\text { mechanic on jet engines and he } \\
\text { drives a horse truck now, but he } \\
\text { had a very responsible job. - } \\
\text { Victor } \\
\text { Ioseph Day festival, etc. I feel } \\
\text { they are happy to participate } \\
\text { and exchange ideas, recipes and } \\
\text { information. SJ8 } \\
\text { family activities. When I see } \\
\text { them taking part in St. Joseph } \\
\text { programs/ Asian festival, St. } \\
\text { In been invited to their }\end{array}$ & $\begin{array}{l}\text { night where I leave the class and } \\
\text { I am not all smiles. They are } \\
\text { wonderful peopie - Beulah } \\
\text { [What I like is] getting to meet } \\
\text { the learners. SKCC3 }\end{array}$ \\
\hline $\begin{array}{l}\text { Theme } 3 \\
\text { When compared to other } \\
\text { volunteer work, volunteer } \\
\text { tutors face unique challenges } \\
\text { including: }\end{array}$ & & \\
\hline
\end{tabular}




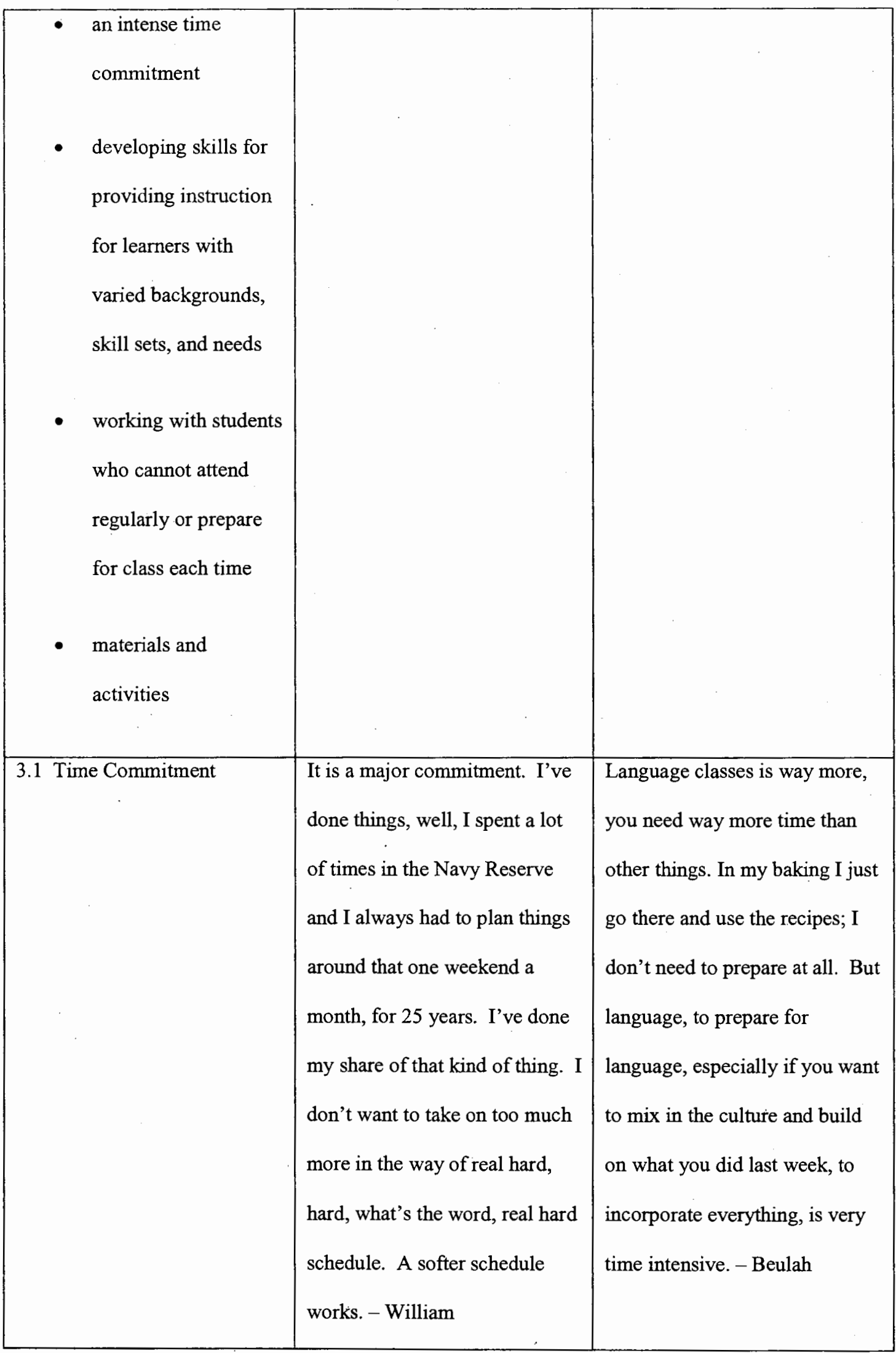




\begin{tabular}{|c|c|c|}
\hline . & $\begin{array}{l}\text { So we are constantly looking } \\
\text { around for materials to } \\
\text { supplement what we are } \\
\text { doing... I always do a lesson } \\
\text { plan before the class. I usually } \\
\text { have five or six things in the } \\
\text { plan that I want to do or that I } \\
\text { hope to do.... You just kind of } \\
\text { scrounge around and find things } \\
\text { that work. - Anita . }\end{array}$ & $\begin{array}{l}\text { It takes much more time than } \\
\text { my Habitat or working with } \\
\text { older people. We have gone to } \\
\text { China several times to teach } \\
\text { English to adults in china. That } \\
\text { took a lot of preparation also. } \\
\text { That was a lot of work. - } \\
\text { George }\end{array}$ \\
\hline $\begin{array}{l}3.2 \text { Providing instruction for a } \\
\text { set of learners with various } \\
\text { skills sets and backgrounds }\end{array}$ & $\begin{array}{l}\text { And then the materials you use, } \\
\text { there is no perfect material and } \\
\text { you know that as well as I do. } \\
\text { So we are constantly looking } \\
\text { around for materials to } \\
\text { supplement what we are doing. } \\
\text { And not having any kind of a } \\
\text { financial base to buy more. And } \\
\text { it is kind of put on us as } \\
\text { individuals if we really feel it } \\
\text { would be important to our } \\
\text { program, then it comes out of } \\
\text { our pocket, which sometimes is } \\
\text { fine, but not always able to do } \\
\text { what we would like. - Anita } \\
\text { Illiteracy in native language; I }\end{array}$ & $\begin{array}{l}\text { At least here you have a real } \\
\text { variety of learners. Some are } \\
\text { very good in the oral part, but } \\
\text { struggle in the written part to } \\
\text { struggle or to find exercises that } \\
\text { everybody can benefit from. I } \\
\text { think it is the most challenging. } \\
\text { It is not really the learners, for } \\
\text { me, the challenging part is to } \\
\text { find the right exercises. - } \\
\text { Beulah } \\
\text { I ask if they have } 6 \text { years of } \\
\text { education or } 8 \text { years of } \\
\text { education in Mexico. They } \\
\text { don't have the grammatical } \\
\text { terminology, for example, like }\end{array}$ \\
\hline
\end{tabular}




\begin{tabular}{|c|c|c|}
\hline . & $\begin{array}{l}\text { need to move away from } \\
\text { "written" materials to more } \\
\text { "visual" and conversational } \\
\text { lessons. - SJ7 } \\
\text { I will say, that different levels } \\
\text { in my group. Each member in } \\
\text { my group has a unique style of } \\
\text { learning. - SJ9 }\end{array}$ & $\begin{array}{l}\text { the simple present or the perfect } \\
\text { past. It doesn't mean anything } \\
\text { to them. -Beulah } \\
\text { I work with a wide variety of } \\
\text { ability, abilities to speak the } \\
\text { language...so to try to develop a } \\
\text { class structure that meets the } \\
\text { needs of a large range of } \\
\text { language abilities is very } \\
\text { difficult is very challenging. - } \\
\text { George } \\
\text { The greatest challenge is } \\
\text { meeting the needs of the } \\
\text { ability groupings. - SKCC } 5 \\
\text { individual class members. } \\
\text { level. - SKCC4 }\end{array}$ \\
\hline $\begin{array}{l}3.3 \text { Working with groups of } \\
\text { learners that have barriers for } \\
\text { attending and preparing for } \\
\text { class. }\end{array}$ & $\begin{array}{l}\text { What frustrates me is that they } \\
\text { don't come in on time. I really } \\
\text { work on a lesson and I get a } \\
\text { little frustrated if they come 10- } \\
15 \text { minutes late. I have to } \\
\text { review what they didn't get. - } \\
\text { Victor } \\
\text { [What frustrates me is] when } \\
\text { not many people show up. }\end{array}$ & $\begin{array}{l}\text { The class varies a lot from week } \\
\text { to week in attendance. - SKCC1 } \\
\text { [A challenge is] students not } \\
\text { being required to attend } \\
\text { regularly. } \\
\text { - SKCC } 4 \\
\text { Sometimes attendance is not as } \\
\text { regular as it could be and } \\
\text { creates the dilemma of trying to }\end{array}$ \\
\hline
\end{tabular}




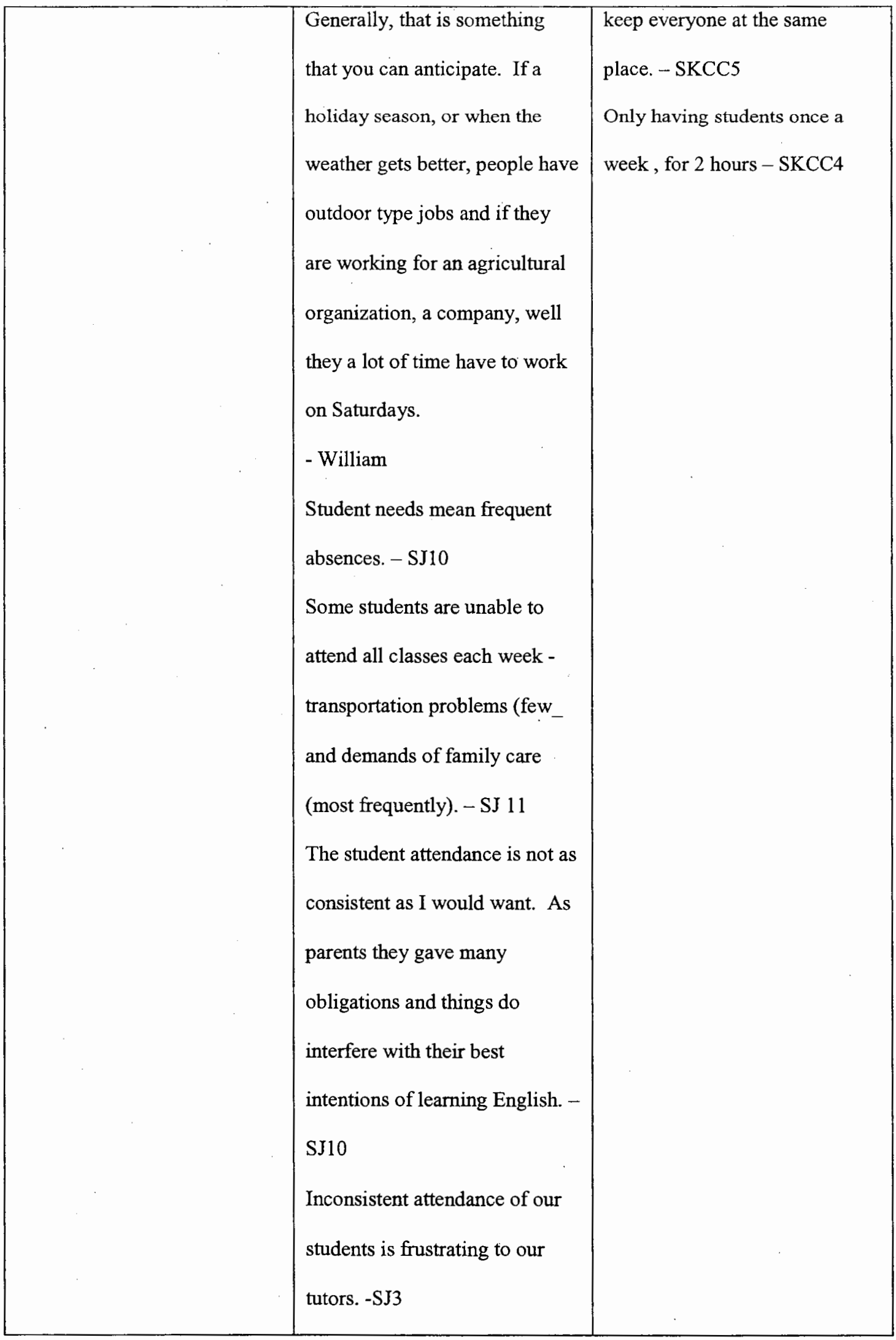




\begin{tabular}{|c|c|c|}
\hline & $\begin{array}{l}\text { learning takes time and practice } \\
\text { - SJ1 } \\
\text { One class a week is not } \\
\text { immediately effective for the } \\
\text { student. - SJ10 }\end{array}$ & \\
\hline 3.4 Materials and Activities & $\begin{array}{l}\text { And then the materials you use, } \\
\text { there is no perfect material and } \\
\text { you know that as well as I do. } \\
\text { So we are constantly looking } \\
\text { around for materials to } \\
\text { supplement what we are doing. } \\
\text { And not having any kind of a } \\
\text { financial base to buy more. And } \\
\text { it is kind of put on us as } \\
\text { individuals if we really feel it } \\
\text { would be important to our } \\
\text { program, then it comes out of } \\
\text { around and find things that } \\
\text { our pocket. - Anita } \\
\text { the paper that day that would be } \\
\text { of interest of the students.... } \\
\text { You just kind of scrounge } \\
\text { internet. We even use the }\end{array}$ & $\begin{array}{l}\text { Another challenge I find is } \\
\text { locating curriculum materials so } \\
\text { that I feel they are pertinent to } \\
\text { where I am with my teaching to } \\
\text { the students. I am also looking } \\
\text { for materials that would be } \\
\text { satisfying to what I am doing. } \\
\text { That is a challenge. -George } \\
\text { I use my own activities and I } \\
\text { challenging. It is not really the } \\
\text { also get ideas from books. They } \\
\text { don't have any workbooks. I } \\
\text { hunt and search and find things } \\
\text { ideas, my own worksheets from } \\
\text { in a variety of workbooks that I } \\
\text { find helpful. I take the } \\
\text { workbook and make my own } \\
\text { theorge }\end{array}$ \\
\hline
\end{tabular}




\begin{tabular}{|c|c|c|}
\hline & & $\begin{array}{l}\text { leamers, for me, the challenging } \\
\text { part is to find the right } \\
\text { exercises. - Beulah }\end{array}$ \\
\hline $\begin{array}{l}\text { Theme } 4 \\
\text { Through volunteering as a } \\
\text { tutor, volunteers gain skills } \\
\text { over time that improve their } \\
\text { effectiveness and develop a } \\
\text { better understanding of issues } \\
\text { that are faced by those with } \\
\text { limited English language skills } \\
\text { that are living in the U.S. }\end{array}$ & 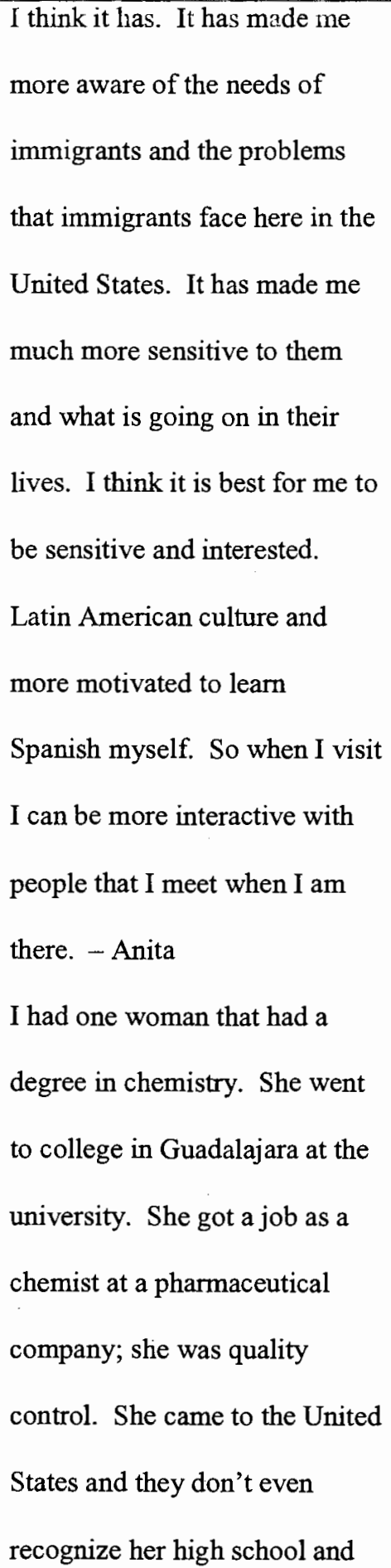 & 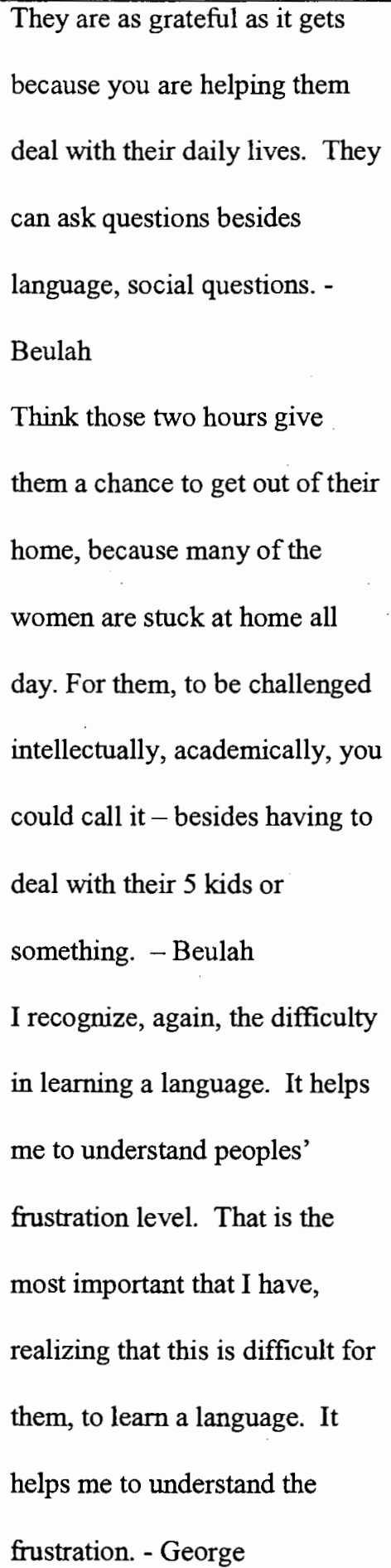 \\
\hline
\end{tabular}




$\left|\begin{array}{l|l|}\hline \text { she is cleaning house. - Victor } \\ \text { Now I feel more confident } \\ \text { about what is going on. With } \\ \text { the people that come to } \\ \text { conversation partners are, have } \\ \text { been coming for some time } \\ \text { now, so, you know, more often } \\ \text { than not, they are folks that } \\ \text { come in Saturday morning that I } \\ \text { know now by sight and not by } \\ \text { sitting down and having a chit- } \\ \text { chat on Saturday morning. That } \\ \text { anxiety and tentative feeling } \\ \text { about it is not there anymore. - } \\ \text { William }\end{array}\right|$




\section{Appendix H: Interview Transcript - George - SKCC}

Participant: George

Interviewer: Troy Hickman

Organization: Southeast Keizer Community Center

Role: Volunteer Tutor

Date: $4 / 28 / 09$

T: How long have you been a tutor?

G: Probably, I started last year. So, it's been a year and a half ago.

$\mathrm{T}$ : have you been involved with the community center before?

G: I've been a member of the church for maybe ten years, nearly, and I've been a participating member of the community center for maybe 6 to 7 years.

T: What else have you been involved in with the community center?

G: I did some tutoring at a local elementary school and at the library.

T: If you can think back to when you first became involved with the ESL tutoring, could you think back to how you got involved and also what interested you about being part of the project?

G: A variety of things. I had been a teacher and I also worked with a variety of settings with teaching. I was a Special Ed teacher for quite a few years. I was also involved in a variety of other educational things. And ..ummm..okay, I felt there were problems in the community center that met my interests so that fed into my interests into working in different settings with persons that needed to have some kind of assistance like picking up language. 
T: Did you have experience with language teaching before?

G: I learned in Brazil for a while. I learned the Portuguese language in my later years and I experienced the reality of learning a new language as an older adult I found very difficult and so that gave me a sense of perhaps empathy for adults who come will go out to the language field to learn a new language.

T: Have you studied Spanish?

G: No

T: Were you approached by Jack or did you read about this at the church, how did you hear about this?

G: Probably Jack. I've been involved with the tutoring center and worked with jack in a variety of settings. I was aware of the interest that the ESL program had been getting. We were aware of this.

$\mathrm{T}$ : Besides the volunteer work that we've talked about thus far, have you done other types of volunteer work?

$\mathrm{G}$ : in our country?

$\mathrm{T}$ : Anywhere

G: I worked for Habitat for Humanity. I do a couple of volunteer things at the church. I run a program for older people. I worked with Farmers for Hunger Relief. My work in Brazil was somewhat volunteering.

T: So, how does volunteering as a language tutor, how is that different from other volunteer work?

G: It is much more structured. The casual setting is not a part of other programs. That was not strange to me as I taught for many years. 
T: What about preparing. Does it take more of your time?

G: It takes much more time than my habitat or working with older people. We have gone to China several times to teach English to adults in china. That took a lot of preparation also. That was a lot of work.

$\mathrm{T}$ : This seems like something you can transfer?

G: Yes, I think so.

T: When comparing it to other volunteer work, what do you like most about it?

G: I suppose one is the fact that the students that I work with have a desire to learn the language and that if a specific need, which they know they would gain by having a ability to speak the language and so they come with a deep desire and sometimes quite timid because they don't think they are going to learn very fast. They become frustrated because of the speed in which they are learning does not satisfy their wishes. Those are some of the frustrations that also are rewards in the fact that they are improving the language skills.

$\mathrm{T}$ : What is it, what are some of your biggest challenges or frustrations?

G: I work with a wide variety of ability, abilities to speak the language. Some are very, very advanced students and some are...can do well in various aspects like listening skills. So to try to develop a class structure that meets the needs of a large range of language abilities is very difficult is very challenging.

T: yeah, absolutely. Also related, do you find the education level of your students, does it vary?

G: That hasn't been a very big thing for me. Another challenge I find is locating curriculum materials so that I feel they are pertinent to where I am with my teaching to 
the students. I am also looking for materials that would be satisfying to what I am doing. That is a challenge.

T: Are you able to use any of the materials that you used in China?

G: no, that is the whole thing with the situation.

T: I'm curious if you could give me, create a picture for me what you do in the classroom. Think back to an activity that worked well for you?

$\mathrm{G}$ : One thing I d do is to type a simple story with lots of nouns and lots of verbs and then I give 8 students a worksheet of this story and then the story is on both sides of the paper. On one side is a 150 or 200 word story. And then I have them find, on the bottom half of the sheet, I have, maybe 15 questions that they have to find the who, what, when, where, why. And they have to find the answer to those, like "who when to the hospital," or "what color was the truck," or "when did he come home from work." That is my activity to look for questions such as who, what, where, and they have to write the answer in a complete sentence. That is a skill to recognize the specific words and skills to write sentences. The other side of the paper, for the same story, I have below it columns for nouns, verbs, and adjectives. They go to the same story and find all of the nouns they can. All of the verbs and adjectives. Later I will add prepositional phrases, pronouns and so on. I found that very helpful. I try to write a story that is at their level and in their interests. Sometimes an applicable experience that has an abundance of nouns and verbs. I find that to be very helpful.

T: How do you know if something is working well?

G: How they respond. Very much, that is how I test what I am doing. The surface response. 
$\mathrm{T}$ : When you are developing your own activities, are there sources that you go to or do you develop a lot on your own?

G: Sometimes I just develop something myself that is of interest to me and also I use some books, yes. There is one more activity that I found that students like is that for quite a while every time I would take my backpack full of ten items. I would pull these items out one by one and they would guess what the item was. And then I write on the chalk board of both the singular and plural of the word. They've done that and they enjoy that and I use that as a starter activity for my class session. I usually try to use a kitchen item, some tools that men would know, the tools that they actually use, but don't know the names of. And then I try to use some food items. I have a smattering, a variety of types of things. That is a fun activity. I use my own activities and I also get ideas from books. They don't have any workbooks. I hunt and search and find things in a variety of workbooks that I find helpful. I take the workbook and make my own ideas, my own worksheets from the ideas in the workbook.

T: Could you tell me about a time where you made a lot of plans and things didn't go as expected?

G: Oh, Yes, I can. One particular activity we tried to have a list of words with certain sounds in them and I think I went to fast and the students didn't know where I was going or what I was doing.'Th" is a hard sound; it is quite difficult. I had a list of words with "th" in them and it was difficult. There are times when I would do an activity, which after doing it, I realized that they weren't realized.

T: How do you react when something like that happens?

G: We just play it by ear and go on and try something else. Sometimes I change up 
the activity anyway and then reflect on what happened in the activity.

T: Do you see any of your students outside of the classroom?

G: No, not necessarily. A couple does [come to church] and a couple have expressed interest in coming. Some of them come to the community center and so there is a relationship, yes.

T: How has being a part of this volunteer work impacted you, how have you changed?

G: I recognize, again, the difficulty in learning a language. It helps me to understand people's frustration level. That is the most important that I have, realizing that this is difficult for them, to learn a language. It helps me to understand the frustration.

T: What skills do you have that benefit you most as a tutor?

G: I'd hardly know how to answer that. One skill is my sense of being a teacher and I can prepare lessons quite well and evaluate the progress quite adequately.

T: If you had advice to give someone training tutors, what needs to be included?

G: Try to be extremely creative. Have activities that engage students in listening skills, if the students could experience listening skills, reading skills, speaking skills in each session that would be helpful. And also the writing skills. I try to do a little bit of that in each session. 
Appendix I: Interview Transcript - Beulah - SKCC

Participant: Beulah

Interviewer: Troy Hickman

Organization: Southeast Keizer Community Center

Role: Volunteer Tutor

Interview Date: $4 / 21 / 2009$

T: When did you begin volunteering as a tutor?

B: At this particular institution or in general?

T: How about both.

B: At SKCC I started a year ago. I started in April of last year, at the end of the spring term or whatever you want to call it. They don't do it during the summer and then begin again in the fall. I went through the winter, until now. I've volunteered tutoring German and English before on a prior basis at different universities: This is the first one that I've done continuously.

T: You've been doing that with universities for a while?

B: When I got my masters in German from the University of Kansas. I did that while I was working on my Masters. At Mt Hood Community College. No they hired me, I didn't do volunteer. This is the first I've done continuously. I like teaching and tutoring languages because you can really feel the students grow.

T: How did you meet Jack and get involved with them.

B: My husband is Mennonite, and when we moved to Oregon and then to this side of the mountains, we started going there. We kind of got in touch with the church and 
then at one point Jack was looking for volunteers, and because I like teaching languages, the thing I'm proficient in now, even though it is my second language, obviously, but I can teach it and also from my experience with learning English myself maybe I have a bit more patience with my students. I do very well with languages, but I struggle with learning languages. I understand what it feels like to be frustrated. Maybe it's my experiences with learning languages myself, that is my ummmm..I try to help other people learn the language.

T: So, could you, you've done that a bit, but describe in more detail what your thought process was when you decide "yes". What was your motivation, was it a need you were addressing, a personal growth thing, or what?

B: Volunteering is for your own benefit. Volunteering is about the most rewarding way of helping people because it makes you feel good about it, but you are also hoping that you are helping the people that you are volunteering for or with. With languages, the students that I have right now, English is all around them. So I hope that by helping them learn English, I hope that I make their daily lives easier. When I taught English in Germany, to college students, it was totally different. The learners they are not, the Spanish, who live in the US The focus is trying to help them on a daily basis with their struggle with being in a totally different society. You know that language is all culture. Culture and language are tied together. That hopefully by teaching them the culture, but also making their struggle with a foreign language easier.

T: You work, primarily, with Latino students. Have you worked with the Latino culture previously? 
B: No this is the first time.

T: Do you consider yourself bicultural?

B: Yes, definitely. I'm German American

T: My husband knows German quite well and our boys are raised bilingual. And we wander between the two cultures, pretty easily. On a daily basis, without traveling, we try to go between cultures as much as possible.

$\mathrm{T}$ : In the classroom, doing activities, are there a lot of cultures about American culture come up?

B: Not so much. I think you'd be surprised. I have an advanced class. (takes break to talk with children, in German) Actually I have the advanced class. The basic English is quite well spoken. I am trying to do more grammar. But I try to wrap it around cultural situations like hospitals, school, police officer, supermarket. And not that they are asking for it, but I try to ensure that they learn in a multilevel way, that they learn about the culture while they learn English. Language gives you the opportunity to do that and I am definitely trying to use it. They get exposed to different parts of language use that way.

T: What other types of volunteer work have you done?

B: primarily sports, kids sports. You know, coaching soccer. And also volunteer in local businesses. I volunteer as a baker right now at a local business. But languagewise, this is the big one, the one I've been involved with most.

T: How does this differ from other volunteer work?

B: The preparation is entirely different. Just a second (speaks with kids in German). Language classes is way more, you need way more time than other things. In my 
baking I just go there and use the recipes; I don't need to prepare at all. But language, to prepare for language, especially if you want to mix in the culture and build on what you did last week, to incorporate everything, is very time intensive. It is also very rewarding when it works out that way, but it is definitely way more time intensive than any other thing than I've done. It can be very challenging. But it can also be very rewarding if it works out.

T: What do you like most about tutoring?

$\mathrm{B}$ : Language, or in general?

T: Language, particularly.

B: In this case, the Latino is a very different culture. Using language, you can ask them questions. You can just do this through grammar exercise. I can be very curious. I can ask them to tell me about their culture so that I can learn from them while I teach them something about English. The volunteer or the learners at this institution are very thankful. They really, I mean every single day, none of them leave without telling me how much they appreciate my work and help. That is probably the most rewarding, the people thanking you because they can't give the monetary reward. Working with grateful learners, like this, because I've taught college. The students are there for a grade and so you hardly ever get a thank you. These learners totally appreciate what you are doing with them because you are there and the meaning of helping them is very rewarding as a volunteer.

T: On the flipside. What is the most frustrating part for you?

B: Trying to come up with good exercises that you feel, you know, you don't want to push them too hard, but you want to challenge them, to find a balance. You don't 
want to frustrate them because English can be extremely frustrating. You want to challenge them enough because you want them to learn. That part is the most challenging, to get it right, to find the right level. At least here you have a real variety of learners. Some are very good in the oral part, but struggle in the written part to struggle or to find exercises that everybody can benefit from. I think it is the most challenging. It is not really the learners, for me, the challenging part is to find the right exercises.

T: Could you give me an example of a time when you planned an exercise and it went really well?

B: A specific one or how it turned out? I definitely want, for example right now I have a group of strong English speakers and I'm starting to look for, we did questions, to form questions. We are doing past tense right now. They are struggling; I am doing the irregular forms. Buy\& bought - teach \& taught, all those. I need to see that they understand what is teach - taught, for example means, but I have to find the vocabulary to explain it to them. I ask if they have 6 years of education or 8 years of education in Mexico. They don't have the grammatical terminology, for example, like the simple present or the perfect past. It doesn't mean anything to them. So, to find the ground that I can push them enough with the exercises without having to crank out the terminology, but make it understood what they are supposed to do and also to benefit and understand what they are doing. That is what I am struggling with right now. I.....when they understand what they are doing and they can use it after they have left the classroom. That is when I feel okay; I have accomplished what I was aiming for. The balance during the class, when I see that they are lost. And I try to 
explain it from a different angle. Some of them know the terms and some of them it doesn't' mean anything to them not matter what terms I am using. I can plan an exercise a certain way and I find out it doesn't work for them and I have to find a new angle. That is the most challenging, right now, for them and for me.

T: How has volunteering as a tutor this impacted you, as a person?

B: It is the most rewarding it can get. There is not a single Friday night where I leave the class and I am not all smiles. They are wonderful people. They are as grateful as it gets because you are helping them deal with their daily lives. They can ask questions besides language, social questions. Overall, even though I hope they are getting something out of class on the language side, I think those two hours give them a chance to get out of their home, because many of the women are stuck at home all day. For them, to be challenged intellectually, academically, you could call it - besides having to deal with their 5 kids or something. For me it is really rewarding because I get out of the house and can focus on someone else, other than my kids, and I think it is the same for them. Volunteering, since you don't have to focus on the monetary side, especially if you have thankful learners, it doesn't get more rewarding than that. 
Appendix J: Interview Transcript - Victor - St. Joseph Parish

Participant: Victor

Interviewer: Troy Hickman

Organization: St Joseph Parish

Role: Volunteer Tutor

Interview Date: $4 / 18 / 2009$

T: When did you start volunteering at St. Joe?

$\mathrm{V}$ : I think this is my second year for about two years or so.

T: When you, thinking back to that time that you began volunteering, could you describe how you came to the organization and what you were thinking and how you decided this was a good thing to be doing?

V: What I wanted to do initially, I think I read in the paper that they were having these ESL and conversational practices at the church. I was a student of Spanish. I was trying to learn the language, and I thought this would be nice to get involved with this and I could practice my Spanish. That was my first interest. During the conversation practice it was all English and getting more confident in speaking English. Then I moved on to the educational aspect of it where I could teach them reading, vocabulary, and some writing. And that is what I've been doing now for about a year and a half.

T: What is your relationship with St. Jo, did you attend church there:

V: I think a long time ago, I think my wife and I did attend church there, but when we moved to the South side we attended a different church, a catholic church. 
T: What interested you first was practicing your Spanish; I'm also interested in the role of culture, what was your experience with working with Latinos before.

V: I didn't' have experience before, but once you get into it, you begin to meet people, who they are. Even though there is a language difference, I think the surprising thing is that everybody is the same in a lot of ways. The first thing you realize is the communication difficulties that they have in communicating with English speaking persons. And you also got to be aware that English speaking persons probably don't have a lot of patience for people that are just learning. A lot of people just think take a two week course and you will automatically learn English or Why aren't you speaking our language" It is unfortunate. I have seen a lot of the service people, many Mexican folks, and working at McDonalds or Burger King where people will order something where people say things one way and... an example would be that one woman came in who wanted to know that the chicken menu was hot and she said that of course it was hot. Yes it's hot...well she meant that it was hot not cold and the other woman it meant spicy. The next question that she asked was "what do you have that is not seasoned". And she said well that's not seasoned. And she said "that is what I just asked you. And you said it wasn't hot." She was actually using different terminology. So there is a lot of unfortunate circumstances that I realized that other people by not learning English were not expressing themselves and they cannot express themselves and they are lost in the communication thing;. There are two responsible, the listener and the speaker. Often the listeners do not have the patience to listen to them. I saw a man in another situation where the supervisor wanted this guy to move his trays down to a different building and he wasn't' doing it 
and the guy said with a louder voice, "move the trays now!" And the guy just stood there and he said that there was a problem and he said, "there is no problem, you're the problem, just move it:: The problem, I kind of asked what the problem was and he said that he needed coffee on the cart, no coffee on the cart. The supervisor didn't question why he didn't move the cart, just thought he was dumb person.

T: I'm curious if the language an also a person's preconceptions about the culture influence the perception of a person's intelligence:

V: Well they are treating adults, non English speaking adults, as children. The English American people act like parents, and they are actually talking down to them like they are children; they don't talk cross-wise; adult to adult. They are not giving them the respect; they think that they are dumb. One of the problems, too, is that Spanish people will look at you, and they are shaking their heads, and they are nodding. They have no idea what you are saying. But they are not going to express it because they don't want to embarrass you that they don't understand you. Kind of a negative and I try to teach my students if you don't understand people you need to say that because they think that you're not wanting to do it, but you're going against them and they said that "no I never knew that before." There's interactions and then a little different and you try to go to Mexico and try to teach English to people that try to speak Spanish and see how far you get. I really feel sad that today we can't allow for people to express themselves or we always assume their intelligence is low or something is wrong and I think it is because we are in a fast society we keep moving fast. We don't have time to do it, you know.

T: That's good information. I appreciate that: 
V: I have one person in my class. He is very smart. He did not have the fortune to go to a lot of school. He had to quit school in the $6^{\text {th }}$ grade in Mexico. He had to work and that is what they do, he worked for the family. He works very hard here in the states. He is illegal. He works for minimum wage. There are no benefits. He doesn't get insurance, he doesn't' get time and a half. He gets straight pay and it is a lousy job. I think he is sorting recyclables. And the boss will tell him that tomorrow... In Mexico a day laborer works all day until the boss tells him it is over. And it is a daily rate. So if they are going to make fifteen bucks that is what they will do no matter whether they work 8 or 12 . And here they kind of stretch that with those people too. They tell them that they have to work overtime and they don't pay overtime. So they are taking some exploitation there. The one thing that they do there is that talk to their own groups, their own culture and their own people. They are afraid to get into a team with English people. They don't seem like they are afraid to work into that kind of a group. That prohibits their advancement and they could be the best workers in the world, but they can't do it ummmm I guess you've got me on a soap box. I had one woman that had a degree in chemistry. She went to college in Guadalajara at the university. She got a job as a chemist at a pharmaceutical company; she was quality control. She came to the United States and they don't even recognize her high school and she is cleaning house. She said all of the education that she had was for nothing. She is doing this because she wants her daughter to have a better life. There are no jobs in Mexico that pay as well as they do here. I have a woman that has a CPA. She was an auditor in Mexico and Peru. She works in the school, I think, as an aid in a bicultural, bilingual way. She can't get a job in accounting. 
$\mathrm{T}$ : It is amazing the sacrifices that people make. That is great information. Have you been a volunteer with other organizations?

V: Yes I did Meals on wheels for 17 years. I'm an accountant so I did their accounting and for their computer stuff. I did their payroll.

T: How does this position differ from other volunteer work you've done.

V: The other volunteer work I was working by myself. With this I am working with other people. There is definitely greater satisfaction from working with people. I don't know if you've heard this term, but this term I've coined from someone is that you get a "volunteer high" from working with people. It is so gratifying once you teach them or they catch something, you are so delighted that they understand that you feel more of a high; the endorphins really take over your body when you walk out of there. I walk out of my class o Tuesday nights and I feel great because I was able to give these people something that was very useful and they were extremely grateful to have.

T: Thanks. Could you give me or help me visualize what you do on a nightly basis. Could you describe a sample activity that you do?

V: I have a book and we take turns. I have between 3 to 6 people and they have some books there, like a dictionary. They all read sentences for 30 minutes and then there is a new word that they learn in the sentence. Afterwards I have a page that gives them that word in Spanish. Then they have five choices in English to find the matching word. So that they get the translation from Spanish to English. I do the same thing with English words to Spanish words. It is kind of a gamey thing and they really enjoy that. I never go more than 30 minutes on a topic. Because they are going to 
learn.... interest. I try to keep things going as fast as I can because I keep them interested. In addition to that we started sentence structure. No one likes grammar. I don't like grammar. I had to relearn it. I have a worksheet that I made up that has a line for the subject, a line for the verb, a line for the predicate or object. And on one lesson I'll say this is a prepositional phrase and this is how you make one up. I'll say this is what the subjects are and in another lesson there are the verbs. We go through first, second, and third persons. This was one of the most satisfying things. They didn't realize that there was a person that needed to agree with the verbs. The last thing is the reading. I ask them to read the sentence and what it means. They are very good at reading, at pronouncing English words, but then I ask them to read again, but this time to read for what it is saying. We are also working on writing now. The subject sentence and spelling. We find out the sounds and I do a little bit of phonics with them.

T: You create your own materials and bring them in:

$\mathrm{V}$ : I have, but I go on the internet and I find so much on the internet, free. I bought a workbook from one of the education things. I zerox those, they are copyable. I give them charts for things like relative pronouns. We went through that with worksheets so that they not only had the subject on it, but went through the pronouns.

T: Could you tell me something that has happened in a tutoring situation that you didn't expect to happen?

V: I think that someone came back to me and wrote a paragraph, I was shocked. They actually wrote a paragraph about another person. Another wrote a paragraph, he did copy it off of a church bulletin, but I told him it was fine, that he needed to write 
something in English, even at his level. He had some trouble with verb tenses, but that was to be expected. They went on their own to do it.

T: Is there anything that you don't like about tutoring?

$\mathrm{V}$ : What frustrates me is that they don't come in on time. I really work on a lesson and I get a little frustrated if they come 10-15 minutes late. I have to review what they didn't get. I don't want to be callous, but I was told that there was something called Mexican time and real time; they are 2 different things. We straightened it out. We have an appointment and it is important that you need to be here. For the most part it is time. If they are a no show, I call them. They say that they are working time. That is fine, but you need this too. I hope to see you next week.

T: Do you ever see folks outside of tutoring?

$\mathrm{V}$ : No, usually just in tutoring.

T: Anything else to add?

V: Most of my students have gone to Chemeketa. They say the difference is that there, they are in a classroom. Here we are nearly one on one. We are the ones that are being focused on, not just the whole class. If we don't pay attention, we know that you are going to catch us. What makes it interesting is I say "okay, folks let's do this next week," and they say "what happened?" We've been here an hour and a half because I keep things going. I change things a lot. Right, I get them involved. Once they are involved, they are really focused. And they work all day long. You know, in heat, awful jobs sometimes. They are really realized how important this is and they like the one on one attention. For me it is the "volunteer high." A lot of folks have that. We give them a lot of attention. 
T: Has anything changed about you how has this experience changed you?

V: Yea, I know I've changed a lot of things about .... What I've changed is ...You can't judge a book by its cover. Some of the things that these folks have done in my lifetime, I never would have guessed it. What some of these folks have done in Mexico, per, or Costa Rica, some of them just amaze me. Some of the challenges that they have... One guy was a career air force mechanic on jet engines and he drives a horse truck now, but he had a very responsible job. You don't just judge people by how they look or how they act. You need to find out more about them. 
Appendix K: Interview Transcript - Victor - St. Joseph Parish

Participant: Anita

Interviewer: Troy Hickman

Organization: St. Joseph Parish

Date: $4 / 28 / 2009$

T: How long have you volunteered as a tutor for ESOL?

A: I started down in California in 2001 and so I guess for 8 years now.

T: You have been with St Joseph recently?

A: I just started with St. Joseph in January. I was filling in for a tutor that was gone, teaching English out of country. So I took that group of students for 3 months. No that she is back I am continuing on with another student there at St. Joes. There is one student who is pretty much at a level by herself. Bob assigned her to me.

T: How outside of the ESOL tutoring, do you go to St. Joseph, or how did you end up volunteering with them.

A: We met Bob and his wife Roseanne at another gathering that was for students who were learning Spanish, actually. So we were studying Spanish so we met them there and then he told us about his program and we told him about ours, which was Juntos Podemos. So, then he had a need for tutors so he contacted my husband and myself to help. My husband went and tutored. He started with the fall, last September probably.

T: How long have you been with Juntos Podemos?

A: It will be three years now.

T: Go back to the first time you volunteered as a tutor, if you can think back to 2001, 
could you describe what motivated you and how you approached the organization.

Could you give me a sense of what motivate you to do that?

A: In my career, I was an elementary school teacher. I retired in 2000 and had time to do volunteer work. I was a teacher so I had teaching skills, but I thought I would rather work with adults rather than children for a while, for a change. We had, in California where I was, the Diablo Valley Lit council and they were a group of people who were teaching students very much like we are doing here in Oregon, but they used the Laubach method. So we took that training, and then we were assigned students and we went into the homes of the students and worked with them.

T: What attracted you? Were you working with cultural groups or other attraction? A: the students that I was working with were from Latin America, Mexico and Latin America. They were all Spanish Speaking. I was tutoring during the day. My husband also worked and tutored, went into the labor umm..They had a large building dedicated to the farm laborers and men and women who came to the United States looking to work, and people who wanted them came to pick them up. Bill and I went there three days a week. The people that were not picked up, we would teach them English for an hour. There were other tutors that came in the other two days. I had been studying Spanish. We do go to vacation in Mexico and travel to El Salvador with a church project. I was very interested in the Latino culture, but my students just happened to be Latinos and Latinas.

T: Have you done other types of volunteer work?

A: I volunteer at the elementary school at the library one afternoon per week for two and a half hours. Students find books, check out books, and I return books to the 
shelves. Through our church we've done some volunteer work at their food pantry and things like that. Helping with Interfaith Housing. Families go from church to church and stay overnight and have meals. We've helped with that.

T: How is volunteering as a tutor different?

A: Volunteering as a tutor I am really able to use my skills and interact with people which I very much like to do. My other volunteer positions, it is not much one on one with a student or a group. It is doing a task that needs to be done to make the operation go more smoothly.

T: What do you like most about tutoring?

A: I like the interaction with the person that I am working with. The fact that it is a long term type of thing, you know that you establish a relationship. You are able to see growth. And that is something that I like a lot; I like that interpersonal, you know, the students we have are very motivated, of course, they try very hard. I can be empathetic because I am trying to learn Spanish. I can understand much of the travail there. I do very much like working with them and I love the Latino culture. There is something about them that is very charming and gracious and I do very much enjoy that.

$\mathrm{T}$ : on the flip side, what is the most frustrating thing?

A: I suppose it is the fact that sometimes students do not appear for class and of course they don't have that communication with me. As there tutor, I do not know why they are not there. If something is wrong in their family. That part of it I find a little disconcerting. And then the materials you use, there is no perfect material and you know that as well as I do. So we are constantly looking around for materials to 
supplement what we are doing. And not having any kind of a financial base to buy more. And it is kind of put on us as individuals if we really feel it would be important to our program, then it comes out of our pocket, which sometimes is fine, but not always able to do what we would like.

T: To give me a better sense of what you do when you meet with students, could you outline an activity that sticks out for you that works well. Describe what happens. A: I always do a lesson plan before the class. I usually have five or six things in the plan that I want to do or that I hope to do. Conversation is always a part of each class, for at least 15 or 20 minutes. We will speak, and I really stick to English. I know that some tutors go back and forth between Spanish and English. My Laubach training is to stick with English and they learn it. My students know that and I tell them that up front. I tell them in different ways so that they understand. They do want to talk in English so lots a times I really have to bring it to an end because I'm sure they would talk for the whole hour and a half or two hours. Conversation is always a part of it. I used the textbooks. At St Joseph they use the LifePrints. I use that and with Juntos Podemos the text is English in Action. The group is at level three they are more advanced. I find that with most of my groups, the thing they like best is the stories. They love to read stories and do the activities with the stories and talk about that. I use stories with both of my groups. At St. Jo I use the true stories book at Juntos podemos we use More True Stories. They are stories that they can relate to in their own lives. They really like that and the activities for comprehension and vocabulary. They always say "do we have time for a story". They feel like they are learning from that. For a grammar activity I use Passport to English, which is a program that Bill and I 
bought and you can make your own copies. It is a really progressive grammar lesson. They like that and the checkpoints from time to time they take the tests so they can know what they have mastered so far. And then something with vocabulary. That is pretty much what my regular lesson plan would look like. Time goes quickly.

T: So, you develop your activities through books. Do you use other materials or resources?

A: I find some things on the internet. We even use the newspaper if something was in the paper that day that would be of interest of the students. I make copies of that and we read it and talk about it. Also, I use activities from the book, Going Places, which is actually a picture based book. And that, I find activities, where maybe a daily routine of someone who is getting up, shaving, and preparing for the day. So we do different things like that for verb tenses and verb practice. It also has activities for giving directions. You just kind of scrounge around and find things that work.

T: Tell me about a time where something didn't go like you planned it to go.

A: Now that I know my students so well at Juntos, most of whom I've worked with for two and a half years. With them I pretty much know what they want. At St Joseph, because I'm still new, when I first started with the group that had been working with the other tutor and she would speak to them in Spanish and her Spanish was excellent and they were dismayed with me. So the first couple of weeks with them were very hard work. I thought they would all drop out and never come back. After they got used to it, then when the tutor came back and I moved on they did go out of the way to tell me that they appreciated the fact that I made them speak English. So during that, students that are not familiar with me and hard work that way. I have a hard time 
working with the very beginning students because they really want you to speak in Spanish. I didn't have that problem in CA with the Laubach org because it was understood that you only used English.

T: Can you think back and tell me what ways volunteering as a tutor? How has that impacted your life?

A: I think it has. It has made me more aware of the needs of immigrants and the problems that immigrants face here in the United States. It has made me much more sensitive to them and what is going on in their lives. I think it is best for me to be sensitive and interested. Latin American culture and more motivated to learn Spanish myself. So when I visit I can be more interactive with people that I meet when I am there.

T: Do you see students outside of class?

A: Very rarely. Sometimes students from Juntos will invite us to different family celebrations and we will always go if we can at all go. Generally we don't see them outside of class. That is something that my husband and I are sorry about. We wish we were a bigger part of their lives, but we are not. At St Jo we are new. We don't go there to church, but neither do the students. So we don't run into them. There is still separation and it exists.

$\mathrm{T}$ : one last thing, if you had some comments, talking with someone that wants to become a trainer, what kind of information do you feel is essential in training a new tutor.

A: I think it is a wonderful thing for any adult to volunteer this way. Often times when we are short of tutors we go around the neighborhood and to our friends and put 
up signs. Often, people that have not taught say they would never be able to do that. Whereas retired teachers are the ones that are the most open to it, at least the less fearful of it. But, I just think a training program is so important. And we are disappointed that Chemeketa and the college is closing their training program. It will come to an end at the semester now. They did the last training that they know of that they will ever do. 
Appendix L: Interview Transcript - William - St. Joseph Parish

Participant: William

Interviewer: Troy Hickman

Organization: St Joseph Parish

Role: Volunteer Tutor - Conversation Partners Program

Date: $4 / 28 / 2009$

T: When did you start volunteering at St Joseph Parish?

W: it has been at least a couple of years. Ummm... I don't really know for sure.

Well, time flies, you know. It has been at least two, maybe three years now.

T: How did you get involved? Are you a member of St. Joes?

W: Yes, I saw it in the bulletin. And it sounded kind of interesting.

T: Was Bob active with the program then?

W: Yes, he was, I don't know if anyone else has ever run it. I get the feeling he started it on his own initiative.

T: If you could think back to the time when you saw this in the church bulletin and you thought maybe you would try this out. Could you describe that process? What interested you, and what you thought you could bring to the position?

W: I was attracted to the conversation partner aspect of the program because it seemed more flexible and, for me personally, I didn't have to do a lesson plan. And get into a formal kind of structure. I thought, you know, that I had enough experience in life with my job and my travel and a little exposure to foreign language. I don't speak anything fluent. Just living abroad a little bit, I felt like there was something 
there that I might be able to pass along to somebody else and also having done that, also appreciate... or... the students or the participants' experiences and what it is like living in a foreign land.

T: You've lived abroad and struggled with learning a language.

W: Yea a little bit that sort of thing. It is not easy.

T: So you, have you done other volunteer work?

W: Umm... well yea, I, umm... do volunteer work now, a little bit. My wife and I volunteer over at the public library. I worked there for five years. The library is very straight forward. It is not a give and take kind of thing. We go there and they have a cart full of books for us and we just put them on the shelves. Of course, the thing about it is, and they didn't when I worked there, they don't have the staff to do all the jobs that need to be done at a public library. Volunteers can do some of that. It is a different kind of job.

T: Working at conversation partners, what is unique about the volunteer work that you do there.

W: Well, it is umm... very flexible kind of program. Each week depending on who shows up, first of all, either from the student side, if you want to call them students, it's as good a thing as any - or the tutorial side. Sometimes there are more students than learners. Sometimes we have to go two persons to one tutor and then other times it could be a completely different ratio. One on one is ideal. The thing I like about it is each week there is probably a different person to talk to. Sometimes we kind of get on a roll, if there is something that we talked about the week before that was unresolved. Some information that was pending at the end of the session, bring it back 
to class and talk with the same person again. Generally it is a different person each time. Generally there is a different person sitting at a table with me. I kind of have to watch to see who is more verbal and who, or, who is more shy. So we kind of have to work with that. It is really pretty amazing. Many times, well, more recently I've noticed when I've had a group of people at a table, umm... There is always a couple, at least one that is a little less outgoing, so later on, we've had the opportunity to talk to that person again, just one on one, and as it might start kind of slowly in the first few minutes, the first half hour, but as the person gets more comfortable, then by the time the hour or hour and a half are up, it's a completely different feeling, you know? That is pretty enjoyable. I try to let people know that just sitting there in that hour and a half period of time, I've seen them progress from being shy and halting to being much more comfortable and much more fluent and conversant. I think that is nice for somebody to hear. It gives them some confidence, a little more than sitting there having someone else kind of take the lead for them. I've enjoyed that very much. Not pep talks because that can be kind of phony. Just make them feel like they are making progress. Not in a fake sort of way, but that I do see progress. That is good feedback for them to hear and keep with the program and to keep coming back. That's kind of where I come from. I also like the program because I am retired and so I come every Saturday, but if we have plans to go to go back to Virginia or back East, It is easy to work that in and don't have to feel like I'm letting anybody down. There are always others to step in. They don't have to deal with the lesson plan to work with a formal sense.

$\mathrm{T}$ : Maybe a little less responsibility and a less big of a commitment, maybe, 
W: Yes, that can be difficult if, you know, if there is a volunteer kind of job that requires more of that. It is a major commitment. I've done things, well, I spent a lot of times in the Navy Reserve and I always had to plan things around that one weekend a month, for 25 years. I've done my share of that kind of thing. I don't want to take on too much more in the way of real hard, hard, what's the word, real hard schedule a softer schedule works.

T: So you've mentioned a lot of things that you've liked about conversation partners. What is something about the program that makes it difficult to do?

W: I've never really given any thought to that side of it. Nothing has ever shaded me that way. I think it has been pretty good, very nice experience. I guess the only thing is occasionally when not many people show up. Generally, that is something that you can anticipate. If a holiday season, or when the weather gets better, people have outdoor type jobs and if they are working for an agricultural organization, a company, well they a lot of time have to work on Saturdays. They don't always get the opportunity to call Bob and tell him that. But that is not a...It is kind of minor for me. There is generally more people there to fill in, to spread with other tutors we might go with one student and a couple of tutors to just broaden the discussion a little bit. There have been times when somebody didn't come in, or quite a few people didn't show up and I'd tell Bob that it looks like there are plenty of people here today. I'll just go on home because there is something I want to do. That has only happened a few times.

T: Can you think of a time that you could describe for me, so I can picture what you do, as well, something that went really well. Like maybe you worked with someone 
and you picked up a book or a map or something and it went much better than you expected it got go.

W: I don't have anything that really jumps to mind like that. Umm... generally the people that have been coming there, even the new people are ready to participate, and so that is never been a serious problem. We have, and Bob has got some good material there. If somebody new walks in the door he has some mimeograph sheets. He calls them conversation starters. It is not only something to read, or prompt discussion, but it gives me an idea of that persons reading and comprehension skill and level. And also when we talk, these are all types of questions, like what or how many people are in your family, or what is your favorite color, or hobbies. Sometimes people don't know what that word is so it is another way of expanding the discussion. Those little things, it is like a front and back page of a plain sheet of paper with all of these topic and conversation starters. There is something on there for everybody that will click with one person or another. They are also a good way, a couple of time somebody would show up and I would just eventually tell Bob that the person really isn't quite there at that level. It is like a screening. It ends up bring a screening process. Recommending that person, if they .... To get into the English as a second language part of the program. Or if they get really better grounded and get a little more confidence. I've done that a few times. Bob is easy to work with in that regard. He is a fine individual and he can work with whatever it is. With the materials there, we can always find something to go with, like what is your favorite color, how many kids do you have, or that kind of thing. Some people are more conversant. Like what was it like in your home country or what was your education system like. How did 
you meet your spouse, or those kind of things? People like to talk about those type of things. A lot of them are into slang and idioms. That is always fun to take that on every once in a while.

T: Do people come in with questions like what does this mean?

W: Yes, occasionally. I ask them if there is anything that happened during the week, in a meeting or something that didn't make sense. One woman was ... she was working with her girl at school and we were going through all of the girl's homework and some of her project with her so she could go home and work with her girl on her school project. That went well. We talked about things, like who was the contact, the city or the school district things of that nature. There are a lot of different things that come up and that is what I like about it. You can give advice, if somebody wants it (laughs). You can help out for suggestions or ... We can talk about, not just the weather, but politics, if people want to do that, or culture in their country as opposed to the way things are done here. Talk about things that might be a faux pas, some language things that might seem very innocent, that could have a different meaning in a different setting. That is what's fun about it. There are some nuances there about it that are important for people that are studying the language, to be more conversant or more fluent.

T: Do people come to you with questions about cultural situations. Like how to react or behave in a certain setting?

W: No, not like that. Ummm... These kinds of things come out more in the course of just talking about family, friends, jobs, what's in the newspaper, what's in the bulletin, the holidays, things like that. 
T: Do you see any of the folks you work with outside of the conversation partners. W: No, I thought that I would see them at church more often. They still kind of are more.... feel more comfortable going to Spanish mass and still, it probably means more to them when they are with their community and the mass is in their language. We do have multicultural services at different times of the year, mainly Christmas and Easter. I thought I might run into people there. Since I am up in the choir loft, I guess I've probably, that probably has something to do with that. I can't see people come in and out of the church on the ground floor. I haven't seen anybody, I don't think in town or $\ldots$.

T: My last question for you is, I'm curious if, over this course of time, what has changed about you and how has this impacted you as a person?

$\mathrm{W}$ : In the context of the conversation partners mission itself, I'm feeling a lot more comfortable about it. When it first started, I felt anxious. Those sheets that I was telling you about, conversation starters, I was using those pretty heavily at the beginning because I didn't know where I was going with the program. So it was a little bit tentative. Now I feel more confident about what is going on. With the people that come to conversation partners are, have been coming for some time now, so, you know, more often than not, they are folks that come in Saturday morning that I know now by sight and not by sitting down and having a chit-chat on Saturday morning. That anxiety and tentative feeling about it is not there anymore.

The comfort level and the context of the.... of what conversation partners is about. I think that has been good. It has been good for me in the sense of having a feeling that maybe I'm helping some people get more comfortable in their lives as non-native 
speakers. And coaxing them along, coaching them, I guess, and trying to build up their confidence. A lot of times I point out to them that, they already know this too, but they need to know that we know that they are going to meet people, they do every day, and they will meet people that will be helpful and some people that won't lift a finger to help understand or explain anything. When that happens, all you can do is just go with the flow. Try to keep in mind that there are lots of other people that are glad to be of assistance and glad to help out and not just throw up barriers, pretend that they don't understand, or things like. 